\title{
Nuclear Criticality
}

Safety Guide

Norman L. Pruvost*

Hugh C. Paxton*

${ }^{*}$ Editors

\section{Los Alamos NATIONAL LABORATORY}




\section{DISCLAIMER}

Portions of this document may be illegible in electronic image products. Images are produced from the best available original document. 


\section{DISCLAIMER}

This report was prepared as an account of work sponsored by an agency of the United States Government. Neither the United States Government nor any agency thereof, nor any of their employees, makes any warranty, express or implied, or assumes any legal liability or responsibility for the accuracy, completeness, or usefulness of any information, apparatus, product, or process disclosed, or represents that its use would not infringe privately owned rights. Reference herein to any specific commercial product, process, or service by trade name, trademark, manufacturer, or otherwise does not necessarily constitute or imply its endorsement, recommendation, or favoring by the United States Government or any agency thereof. The views and opinions of authors expressed herein do not necessarily state or reflect those of the United States Government or any agency thereof. 


\section{Contents}

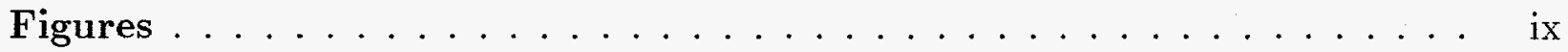

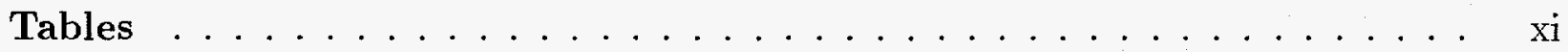

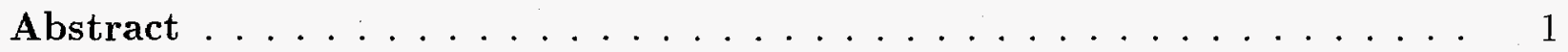

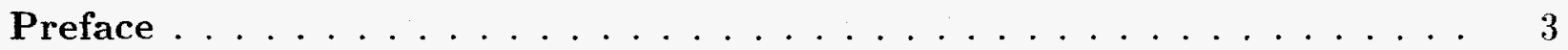

I. BACKGROUND 5

A. The Nuclear Criticality Safety Problem . . . . . . . . . . . . 5

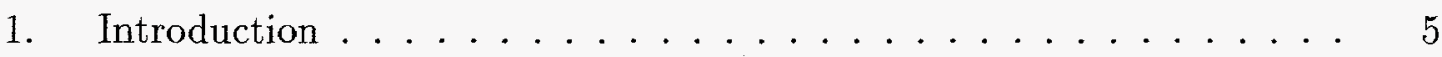

2. Criticality Safety Principles $\ldots \ldots \ldots \ldots \ldots$

3. Factors Affecting Criticality $\ldots \ldots \ldots \ldots \ldots \ldots$

4. Criticality Information $\ldots \ldots \ldots \ldots \ldots$

5. Criticality Indices . . . . . . . . . . . . . . 11

B. Nuclear Criticality Safety Practices . . . . . . . . . . . . . . 12

1. The General Criticality Safety Standards . . . . . . . . . . . 12

2. Administrative Practices . . . . . . . . . . . . . 12

3. Technical Practices . . . . . . . . . . . . . . . 14

4. The Role of Calculational Validation $\ldots \ldots \ldots \ldots$

5. Interaction of Safeguards Procedures and Criticality Control $\ldots \ldots 18$ 


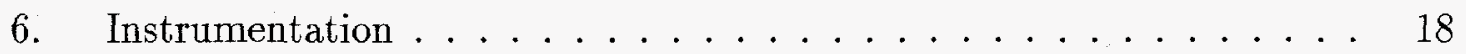

7. Quality Assurance for Criticality Safety . . . . . . . . . . . 19

8. Probabilistic Methods . . . . . . . . . . . . . . . 21

II. SAFETY EXPERIENCE

A. Criticality Accidents ..................... 23

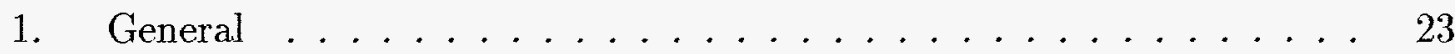

2. Criticality Accidents in Processing Plants . . . . . . . . . . . . 24

3. Examples of Radioactive Contamination from Chemical Explosions . 30

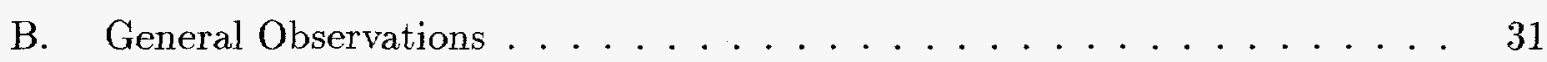

III. LIMITS FOR INDTVIDUAL UNITS

A. Subcritical Limits of Controlling Parameters . . . . . . . . . . . 35

B. Subcritical Limits for Systems of Fissile Nuclides . . . . . . . . . . 36

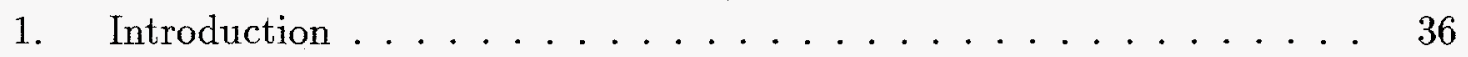

2. Hydrogen-Moderated Systems ............... 36

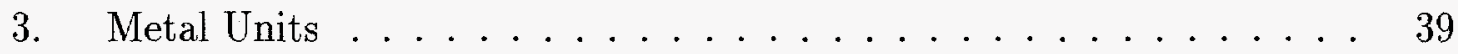

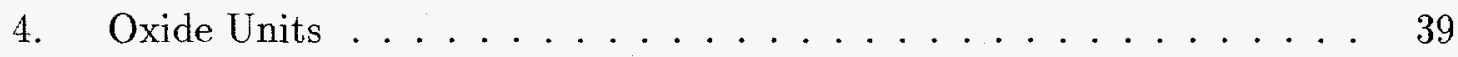

C. Fissile Density Dependent Limits . . . . . . . . . . . . . . . . 42

1. Solutions and Metal-Water Mixtures . . . . . . . . . . . 42

2. Low-Enriched Uranium . . . . . . . . . . . . . . 57

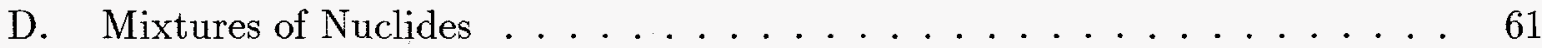

1. Mixtures of ${ }^{233} \mathrm{U}$, Carbon, Water, and Thorium ......... 61

2. ${ }^{235} \mathrm{U}$-Water-Graphite Mixtures .................. 61

3. Plutonium-Uranium Mixtures ................ 63 
E. Special Geometries . . . . . . . . . . . . . . . . . 72

1. Annular Cylinders. . . . . . . . . . . . . . . . 72

2. Pipe Intersections . . . . . . . . . . . . . . . 72

F. Factors Affecting Limits of Individual Units . . . . . . . . . . 74

1. Abnormal Conditions . . . . . . . . . . . . . . . 74

2. Extended Subcritical Limits . . . . . . . . . . . . . 75

3. Neutron Absorbers in Solutions of Fissile Material . . . . . . . 76

4. Concrete as a Reflector . . . . . . . . . . . . . . . . 80

$\begin{array}{lrl}\text { IV. MULTIPLE UNITS } & 81\end{array}$

A. Neutron Interaction . . . . . . . . . . . . . . 81

1. Surface-Density, Density-Analog, and Solid-Angle Methods . . . . . 81

2. Other Methods ..................... 82

B. Storage of Metal and Compounds . . . . . . . . . . . . 83

1. Introduction . . . . . . . . . . . . . . 83

2. Commingling of Dissimilar Units . . . . . . . . . . 85

3. Alternative Representation of Storage Arrays . . . . . . . . . . 85

C. Storage of Solutions . . . . . . . . . . . . . . . . . 92

1. Tanks and Bottles.................... 92

2. Solution Storage using Pipe or Tubing . . . . . . . . . . 94

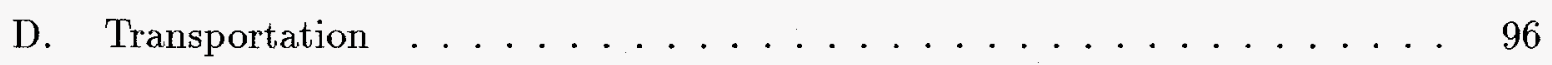

V. CRITICALITY SAFETY IN PROCESSING PLANTS 97

A. Plant Features with Criticality Potential . . . . . . . . . . 97

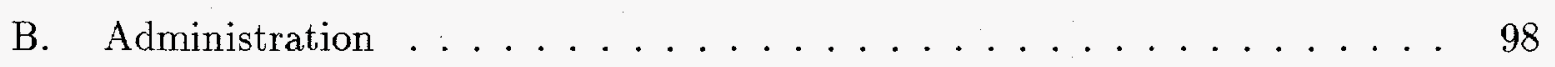

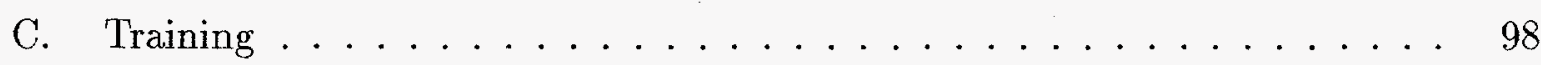

vii 
D. Criticality Alarms and Response . . . . . . . . . . . . . . 98

E. Material Control ....................... 99

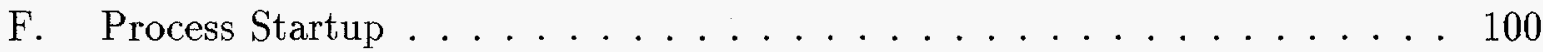

G. Maintaining Safety Provisions . . . . . . . . . . . . . . 101

H. Examples of Plant Application . . . . . . . . . . . . . . 101

1. Dissolver for Water-Reactor Fuel . . . . . . . . . . . . . . 101

2. Storage of Low-Enriched Uranium Solution . . . . . . . . . . . . . 102

3. Solution in Tanks Packed with Boron-Containing Raschig Rings . . . 103

4. Solution Holdup Design . . . . . . . . . . . . . . . . . . 104

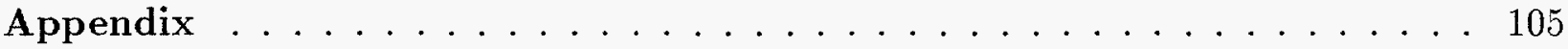

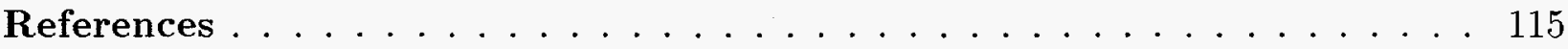




\section{Figures}

1. Approximate Correlations of Dose With Distance from Excursions Normal-

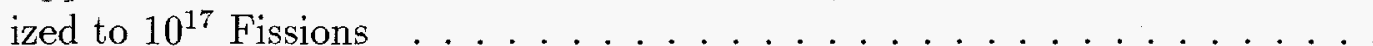

2. Masses of Spheres of Homogeneous Water-Moderated ${ }^{233} \mathrm{U}$ as Functions of ${ }^{233} \mathrm{U}$ Density . . . . . . . . . . . . . . . . . . . . . . . .

3. Volumes of Spheres of Homogeneous Water-Moderated ${ }^{233} \mathrm{U}$ as Functions of ${ }^{233} \mathrm{U}$ Density . . . . . . . . . . . . . . . . . . . . . . . . .

4. Diameters of Infinite Cylinders of Homogeneous Water-Moderated ${ }^{233} \mathrm{U}$ as Functions of ${ }^{233} \mathrm{U}$ Density . . . . . . . . . . . . . . . . .

5. Thicknesses of Infinite Slabs of Homogeneous Water-Moderated ${ }^{233} \mathrm{U}$ as Functions of ${ }^{233} \mathrm{U}$ Density . . . . . . . . . . . . . . . . . .

6. Masses of Spheres of Homogeneous Water-Moderated U(93.2) as Functions of ${ }^{235} \mathrm{U}$ Density . . . . . . . . . . . . . . . . . . .

7. Volumes of Spheres of Homogeneous Water-Moderated U(93.2) as Functions of ${ }^{235} \mathrm{U}$ Density . . . . . . . . . . . . . . . . . . . .

8. Diameters of Infinite Cylinders of Homogeneous Water-Moderated U(93.2) as

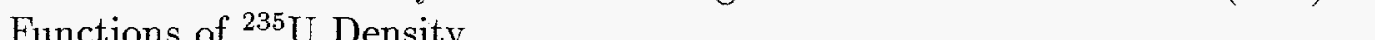

9. Thicknesses of Infinite Slabs of Homogeneous Water-Moderated U(93.2) as Functions of ${ }^{235} \mathrm{U}$ Density . . . . . . . . . . . . . . . .

10. Masses of Spheres of Homogeneous Water-Moderated ${ }^{239} \mathrm{Pu}$ as Functions of ${ }^{239} \mathrm{Pu}$ Density . . . . . . . . . . . . . . . . . . . . .

11. Volumes of Spheres of Homogeneous Water-Moderated ${ }^{239} \mathrm{Pu}$ as Functions of ${ }^{239} \mathrm{Pu}$ Density

12. Diameters of Infinite Cylinders of Homogeneous Water-Moderated ${ }^{239} \mathrm{Pu}$ as Functions of ${ }^{239} \mathrm{Pu}$ Density . . . . . . . . . . . . . . . . . . . . 
13. Thicknesses of Infinite Slabs of Homogeneous Water-Moderated ${ }^{239} \mathrm{Pu}$ as Functions of ${ }^{239} \mathrm{Pu}$ Density . . . . . . . . . . . . . . . . . .

14. Subcritical Mass Limits for Water-Reflected Spheres of Aqueous Mixtures of $\mathrm{PuO}_{2}$ and $\mathrm{U}(0.7) \mathrm{O}_{2} \ldots \ldots \ldots \ldots \ldots \ldots$

15. Subcritical Volume Limits for Water-Reflected Spheres of Aqueous Mixtures of $\mathrm{PuO}_{2}$ and $\mathrm{U}(0.7) \mathrm{O}_{2} \ldots \ldots \ldots \ldots \ldots$

16. Subcritical Diameter Limits for Water-Reflected Infinite Cylinders of Aqueous Mixtures of $\mathrm{PuO}_{2}$ and $\mathrm{U}(0.7) \mathrm{O}_{2} \ldots \ldots \ldots \ldots$

17. Subcritical Thickness Limits for Water-Reflected Infinite Slabs of Aqueous Mixtures of $\mathrm{PuO}_{2}$ and $\mathrm{U}(0.7) \mathrm{O}_{2} \ldots \ldots \ldots \ldots$

18. Boron-to- ${ }^{235} \mathrm{U}$ Atomic Ratio for Subcriticality of Solutions of $\mathrm{UO}_{2}\left(\mathrm{NO}_{3}\right)_{2}$ and $\mathrm{UO}_{3}$-Water Mixtures for Uranium Containing No More Than $5 \mathrm{wt} \%{ }^{235} \mathrm{U}$. .

19. Subcritical Reflected Arrays of Spherical Units of U(93.2) Metal . . . . . 86

20. Subcritical Reflected Arrays of Spherical Units of U(93.2) Oxide at $\mathrm{H} / \mathrm{U} \leq 0.40 \ldots \ldots \ldots \ldots \ldots \ldots \ldots$

21. Subcritical Reflected Arrays of Spherical Units of U(50) Oxide at

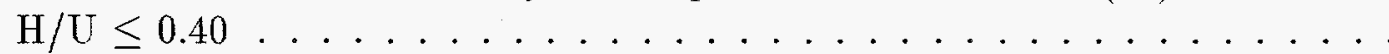

22. Subcritical Reflected Arrays of Spherical Units of $\mathrm{Pu}(94.8)$ Metal . . . . .

23. Subcritical Reflected Arrays of Spherical Units of $\mathrm{Pu}(94.8)$ Oxide at

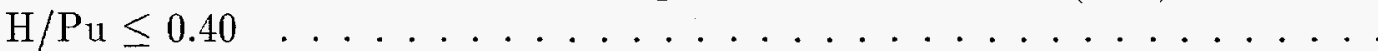

24. Relationship Between Cell Volume and Edge Length of Cubic Cell . . . . . . 


\section{Tables}

1. Single-Parameter Subcritical Limits for Uranium and Plutonium Solutions, Reflected by an Effectively Infinite Thickness of Water . . . . . . . . 38

2. Subcritical Limits for Solutions of $\mathrm{Pu}\left(\mathrm{NO}_{3}\right)_{4}$ Containing ${ }^{240} \mathrm{Pu}$, Reflected by an Effectively Infinite Thickness of Water . . . . . . . . . . . . .

3. Single-Parameter Subcritical Limits for Metal Units, Reflected by an Effectively Infinite Thickness of Water . . . . . . . . . . . . . . .

4. Subcritical Limits for Oxides Containing No More Than $1.5 \mathrm{wt} \%$ Water, at Full Density, Reflected by an Effectively Infinite Thickness of Water . . . . .

5. Subcritical Limits for Oxides Containing No More Than $1.5 \mathrm{wt} \%$ Water, at No More Than Half Density, Reflected by an Effectively Infinite Thickness of

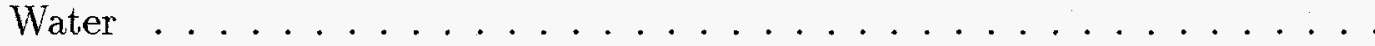

6. Thickness of Reflectors Required for the Criticality of a $21.24-\mathrm{kg}{ }^{235} \mathrm{U}$ Metal Sphere at $18.81 \mathrm{~g} / \mathrm{cm}^{3} \ldots \ldots \ldots \ldots \ldots \ldots$

7. Thickness of Reflectors Required for the Criticality of a $5.32-\mathrm{kg}{ }^{239} \mathrm{Pu}$ Metal Sphere at $19.85 \mathrm{~g} / \mathrm{cm}^{3} \ldots \ldots \ldots \ldots \ldots \ldots \ldots$

8. Subcritical Limits for Solutions of Low-Enriched Uranium, Thick Water Reflector . . . . . . . . . . . . . . . . . . .

9. Subcritical Limits for Low-Enriched Uranium as Oxide-Water and MetalWater Lattices, Thick Water Reflector $\ldots \ldots \ldots \ldots$. . . . . .

10. Subcritical ${ }^{235} \mathrm{U}$ Enrichment Limits for Uranium Mixed Homogeneously with Water . . . . . . . . . . . . . . . . . . .

11. Subcritical Limits for Spheres, Cylinders and Slabs of U(93.5) Metal-WaterGraphite Mixtures . . . . . . . . . . . . . . .

12. Subcritical Mass Limits for Single Units of Mixed Oxides of Plutonium and Natural Uranium, Thick Water Reflector . . . . . . . . . . . . . . . 
13. Subcritical Limits for Plutonium in Plutonium and Natural Uranium Mixtures of Unlimited Mass . . . . . . . . . . . . . . . . . . . .

14. Limiting Subcritical Densities of Unlimited Volumes of Uniform Aqueous Mixtures of $\mathrm{PuO}_{2}$ and $\mathrm{UO}_{2}\left({ }^{235} \mathrm{U} \leq 0.72 \mathrm{wt} \%\right) \ldots \ldots \ldots$

15. Maximum Permissible Densities of Solutions of Fissile Material in Vessels of Unlimited Size Packed With Borosilicate-Glass Raschig Rings . . . . . .

16. Nuclides, Cross-Section Evaluations, and Atomic Weights Used for Calculational Results . . . . . . . . . . . . . . . . . . . . 106

17. Mass Densities Assumed for Water and Fissile Metal . . . . . . . . . 107

18. Calculated Number Densities for the $15.2 \mathrm{~cm}$ Water Reflector . . . . . . 107

19. Fissile Mass Densities and Calculated Number Densities for ${ }^{233} \mathrm{U}$ Metal-Water Mixtures . . . . . . . . . . . . . . . . . . . . . . . . 108

20. Fissile Mass Densities and Calculated Number Densities for U(93.2) MetalWater Mixtures . . . . . . . . . . . . . . . . . . . . . . . . . . . 109

21. Fissile Mass Densities and Calculated Number Densities for ${ }^{239} \mathrm{Pu}$ MetalWater Mixtures . . . . . . . . . . . . . . . . . . . . . . 110

22. Calculated Dimensions for ${ }^{233} \mathrm{U}$ Metal-Water Mixtures . . . . . . . . . 111

23. Calculated Dimensions for U(93.2) Metal-Water Mixtures . . . . . . . . . 112

24. Calculated Dimensions for ${ }^{239} \mathrm{P} u$ Metal-Water Mixtures . . . . . . . . . . . 113 


\section{ABSTRACT}

This technical reference document cites information related to nuclear criticality safety principles, experience, and practice. The document also provides general guidance for criticality safety personnel and regulators. 


\section{PREFACE}

This document is, in spirit, Revision 3 of $T I D$-7016, Nuclear Safety Guide. ${ }^{1}$ Due to changes in the US regulatory climate since the appearance of TID-7016, Nuclear Safety Guide Revision $2{ }^{2}$ we have concluded that a formal Revision 3 is not possible and have elected to change the title to "Nuclear Criticality Safety Guide" to better reflect the scope of the document. This document corrects all known errors in the previous $T I D-7016$ series and incorporates many changes that have been suggested by the criticality safety community.

TID-7016, Nuclear Safety Guide, published in 1957, allowed nuclear criticality data to be made available outside the family of Atomic Energy Commission installations as a result of declassification. Revision 1 of $T I D-7016,{ }^{3}$ four years later, was primarily a refinement based upon experience with the document. An accumulated wealth of experimental data and computational results led to Revision 2 in 1978.

During the past two decades, little new experimental information has been reported, but abundant computational effort has been made. Stimulated by the American Nuclear Society Nuclear Criticality Safety Division, criticality-control problems and their resolution have been frequent topics of discussion. Consequently, this document incorporates little new experimental data, but incorporates modifications intended to extend the document's usefulness. It remains directed toward beginning criticality safety specialists who do not have the traditional background.

In August 1995, this document was reviewed in depth by the editors, four individuals with intimate technical knowledge of the history of the TID-7016 document series, and two individuals from the two funding organizations, the Department of Energy and the Nuclear Regulatory Commission. These eight individuals are listed below.

- Dixon Callihan, Oak Ridge National Laboratory, retired

- Charles Harmon, Nuclear Regulatory Commission

- Calvin Hopper, Oak Ridge National Laboratory

- Elizabeth Johnson, Oak Ridge National Laboratory, retired

- Hugh Paxton, Los Alamos National Laboratory, retired

- Norman Pruvost, Los Alamos National Laboratory, retired

- Burton Rothleder, Department of Energy

- Joseph Thomas, Oak Ridge National Laboratory, retired 
Special thanks is given to Thomas P. McLaughlin, leader of the Nuclear Criticality Safety Group at Los Alamos National Laboratory, to Charles Rombough of CTR Technical Services for his contributions in performing the MCNP calculations and formatting the document, and to Barbara D. Henderson, Los Alamos National Laboratory, for her efforts in editing, proofing, and cataloguing the reference material. We also wish to acknowledge Charles Nilsen of the Nuclear Regulatory Commission for his patient support during the preparation of this document. 


\section{Chapter I}

\section{BACKGROUND}

\section{A. The Nuclear Criticality Safety Problem}

\section{Introduction}

The specific subject of this document is nuclear criticality safety. Nuclear criticality safety is defined as "protection against the consequences of an inadvertent nuclear chain reaction, preferably by prevention of the reaction." ${ }^{4}$ This document treats the fissile nuclides ${ }^{233} \mathrm{U}$, ${ }^{235} \mathrm{U}$, and ${ }^{239} \mathrm{Pu}$. These are the prevalent materials capable of criticality, i.e., capable of sustaining a nuclear chain reaction. ${ }^{*}$ Potential criticality of other, less available nuclides, is discussed in American National Standard Criticality Control of Special Actinide Elements, ANSI/ANS-8.15-1981, ${ }^{5}$ for consideration if a significant separated quantity should become available.

An excursion, the consequence of a nuclear chain reaction, can result if a sufficient quantity of fissile material is arranged into a critical configuration. An excursion resulting from such an accidental configuration is referred to as a criticality accident. The most adverse and potentially dangerous aspect of a criticality accident is the release of nuclear radiation. The radiation released from a criticality accident can be lethal to personnel in the vicinity of the accident. The potential for the accident and associated radiation to damage inanimate objects $^{\dagger}$ or the environment is of some, but relatively minor, concern. Regardless of consequences, the objective of criticality safety remains the prevention of a criticality accident. ${ }^{\ddagger}$

*In this document, "nuclear chain reaction" will be understood to mean "neutron-fission chain reaction."

${ }^{\dagger}$ Some equipment in which a criticality accident has occurred has been returned to service.

${ }^{\ddagger}$ Criticality excursions have occurred in nature. ${ }^{6}$ The practice of nuclear criticality safety, however, is restricted to those situations where man-made processes have the potential for an excursion that is not intended. 
Chapter I presents the principles on which this document is based. For the most part, these principles arise from operational experience instead of abstract reasoning. A statement noted at a Russian conference, Nuclear Energy and Human Safety (NE-93), ${ }^{7}$ goes further: "Safety is based only on experience." Experience has led to the development of criticality safety technology as addressed in this document.

Criticality safety is practiced under well-established limitations which are sometimes overlooked or forgotten. Some of these limitations are imposed by nature. For example, no environment is entirely free of ionizing radiation, even if fissile material is not present. Therefore, exposures to radiation cannot be entirely eliminated. Other limitations result because neither physical nor administrative controls can achieve perfection. For example, safety budget limitations impose the condition that unlimited time and effort cannot be expended in an attempt to establish quantitatively the margin of safety for a particular process. Limitations such as these reduce concepts of perfect safety and a radiation-free environment to simplistic and unachievable idealizations. Recognition of these limitations avoids a diversion from practical criticality safety control.

This document is not intended to substitute for the advice of an experienced criticality safety specialist. It is intended to be a useful reference for the specialist to provide starting points for criticality safety evaluations. Although the document does not address formal regulation, it is expected to provide information that regulators will find useful. The document may benefit people other than specialists or regulators. For example, it may allow managers to confirm criticality safety advice. It may help planners produce preliminary plant layouts that are favorable for criticality control. It can tell the plant superintendent whether a borderline situation may exist in which the advice of a criticality safety specialist is needed.

Terms in this document are used in accordance with definitions in report $L A-11627-M S$, Glossary of Nuclear Criticality Terms, ${ }^{8}$ or the American Nuclear Society publication, Glossary of Terms in Nuclear Science and Technology. ${ }^{9}$

\section{Criticality Safety Principles}

The techniques employed in the practice of criticality safety have been developed since about 1945 and are still evolving. For example, the results of computer calculations are playing an ever larger role in providing guidance for criticality safety. Nevertheless, the safety fundamentals established when criticality safety was in its infancy stand unchallenged to date. These fundamentals are

- All processes with fissile material should be examined during the design phase in order to identify potentially critical configurations. Equipment and procedures should be tailored to preclude those configurations without unnecessarily sacrificing process efficiency. Review is usually iterative, calling for reexamination as the design progresses. This iterative review implies continuing cooperation among members of 
the design team, especially the criticality safety specialists, the designers, and the operators.

- Simple, convenient criticality safety controls are more effective than complex or awkward measures. Above all, criticality controls should be practical because poorly conceived controls that are difficult or impractical to follow invite violations. Stated differently, nuclear criticality safety is enhanced by arrangements of material and equipment that tend to make proper operations convenient and improper operations inconvenient. Unusual situations, however, may call for unusual controls.

- Safety regulations and practices should be based on professionally generated Standards. The ANSI/ANS 8.xx series are consensus Standards and are designed specifically for the practice of criticality safety.

- The criticality safety specialist must examine whether criticality safety restrictions place constraints on the process which might increase the risk in other types of safety.

- Accountability for safety should reside with personnel closest to the operation of the process. These personnel have the most complete knowledge of how all elements of the process come together. Good safety practices must address the specific elements of each process in the language of the operating personnel.

The above principles could be interpreted to suggest that the practice of criticality safety might be reduced to a routine handbook exercise or formulated as a comprehensive methodology. This is not the case for two reasons. First, the experimental data or computational results needed for direct applicability to a process do not always exist. In this case, the criticality safety specialist must be innovative in constructing the analysis which establishes an adequate margin of safety for the process, and must ensure compliance with regulations. Second, in almost all cases, the practicing criticality safety specialist finds that judgment is required to formulate criticality safety guidance. Such judgments are, of course, ultimately influenced by either personal or documented experience. Sound judgment is crucial. This exercise of judgment requires comprehensive understanding of the above principles. The criticality safety specialist must focus on the question, "Have all factors, existing and potential, been taken into account in evaluating the process?"

An advantage of reviews by personnel independent of operations is, for example, to detect deficiencies that may have escaped notice. These reviews may serve other purposes, such as comparing operations with criticality safety standards to uncover possible deviations. Reviews may include internal or external quality assurance audits.

\section{Factors Affecting Criticality}

A system containing fissile material is critical if it maintains a steady self-sustaining nuclear chain reaction. Strictly speaking, in the absence of a neutron source other than fission, this is "delayed criticality." In a critical configuration, then, of the several neutrons produced 
by a single fission, an average of one leads to a new fission, so that the neutron population remains statistically constant with time. The other neutrons are lost either by capture that does not produce fission or by escape from the system. The delicate balance required for criticality depends upon the composition, quantity, and shape of the material, and its environment. In many cases, however, critical specifications need not be complicated. For example, composition and critical mass or critical volume provide specifications adequate for evaluating criticality of a water-reflected sphere. In a subcritical configuration all neutron chains eventually die away to extinction. In a supercritical system, the neutron chains grow until the energy released in the fission process is sufficient to alter at least one of the controlling factors and cause the configuration to become subcritical. This episode, during which the fission rate increases, peaks, then decreases to a low value, is the nuclear excursion referred to in the introduction. In general, criticality can be affected by system mass, shape, volume, moderation, interaction, neutron absorption, reflection, and density.

If a given volume of fissile solution departs from spherical shape, there is an increase of surface area through which neutrons can escape. The neutron deficit resulting from this greater "leakage" makes the system less reactive. This fact underlies the important concept of criticality control by means of favorable geometry. ${ }^{8}$ The most practical shape for criticality control is an elongated cylinder of sufficiently small diameter that the contents will remain subcritical. Another favorable shape is an extensive slab of restricted thickness. Subcritical limits for these shapes are provided in Chapter III. They are expressed as the diameter of a cylinder of unlimited length, and the thickness of a slab of unlimited extent. As with mass and volume limits for spheres, the assumed reflector is thick water.

The critical configuration of fissile material is sensitive to the presence of neutronmoderating nuclides ${ }^{9}$ that reduce the energy of neutrons, for example, hydrogen in water mixed with the fissile nuclide. The subcritical specifications for individual units presented in this document apply primarily to solutions* or mixtures with water, in which hydrogen is the moderating material. The relative amount of hydrogen may be expressed as the atomic ratio of hydrogen to fissile species. This ratio ranges from zero for metal to several thousand for a dilute solution. For a specific solution or uniform mixture, a value of mass of fissile species per unit volume implies a specific hydrogen content. As hydrogen content increases, the critical mass may vary from a few tens of kilograms, through a minimum of a few hundred grams, to unlimited quantities for very dilute solutions. In the latter case, neutron absorption by hydrogen predominates, making criticality impossible provided the hydrogen content is maintained.

With the exception of uranium enriched to less than about 6 weight percent (wt\%) ${ }^{235} \mathrm{U}$, subcritical masses for solutions apply conservatively to other distributions in water at the same hydrogen-to-fissile atomic ratio. The exception for low-enriched uranium is discussed in Chapter III, Section C-2, Low-Enriched Uranium.

\footnotetext{
*Unless specified otherwise, "solution" means "uniform aqueous solution" throughout this document.
} 
The critical mass of a fissile material also depends upon its density and distribution in intimate mixtures with materials other than water. Under most practical circumstances, the critical mass increases as the fissile density decreases, other parameters being constant. The critical mass of a sphere of ${ }^{239} \mathrm{Pu}$ metal, for example, is much less than that of a sphere containing unmoderated ${ }^{239} \mathrm{Pu}$ filings or chips. Exceptions are discussed in Reference 10.

The use of neutron-absorbing materials, such as cadmium and boron, distributed within the fissile material can render an otherwise critical system subcritical. Vigilance must be exercised to avoid unexpected loss of the absorber or change of its prescribed distribution, e.g., by corrosion or physical displacement. Solid absorbers may be included in the construction and assembly of equipment, or solutions of a neutron absorber may be added to process streams. Administrative controls, however, are required to ensure the continued presence and intended distribution of the neutron absorber. Intended neutron absorbers may not be effective if inappropriately located. For example, in the absence of external water, cadmium surrounding a process vessel will serve as a neutron reflector instead of an absorber. This topic is discussed further in Chapter III.

The nitrogen in nitrate solutions often used in chemical processing and the ${ }^{240} \mathrm{Pu}$ present in plutonium solutions are examples of naturally present absorbers. It should be noted, however, that ${ }^{240} \mathrm{Pu}$ is not an effective neutron absorber if little or no hydrogen or other moderator is present.*

The preceding comments have referred to individual units. The effects, however, of the mutual exchange of neutrons between subcritical units in a process or storage area must be considered in order to assess the nuclear safety of the system as a whole (see Chapter IV). Adequate criteria must be established for the separation of units in such arrays. Precautions taken to ensure the integrity of the spacing should receive careful attention, both in the design of plant facilities and in the storage and transport of units. The desire for compactness of storage and shipping arrays, customary in industrial practice, must be tempered where criticality is a possibility.

Neutron interaction in an array of fissile units is dependent upon such geometric factors as the size, shape, and separation of the units, as well as on the over-all size and shape of the array. Materials that may be intermingled among the units or that may surround the array are also important. A close-packed subcritical array may become critical if flooded. Conversely, a flooded subcritical array of large, less closely packed units may become critical if the water is removed, since the water, as a neutron absorber, may diminish neutron coupling of the units. (See Fig. 30 of Ref. 10.) An array that is subcritical when reflected by water may become critical when reflected by closely fitting concrete. These are some of the factors that must be recognized in establishing safe-separation criteria for handling fissile material.

\footnotetext{
${ }^{*}$ A system of metallic ${ }^{240} \mathrm{Pu}$ can become critical.
} 


\section{Criticality Information}

Data from experiments provide the basis for criticality safety, either by direct application or by validation of computations (discussed below). Only rarely, however, do experimental conditions match those of the desired application. Sometimes a close match is unnecessary; that is, measured critical specifications known to be more restrictive than necessary may be adequate. For example, the critical volume of a sphere is a conservative representation* of the critical volume of an elongated cylinder of the same composition. Frequently, however, a validated calculation is required for interpolation or extrapolation of experimental data. In general, experimental data and calculational results are complementary in that each may implement the interpretation of the other.

\section{Experimental Data}

A convenient source of criticality data from experiments through 1985 is the 1986 revision of Critical Dimensions of Systems Containing ${ }^{235} \mathrm{U},{ }^{239} \mathrm{Pu}$, and ${ }^{233} \mathrm{U} \cdot{ }^{11}$ More recent results must be obtained from journals or Transactions of the American Nuclear Society.

Even when criticality is determined experimentally, uncertainties reside in the description of the system. These uncertainties can be expressed as standard deviations of composition and dimensions. In an application of the experimental data, these indexes of uncertainty may be translated into an increment of the effective neutron multiplication factor, $k_{\text {eff }}$, discussed below. This increment must be included to establish the desired margin of safety.

\section{Computational Results}

Insufficient experimental data may be augmented by calculational results of computer criticality codes. The most versatile are Monte Carlo codes, such as KENO, ${ }^{12} \mathrm{MCNP}^{13}$ and MONK, ${ }^{14}$ which are capable of detailed geometric modeling.

Wide use of criticality codes has been made possible by modern, high-performance computers. As with experimental results, computed critical conditions must be evaluated for reliability before they can be applied. The best means of judging the reliability of a computational method is to validate it by comparing its results with appropriate experimental data.

Requirements for code validation are set forth in Paragraph 4.3 of Reference 4. This Standard emphasizes establishment of a bias by correlating experimental and computational results, and by adjusting the computational results to allow for both the bias and the uncertainty in the bias. Tests are required to confirm that the mathematical operations are performed as intended and to reconfirm whenever there is a change in the computer

\footnotetext{
*A conservative representation is one that provides a greater margin of safety than does an accurate representation of the system.
} 
program. Misapplication of codes is not addressed in the Standard because a knowledgeable user would be expected to detect resulting errors.

The provider of requested information concerning validation should not simply extract the desired number from a computer printout and pass it on to the requester. Beforehand, the provider should carefully verify the input file to be free of errors. More generally, as required by the Standard, the provider has the obligation to document the validation of the results.

\section{Criticality Indices}

Simplified methods* for calculating criticality that are found in reactor physics texts ${ }^{15-24}$ do not usually substitute for detailed calculations using computer codes. However, comparison of simple calculational results with results from detailed computer calculations can expose the presence of error. In addition, simplified methods can sharpen the picture of neutron processes that influence criticality, can introduce useful criticality indices, and may even suggest forms for empirical correlations of criticality data.

Two common indices of criticality are the effective neutron multiplication factor and the buckling. The neutron multiplication factor, $k_{\text {eff }}$, is the ratio of the average rate of neutron production by fission to the average rate of loss by absorption and leakage. It follows that a system is critical if $k_{\text {eff }}=1$, subcritical if $k_{\text {eff }}<1$, and supercritical if $k_{\text {eff }}>1$. The multiplication factor is a calculable parameter and is a standard result of criticality computer codes.

A $1 \%$ change in $k_{\text {eff }}$ at critical corresponds to about a $3 \%$ change in critical mass or critical volume for solids, and solutions of ${ }^{233} \mathrm{U},{ }^{239} \mathrm{Pu}$, or uranium highly enriched in ${ }^{235} \mathrm{U}$, over most of the density range. The value is greater for very dilute solutions. For solutions of uranium enriched to $10 \mathrm{wt} \%$ in ${ }^{235} \mathrm{U}$, the increment of critical mass or volume corresponding to $\Delta \mathrm{k}_{\text {eff }}=0.01$ is about $6 \%$ and becomes still larger at lower enrichment. Additional relationships between $\Delta \mathrm{k}_{\text {eff }}$ and increments of criticality parameters are shown in Chapter III, Limits for Individual Units.

The other index, called "buckling" and symbolized by $\mathrm{B}^{2}$, depends only upon the composition of the fissile system and can be used to estimate the critical dimensions of various geometrical configurations. If the buckling is negative, the material is subcritical regardless of the quantity; ${ }^{\dagger}$ if zero, the composition is critical only if the size be infinite; if positive, the material can be critical in finite quantities. The buckling is then simply related by elementary theory to the critical dimensions of spheres, cylinders, and slabs. The

\footnotetext{
*These methods include the four-factor formula, age theory, and one- or two-group diffusion theory.

${ }^{\dagger}$ Some units composed of a material having a negative buckling may achieve criticality with an appropriate reflector.
} 
equations giving these relationships provide the form of empirical expressions for converting from one critical shape to another. ${ }^{23}$

\section{B. Nuclear Criticality Safety Practices}

\section{The General Criticality Safety Standards}

This section expands upon American National Standard Administrative Practices for $\mathrm{Nu}$ clear Criticality Safety, ANSI/ANS-8.19, ${ }^{25}$ and American National Standard for Nuclear Criticality Safety in Operations with Fissionable Materials Outside Reactors, ANSI/ANS8.1. The latter Standard presents generalized basic criteria and specifies numerical subcritical limits for certain simple single fissile units but not for multiunit arrays. The other Standard is also general. It was inappropriate to include in these Standards the details of administrative controls, the design of processes or equipment, the description of instrumentation for process control, or detailed criteria to be met in transporting fissile material because these are items related to specific conditions. The intent here is to provide some of this supplementary guidance.

The predecessor of $A N S I / A N S-8.1$ was prepared in 1958 and adopted in 1964 as American National Standard N6.1-1964. An expanded version was approved as N16.1-1969 and was revised with minor changes in 1975, revised again in 1983 when it was designated ANSI/ANS-8.1, and reaffirmed in 1988. Thus, this Standard benefits from more than three decades of experience following the original version.

Both Standards, ANSI/ANS-8.1 and 8.19, treat Administrative Practices in somewhat different but consistent terms. Technical Practices are considered in ANSI/ANS-8.1.

\section{Administrative Practices}

\section{Responsibilities}

The two Standards require that management establish responsibility for criticality safety and the Standards recommend that supervision be made as responsible for criticality safety as it is for production, development, research, and other functions. Training is called for in accordance with American National Standard Nuclear Criticality Safety Training, ANSI/ANS-8.20. ${ }^{26}$

The Standards require that management provide personnel skilled in the interpretation of data pertinent to criticality safety and familiar with operations, to serve as advisers to supervision. They advise that these specialists, to the extent practicable, be independent of process supervision. This recommendation is not made binding in order to avoid penalizing small operations in which the skill exists in the line organization and a separate adviser 
would be of questionable value. The intent is also to recognize that successful criticality control depends more upon the competence of personnel than on the form of organization.

There is the further requirement that management establish criteria to be satisfied by criticality safety controls. Of course, criteria existing in regulations, Standards, or guides may be either adopted or adapted to special conditions that may exist. In the complementary American National Standard Criteria for Nuclear Criticality Safety Controls in Operations with Shielding and Confinement, ANSI/ANS-8.10, ${ }^{27}$ there is allowance for distinction between shielded and unshielded facilities, so it is recognized that the criteria may be less stringent when adequate shielding protects personnel.

The distinction between "management" and "supervision" is clarified by the following definition that is borrowed from another Standard: ${ }^{28}$ "Management: the administrative body to which the supervision of a facility reports."

\section{Other Administrative Practices}

Standards $A N S I / A N S-8.1$ and 8.19 call for the following additional administrative practices:

"Before a new operation with fissile material is begun or before an existing operation is changed, it shall be determined that the entire process will be subcritical under both normal and credible abnormal conditions." (ANS-8.19, Section 8.1)

This requirement interplays with the technical practices discussed below, especially the double contingency principle and geometry control. In some cases it may be desirable to resort to in situ neutron multiplication measurements to confirm the subcriticality of proposed configurations. Guidance for safety in performing such measurements appears in the American National Standard for Safety in Conducting Subcritical Neutron-Multiplication Measurements in Situ, ANSI/ANS-8.6. ${ }^{29}$

"Operations to which nuclear criticality safety is pertinent shall be governed by written procedures. All persons participating in these operations shall understand and be familiar with the procedures." (ANS-8.1, Section 4.1.3)

"The movement of fissile material shall be controlled. Appropriate materials labeling and area posting shall be maintained specifying material identification and all limits on parameters that are subjected to procedural control." (ANS8.19, Sections 9.1-9.2)

Of course, movement of fissile material is included in the operations to be governed by written procedures. 
"Deviations from procedures and unforeseen alterations in process conditions that affect nuclear criticality safety shall be documented, reported to management and investigated promptly. Action shall be taken to prevent a recurrence." (ANS-8.19, Sections 7.6-7.7)

It is expected that the preventive action, which might include modification of procedures, will be implemented before routine process operations are resumed.

"Operations shall be reviewed frequently (at least annually) to ascertain that procedures are being followed and that process conditions have not been altered so as to affect the nuclear criticality safety evaluation. These reviews shall be conducted, in consultation with operating personnel, by individuals who are knowledgeable in nuclear criticality safety and who, to the extent practicable, are not immediately responsible for the operation." (ANS-8.1, Section 4.1.6)

Again, this recommendation is tempered to avoid penalizing small, inflexible operations or forcing a change in a demonstrably successful organization.

"Emergency procedures shall be prepared and approved by management. Organizations, local and off-site, that are expected to respond to emergencies shall be made aware of conditions that might be encountered, and they should be assisted in preparing suitable procedures governing their responses." (ANS-8.1, Section 4.1.7)

\section{Technical Practices}

Obviously, criticality safety depends upon control of the factors affecting criticality which were discussed in Section A of this chapter. An equivalent statement is that criticality safety is achieved by exercising control over the quantity and distribution of fissile material and associated material. Standard $A N S I / A N S-8.1$, which addresses technical aspects of such control, leads to the following.

\section{Double Contingency Principle}

The double contingency principle is expressed in this Standard as follows.

Double Contingency Principle. Process designs should, in general, incorporate sufficient factors of safety to require at least two unlikely, independent, and concurrent changes in process conditions before a criticality accident is possible.

The principle implies good judgment that is difficult to specify in detail and to confirm. Nevertheless, consideration of this time-honored principle is a part of sound criticality safety practice. 


\section{Geometry Control}

The Standard also recommends that reliance for criticality control be placed, where practicable, on equipment in which dimensions are fixed and limited rather than on administrative controls. There is the requirement, however, that all dimensions and fissile material properties on which the reliance is placed be controlled. It is pointed out that full advantage may be taken of fissile material characteristics and of equipment. Of course, controls must be effective during inventory procedures and while equipment is being loaded or unloaded with fissile material.

\section{Control by Neutron Absorbers}

Because of accidents that have occurred during inventory, ${ }^{30}$ the trend is to "poison" large vessels for which geometry control is impractical. The Standard permits reliance upon neutron-absorbing materials, such as cadmium, boron, or gadolinium, in process streams or equipment, provided there is assurance that the absorber continues to be effective. Particular care is required when the absorbers are in solution.

A proven and often effective means of preventing criticality in a large vessel is to pack it with borosilicate glass Raschig rings. Guidance for permissible usage, degree of protection, and appropriate surveillance is given by American National Standard Use of Borosilicate-Glass Raschig Rings as a Neutron Absorber in Solutions of Fissile Material, ANSI/ANS-8.5. ${ }^{31}$

\section{Subcritical Limits}

The Standard ANSI/ANS-8.1 emphasizes subcritical limits, discussed earlier, and defines them as follows.

Subcritical limit (limit). The limiting value assigned to a controlled parameter that results in a subcritical system under specified conditions. The subcritical limit allows for uncertainties in the calculations and experimental data used in its derivation but not for contingencies, e.g., double batching or failure of analytical techniques* to yield accurate values.

The above definition, however, does not explicitly clarify that, in practice, subcritical limits are adjusted criticality data. The adjustments to the data allow for uncertainties in the data. It should be understood that subcritical limits do not apply directly to the conditions encountered in operations with fissile material. Criticality safety analysis incorporates subcritical limits and contingencies that could be encountered in the operation. Where applicable data are available, the Standard requires that subcritical limits be established on bases derived from experiments with adequate allowance for uncertainties in the data. In the absence of directly applicable experimental measurements, it is permissible to derive the limits from calculations validated in accordance with Paragraph 4.3 of the Standard. It

* Examples of such analytical techniques are radiological, chemical, and isotopic analyses. 
should be reiterated that allowances must be sufficient to cover uncertainties in the data and in the calculations.

Subcritical limits for mass, volume, and other parameters, which appear in Chapter III, assume the equivalent of a contiguous water reflector of unlimited thickness (thick water reflector), and allow for experimental and computational uncertainties. They do not, however, cover contingencies such as errors in quantitative measurements or sample analyses, misinterpretation of procedures, and human fallibility. Allowance for these depends upon process specifics, and, for evaluation, calls for the judgment of plant personnel and the advice of a criticality safety specialist.

The assumed thick water reflector is seldom encountered in practice. Nevertheless, the thick water reflector is a useful reference condition. As discussed later, some materials, when thick and closely fitting, can be more effective as reflectors than ordinary water. If such materials are present, special evaluation is needed, probably requiring the use of experimental data. In the absence of such materials, the equivalent of a thick water reflector $(15 \mathrm{~cm}$ or more) is a reasonably conservative representation of other common reflector materials.

A nearby interacting fissile unit may also be more effective than a water reflector, so would require special consideration. In evaluating interaction of a few units, comparison with a larger, somewhat more reactive, array from Chapter IV may be a useful conservative extreme. Sometimes, however, a more appropriate experimental system may be found in other references, for example, in Reference 11, Critical Dimensions of Systems Containing ${ }^{235} \mathrm{U},{ }^{239} \mathrm{Pu}$, and ${ }^{233} \mathrm{U}$. Where interaction of several vessels, such as those in a processing plant must be judged, one of the semi-empirical methods of Chapter IV may be adequate.

\section{The Role of Calculational Validation}

The need for calculational validation arises when the system of interest has not been built as an experimental configuration. In practice, this is almost always the situation. The purpose of calculational validation is to establish a credible calculational model relating experimental data and the system of interest. In this context, calculational model means both the mathematical model for neutron transport and the evaluated cross section data used in the model. The experimental data must be derived from an experimental critical configuration that is similar in geometry and material composition to the system of interest. Similarity is a matter of judgment. The spirit of validation is to recognize that uncertainties are inherent in both the calculational model and experimental data. The usefulness of validation is that credible information can be gained about the system of interest even though these uncertainties exist.

Reported experiments do not always include the details needed to reduce the experiment to an ideal macroscopic description of the system geometry and material. Different evaluators may derive different macroscopic descriptions from the same experimental results. There is no assurance, therefore, that reported experimental results, when evaluated by different 
evaluators, will lead to a unique macroscopic description of the system. Also, very few reported experimental critical configurations include any analysis of the uncertainty. References 32 and 33 are unusual in that examples of the experimental uncertainties in the experimental results were given. The uncertainties were estimated from calculational corrections in both geometry and the material composition. In each case, these corrections were used to simplify the description of the system. Such calculational corrections are imperfect and are incapable of eliminating the experimental error. In practice, it must be understood that experimental results can never be made free of error and that the estimation of experimental error unavoidably involves judgment. Such judgment is involved whether adjustments to experimental results are based on calculations or on experimental measurements.

Calculational validation requires that $k_{\text {eff }}$ be calculated for at least one experimental critical system similar to the system of interest. Comparison of the calculated $k_{\text {eff }}$ with unity establishes a numerical difference. Standard ANSI/ANS-8.1 appears to make a working assumption when determining the bias between calculational results and experimental data. This apparent assumption is that experimental and calculational uncertainties are negligible or zero compared to the bias. Such an assumption leads to assigning the bias as equal to the numerical difference. At this stage of the validation process, however, the practitioner should review the definition of bias provided in the Standard's glossary of terms. Simply assigning the bias to be equal to the numerical difference may not be sufficient to be in compliance with the Standard. In the Standard, bias is defined as "A measure of the systematic disagreement between the results calculated by a method and experimental data. The uncertainty in the bias is a measure of both the precision of the calculations and the accuracy of the experimental data." Clearly, this definition requires the practitioner to establish the bias on the basis of the numerical difference and assessment of the potential experimental uncertainties.

The Standard leaves several matters of judgment to the practitioner. For example, if only a single experimental system is available to establish a numerical difference, this single difference would not constitute a "systematic disagreement between the results calculated by a method and experimental data." With regard to the uncertainty in the bias, the bias becomes undefined when the uncertainty of the experimental data is large compared to the numerical difference. As mentioned above, reported experimental results do not always include the experimental uncertainty. The Standard points out "generally neither the bias nor its uncertainty is constant; both should be expected to be functions of composition and other variables." Judgmental matters such as these play a crucial role when extrapolating the applicability of a calculational method beyond the range of experimental conditions over which the bias was established. 


\section{Interaction of Safeguards Procedures and Criticality Control}

Safeguards procedures may have either a favorable or detrimental effect on criticality control, so interaction of these procedures with criticality safety should be examined before they are instituted. Periodic surveys of chemical processing lines for material accountability can actually contribute to criticality safety by detecting unanticipated deposits of fissile material. ${ }^{34-36}$

On the other hand, the implementation of safeguards procedures may favor arrangements of fissionable objects that detract from criticality safety. For example, it may be convenient to cluster the objects in an easily protected location instead of spreading them out for better criticality control. When recognized, such conflicts should be readily resolved.

\section{Instrumentation}

An important contribution of instrumentation to criticality safety is demonstration of adequate subcriticality of a fissile system. For example, this demonstration can be the quantitative measurement of $k_{\text {eff }}$ by means of the ${ }^{252} \mathrm{Cf}$-source-driven neutron noise analysis method. ${ }^{37}$ This method has been used to measure the subcriticality of a multiplying system to a $k_{\text {eff }}$ as low as 0.3 with data accumulation in as little as six seconds for a uranyl nitrate solution tank. Before this technique was developed, measurements of characteristic radiation* could indicate changes in quantity of fissile material, but required calibration to give quantitative results. ${ }^{38-40}$ Special instrumentation for measuring the ${ }^{235} \mathrm{U}$ content of uranium involves the so-called random-source technique. ${ }^{\mathbf{4 1 - 4 2}}$

Another contribution of instrumentation to criticality safety is the identification of unplanned deposits of fissile material by means of changes of characteristic radiation. Periodic surveys of deposits are desirable where fissile material may accumulate in locations such as filters, tank walls, or solution residues. ${ }^{\dagger}$ In gaseous diffusion plants, for example, accumulations of ${ }^{235} \mathrm{U}$ have been detected by periodic measurement of characteristic gamma radiation from ${ }^{235} \mathrm{U}$. Such measurements allow removal of the accumulations before they became dangerous. $^{36}$

Another method makes use of the high spontaneous fission rate of the ${ }^{240} \mathrm{Pu}$ isotope which accompanies ${ }^{239} \mathrm{Pu}$ in a proportion characteristic of the material history. The neutron background in a plutonium process is therefore a measure of the plutonium density, and a change in an established background can signal an abnormal condition in a process stream. Because of this effect, surveys with neutron detectors can establish the location of

\footnotetext{
${ }^{*}$ Characteristic radiations include 1) gamma rays from ${ }^{235} \mathrm{U}$ and plutonium, 2) neutrons from spontaneous fission of ${ }^{240} \mathrm{Pu}$ and $\left.{ }^{238} \mathrm{U}, 3\right)$ neutrons from $(\alpha, \mathrm{n})$ reactions of fissile oxides, carbides, and fluorides, and 4) high energy gamma radiation from ${ }^{208} \mathrm{Tl}$, a decay product of ${ }^{232} \mathrm{U}$ that usually accompanies ${ }^{233} \mathrm{U}$.
}

†In some cases, inventory discrepancies can indicate the possibility of such deposits. See Ref. 35. 
unplanned plutonium deposits. ${ }^{43}$ These indirect methods of criticality control are empirical and must be based on the calibration of appropriate instruments.

It might seem that warning of an accidental approach to criticality could be given by a neutron detector. Such a warning would require an appropriately placed neutron source such as those used for subcritical in situ multiplication measurements. ${ }^{29}$ It is rare, however, that plant process conditions are sufficiently favorable and stable for a meaningful indication of increased neutron multiplication before criticality would be attained. The warning probably would be too late except to signal personnel evacuation. However, absorption by the fissionable material of gamma rays or neutrons directed through a process stream depends upon the fissile density of the solution and can be used for fissile density control if there is a suitable source and detector. ${ }^{44-45}$

Instruments for the detection of radiation are also useful in criticality accident alarm systems that provide a signal for evacuation. The value of these systems has been clearly demonstrated as will be seen in Chapter II. Gamma-ray detectors rather than neutron detectors are usually selected. Reliable instrumentation and freedom from false alarms are more important than sensitivity. The requirements on such instrumentation are addressed in American National Standard Criticality Accident Alarm System, ANSI/ANS-8.3. ${ }^{46}$

\section{Quality Assurance for Criticality Safety}

Quality assurance is defined as follows in the Quality Control Handbook. "Quality assurance is the activity of providing, to all concerned, the evidence needed to establish confidence that the quality function is being performed adequately." "The quality function is the entire collection of activities through which we achieve fitness for use, no matter where these activities are performed."

The relevant quality assurance Standards are American National Standard Quality Assurance Program Requirements for Nuclear Facilities, ASME NQA-1-1989, ${ }^{48}$ issued by the American Society of Mechanical Engineers and supplementary American National Standard Quality Assurance Requirements for Nuclear Facility Applications, ASME NQA2-1989. ${ }^{49}$ Between them they contain the essence of 15 quality assurance standards of the ANSI/ASME N45.2 series. The 18 Basic Requirements of NQA-1 with Supplements have been applied in full to power reactors but are intended to be selective for other applications. As stated in the foreword, "The extent to which this document should be applied, either wholly or in part, will depend upon the nature and scope of the work to be performed and the relative importance of the items or services being produced. The extent of application is to be determined by the organization imposing this document. For example, it may only involve the Basic Requirements; Basic Requirements in combination with selected Supplements; Basic Requirements in combination with Supplements with appropriate changes; or the entire document." 
The complexity and sensitivity of power reactors led to adoption of all Supplements as well as Basic Requirements. The Basic Requirements are generally adequate for nonreactor operations with fissile material, which are much simpler and avoid the critical condition that is maintained so sensitively in reactors.

The 18 Basic Requirements of $N Q A-1$ are summarized as follows. Titles from the Standard are in boldface.

Basic Requirements of Standard NQA-1:

1. Description of organization, assignments of responsibility and authority.

2. Description of quality assurance program and its implementation including training.

3. Design control and verification, design change control.

4. Procurement document control, applicable design bases.

5. Instructions, procedures, and drawings governing activities.

6. Document control, including distribution, changes, and reviews for adequacy.

7. Control of purchased items and services, suppliers' evidence of quality.

8. Identification and control of items, maintenance thereof.

9. Control of processes, qualification of personnel such as welding personnel, and procedures.

10. Inspection by persons not directly involved in operations.

11. Test control, including plans, documentation, and evaluation.

12. Control of measuring and test equipment, including periodic calibration.

13. Handling, storage, and shipping, cleaning and packaging.

14. Inspection, test, and operating status, prevention of inadvertent operation.

15. Identification and control of nonconforming items to prevent inadvertent use.

16. Corrective action of conditions adverse to quality.

17. Quality assurance records, retrievability and protection.

18. Audits by persons independent of operations, written procedures or checklists. 
The Standard ANSI/ANS-8.19, Administrative Practices for Nuclear Criticality Safety, addresses Basic Requirements 1, 3, 5, 6, 8, 10, 13, 14, 16, and 18. Guidance is given in ANSI/ANS-8.20 for the training portion of 2, 9, and 11. Thus, observing these standards takes a major step toward satisfying quality assurance requirements. Application of the remaining Basic Requirements depends upon the nature of the operation, for example, the degree to which there is dependence on procured items, or reliance on tests.

It follows that provisions of Standards ANSI/ANS-8.19 and 8.20, and several selected Basic Requirements of $N Q A-1$, can constitute an appropriate checklist for monitoring quality assurance conformance of nonreactor operations that require criticality control. With this checklist, quality assurance auditing can become more than a formality.

Adequate documentation is necessary even when good practices are observed. Without adequate documentation, surveys and audits become unnecessarily burdensome.

\section{Probabilistic Methods}

It is not obvious that power-reactor safety practices such as Probabilistic Risk Assessment (PRA) should be applied to other operations such as operations with fissile material in which consequences of potential accidents may be orders of magnitude less than those for power reactors. Guidance for deciding in a given situation whether PRA is appropiate as opposed to qualitative evaluation is given in a JBF Associates report, Evaluating Process Safety in the Chemical Industry, A Manager's Guide to Quantitative Risk Analysis. ${ }^{50}$

Residual fission products in a fuel reprocessing plant increase the presumed consequences of a criticality accident. This presumption can lead to interpreting Reference 50 guidance as recommending PRA. Wilson ${ }^{51}$ of the Idaho Chemical Processing Plant concludes the following about the application of PRA.

"PRAs can be a very useful tool in setting criticality safety margins as long as careful planning goes into deciding when and how to use PRAs, particularlý:

1. Don't allow the mystique of PRA to cause you to take actions which are inappropiate or not cost effective.

2. Recognize the power of PRA and exert your full efforts to bring it to bear on your problems.

3. Structure your PRA program from the ground up (be involved in setting safety goals and training).

4. Until the remaining subjectivity and predictive uncertainty can be removed from PRAs, a companion qualitative goal, such as the contingency approach, should also be employed." 
Regarding item 4 above, it should be recognized that the "remaining subjectivity and predictive uncertainty" may never be removed from PRAs. Experts in the application of PRA emphasize its usefulness early in the life of a project. ${ }^{52}$ The need for updating, as appropriate, is implied.

In addition to its part in criticality control, PRA can be a useful regulatory adjunct when combined with Nuclear Regulatory Commission Regulatory Guide 3.33..$^{53}$ An illustration by Thomas and $\mathrm{Gmal}^{54}$ is the application of PRA to satisfy a licensing requirement for accident dose restriction outside a German fuel reprocessing plant.

For a situation different from a fuel reprocessing plant, PRA has been tested for one operation at the Plutonium Facility at Los Alamos. This exercise was conducted by an independent organization, and is mentioned in a paper by McLaughlin. ${ }^{55}$ McLaughlin argues in his paper that the estimated few million dollars cost of PRA for the entire Plutonium Facility "could be better used on control measures such as more criticality staff presence on the process floor." This observation is not surprising if the guidance of Reference 50 is considered. In the absence of fission products, foreseeable consequences of a criticality accident with plutonium are so limited that this guidance calls for qualitative analysis instead of PRA.

Many applications of criticality safety involve systems where hands-on operations take place with a few fissile-bearing components. In addition, only two or three persons may be authorized to carry out the work. The elements which need be considered to carry out a criticality safety analysis in such a situation appear relatively simple when compared with the complexity inherent in power-reactor safety analysis. In the exercise described by McLaughlin, the application of PRA did not reveal any elements that were not incorporated by prior qualitative criticality safety analysis. Experience, however, indicates that this may not always be the case for complex systems. System complexity and the potential consequences of an accident can both play a role in the decision to apply PRA.

The use of PRA in criticality safety was the subject of several papers presented at the Fifth International Conference on Nuclear Criticality Safety (ICNC '95) ${ }^{56}$ The conclusion of the ICNC ' 95 reviewers was, "It is evident that more experience is needed before these methods will be generally accepted."*

\footnotetext{
*C. V. Parks and G. E. Whitesides, "Summary of ICNC '95," distributed to conference attendees after the meeting.
} 


\section{Chapter II}

\section{SAFETY EXPERIENCE}

\section{A. Criticality Accidents}

\section{General}

Present-day criticality controls have been influenced strongly by accidental excursions that have occurred in processing plants in the United States and the United Kingdom. The effectiveness of resulting controls is suggested by the fact that there have been few accidents since the cluster of six that occurred between 1958 and 1964.

There have been eight supercritical accidents in chemical process equipment but none associated with mechanical processing, storage, or transportation. All occurred with aqueous solutions: five involved highly enriched uranium and three involved plutonium. Three of the excursions took place in shielded areas designed for processing irradiated fuel, consequently personnel were protected from the direct radiation.

The consequences of the eight accidents have been two deaths, nineteen significant overexposures of personnel to radiation, no equipment damage, and negligible loss of fissile material. In no case was there any danger to the general public. No incident is attributable to faulty criticality information or to error in its interpretation. Rather, in each case, the cause was related to misuse of equipment, procedural inadequacies or violations, or combinations of these. Most of these accidents resulted in prompt criticality.

Before proceeding from these general remarks to more specific features of the accidents, it may be useful to picture the usual characteristics of a prompt power excursion ${ }^{8}$ in a solution. ${ }^{57}$ Typically, there is a "fission spike" which may or may not be followed by an oscillatory fluctuation of power. Depending upon the circumstances, secondary spikes or pulses may occur. The fission spike may be described as beginning with an exponential rise in power upon achievement of supercriticality. The rise is arrested by bubbles formed principally by radiolytic dissociation of water, and the solution is driven subcritical causing the power to decrease. The sharp rise and fall in power, i.e., the release of energy at high 
power but limited to short duration, characterizes the fission spike. If there is no immediate terminating mechanism, this process may be repeated, usually less energetically. Ultimately, upon disappearance of the bubbles, increase in temperature and possible boiling may lead to a quasi-equilibrium condition. This course of events would be affected by changes in conditions that may occur, such as continued addition of material, or loss of material by splashing or evaporation. Of course, loss of solution or redistribution of material may terminate the reaction after the initial burst.

The energy releases associated with the occurrences described below are expressed as numbers of fissions. For convenience, it is noted that $3 \times 10^{16}$ fissions release $1 \mathrm{MW}$-sec, or $10^{6} \mathrm{~J}$, or $240 \mathrm{kcal}$, or $950 \mathrm{BTU}$ of energy. Most of this energy is deposited in the solution as heat.

A complete listing of criticality accidents before 1990 appears in a review by Stratton, revised by Smith. ${ }^{30}$ Details are given in the references cited. Although we will confine our attention to accidents in processing plants, conditions that have led to accidental excursions in critical facilities* are also instructive, and are discussed in the above review. The following accounts of plant accidents are intended to provide not only an idea of the consequences but a general introduction to nuclear criticality safety practices.

\section{Criticality Accidents in Processing Plants}

\section{The Y-12 Plant, Oak Ridge National Laboratory, TN - June 16, 1958 ${ }^{30,57-60}$}

The first of the eight plant excursions was the result of solution leaking into a cleaned cylindrical vessel and being collected with wash water in a 55-gal drum. As a consequence, five persons were exposed severely and three others significantly.

The accident occurred in an area in which highly enriched uranium was being recovered from scrap. In the course of a material inventory, a bank of geometrically subcritical storage vessels had been disassembled and cleaned. Following reassembly, procedures called for leak testing with water, which was to be subsequently drained into a 55-gal drum. In the interval between reassembly and leak testing, uranium solution had accumulated in the vessels through a valve that was supposed to provide isolation from operating equipment upstream. The water being drained into the drum was preceded by this solution. Initial criticality occurred with about $2.1 \mathrm{~kg}$ of ${ }^{235} \mathrm{U}$ in 56 liters of solution. A succession of pulses then produced a total of $1.3 \times 10^{18}$ fissions (mostly within $2.8 \mathrm{~min}$ ) before further dilution decreased the uranium density until the system became subcritical after about $20 \mathrm{~min}$. Although the magnitude of the first and largest pulse was not recorded, subsequent excursion experiments ${ }^{57}$ suggest a probable value of about $10^{16}$ fissions. An initial "blue flash" was observed, and there was no evidence that solution splashed out of the open container.

${ }^{*} \mathrm{~A}$ critical facility is a facility where the critical condition is approached or achieved by plan. 
One person who was about 2 meters from the drum at the onset of the excursion received a whole-body dose of $\sim 461 \mathrm{rem}^{8}(4.61 \mathrm{~Sv})$. Other exposures were $428 \mathrm{rem}$ at $\sim 5.5 \mathrm{~m}$, $413 \mathrm{rem}$ at $\sim 4.9 \mathrm{~m}, 341 \mathrm{rem}$ at $\sim 4.6 \mathrm{~m}, 298 \mathrm{rem}$ at $6.7 \mathrm{~m}, 86.5 \mathrm{rem}$ at $9.4 \mathrm{~m}, 86.5 \mathrm{rem}$ at $11 \mathrm{~m}$, and $28.8 \mathrm{rem}$ at $15.2 \mathrm{~m}$. These exposures and distances from the drum do not correlate in detail because some exposure may have been incurred during evacuation. Further, it appears that the closest man, who left most rapidly, was exposed for about 5 sec to radiation associated with the initial pulse. Others, responding to the evacuation alarm, presumably were exposed for about $15 \mathrm{sec}$, which is roughly the interval between the first two pulses. It is apparent that exposures were limited by prompt evacuation.

The following two changes in operating procedures were adopted following the accident. First, whenever transfer lines containing fissile material needed to be isolated from other equipment, they were physically disconnected instead of relying on valves. Second, only vessels that would be subcritical when filled with ${ }^{235} \mathrm{U}$-enriched uranium solutions, that is, those with favorable geometry, ${ }^{8}$ were permitted in solution areas.

\section{The Los Alamos Scientific Laboratory, NM - December 30, $1958^{30,57,61}$}

The next accident resulted from concentrated plutonium in a solvent layer which was found in a large tank that was supposed to contain only lean aqueous-organic emulsion. A transient change of shape of the solvent layer when a stirrer was started established criticality of short duration. The result was a fatality and two other significant exposures.

The accident occurred in an area where residual plutonium, usually about $0.1 \mathrm{~g} / \mathrm{L}$, and americium were recovered from dilute raffinate. Because the normal plutonium inventory was only $0.1 \mathrm{~kg}$, solvent extraction was conducted in large closed tanks. As at Y-12, a material inventory was in progress and it was intended that the tanks be emptied and cleaned individually. Instead, residues and acidic wash solutions from four vessels were combined in a single 850-liter, 96.5-cm-diameter tank. Many interconnecting transfer lines made this possible. An excursion of $1.5 \times 10^{17}$ fissions occurred when a stirrer in this tank was started.

As discovered later, a 20.3-cm-thick, 160 liter, organic layer floating on a dilute aqueous solution contained $3.10 \mathrm{~kg}$ of plutonium. It is presumed that the source of this plutonium was solids that had accumulated gradually in the tanks and transfer lines during 7.5 years of operations. The initial effect of the stirrer was to disturb the organic layer sufficiently for supercriticality. The stirring rapidly mixed the two phases, diluting the plutonium to a subcritical density. 
The operator, who was looking into the tank through a viewport, received an exposure of $(12 \pm 6) \times 10^{3}$ rem and died 36 hours later. Two men who went to aid the victim received doses of 134 and $53 \mathrm{rem}$. There was neither damage to equipment nor contamination although a shock displaced the tank support about $1 \mathrm{~cm}$. A recording radiation detector ${ }^{62}$ 53 meters away was activated ${ }^{*}$ and a flash of light was seen from an adjoining room.

The entire recovery plant, which had been scheduled for rebuilding after another six months of operation, was retired immediately. After ultimate conversion to geometrically subcritical equipment, the following corrective measures were adopted. Unnecessary solution-transfer lines were avoided, and auxiliary vessels such as vent tanks and vacuum-buffer tanks were "poisoned" with borosilicate glass Raschig rings. Additionally, written procedures and nuclear-safety training were improved. Periodic surveys with portable neutron detectors to locate abnormal plutonium deposits were instituted. The accident also led to more complete coverage of process areas by improved gamma-ray-sensing radiation alarms.

\section{The Idaho Chemical Processing Plant, Idaho Reactor Testing Area, ID - October 16, $1959^{30,57}$}

This excursion was the result of inadvertently siphoning highly enriched uranium solution from a bank of geometrically subcritical storage cylinders into a large waste tank. Although heavy shielding required for irradiated-fuel processing protected personnel from direct radiation, fission products vented into working areas resulted in two significant dosages, of 50 and $32 \mathrm{R}$ (roentgen $)^{8}$, mostly as beta radiation to the skin.

The siphoning, through a trapped vent system to the waste tank, started as a result of air sparging the storage cylinders. About 200 liters of solution containing $34 \mathrm{~kg}$ of ${ }^{235} \mathrm{U}$ transferred into about 600 liters of water in the $1.9 \times 10^{4}$-liter waste tank. Criticality in this tank led to a total of $4 \times 10^{19}$ fissions over a period of about $20 \mathrm{~min}$. It is postulated that an initial spike of $\sim 10^{17}$ fissions was followed by smaller pulses, then by more-or-less stable boiling that distilled 400 liters of water into another tank. The exceptionally large yield was the result of the large solution volume and long duration of the reaction, not of the intensity of the excursion.

The incident disclosed the need for improved evacuation procedures and demonstrated the value of radiation alarms in areas that might be affected by an excursion elsewhere. Equipment and operating procedures were modified to establish several lines of defense against inadvertent transfer of fissile material.

\footnotetext{
${ }^{*}$ The radiation detector did not produce an audible warning sound and hence was not a criticality accident alarm.
} 


\section{The Idaho Chemical Processing Plant, Idaho Reactor Testing Area, ID -}

January 25, $1961^{30,57}$

This excursion occurred when a large air bubble forced enriched-uranium solution out the top of a 12.7-cm-diameter section of an evaporator and into a $61-\mathrm{cm}$-diameter vapordisengagement cylinder above the normal solution level. The heavy concrete shielding required for irradiated-fuel processing protected personnel from direct radiation, the ventilation system prevented airborne activity from entering work areas, and equipment design excluded the possibility of a destructive or persistent excursion. Nevertheless, this incident is instructive because consequences could have been serious in an unshielded area.

Apparently air used to clear a plugged line and to improve operation of two pumps was the source of the bubble that forced 40 liters of solution containing $8 \mathrm{~kg}$ of ${ }^{235} \mathrm{U}$ into the larger-diameter section. The resulting excursion, probably a single pulse, had a magnitude of $6 \times 10^{17}$ fissions. Operation was resumed within an hour.

Because the possibility of an excursion in the vapor-disengagement cylinder had been foreseen, there was provision for drainage into a subcritical configuration, which prevented both pressure buildup and a sustained reaction. Although consequences were minor, the 61-cm-diameter cylinder ultimately was "poisoned" by a grid of stainless steel plates containing $1 \mathrm{wt} \%$ natural boron. Steps were also taken to prevent the introduction of air into solution lines where the effect could be undesirable.

\section{The Recuplex Plant, Hanford Works, WA - April 7, 1962 ${ }^{30,57,63}$}

This incident occurred when liquid from a sump was collected in a 69-liter, 45.7-cm-diameter vessel. The liquid, unidentified at the time, was subsequently shown to contain between 1400 and $1500 \mathrm{~g}$ of plutonium in a volume of about 46 liters after the addition of lean solutions. The only significant exposures were 110,43 , and 19 rem, received by personnel at distances from the excursion of about $2.1,3.2$, and $7 \mathrm{~m}$, respectively.

The accident took place in plutonium-recovery equipment located in a room-size glove box. The vessel in which the excursion occurred was normally used for transfer of a dilute sidestream from solvent-extraction columns to a secondary recovery process, similar to the raffinate-treatment process of the Los Alamos accident. Apparently the concentrated solution had overflowed from a favorable geometry tank and was sucked into the $45.7-\mathrm{cm}$ diameter vessel through a temporary line used for cleanup operations that were in progress. A total yield of $8.2 \times 10^{17}$ fissions occurred over 37 hours, with about $20 \%$ of the energy released in the first half hour. An initial pulse of no more than $10^{16}$ fissions was followed by smaller pulses for about $20 \mathrm{~min}$., after which boiling ultimately distilled off enough water to stop the reaction.

The initial pulse, accompanied by the usual blue flash, triggered a criticality accident alarm, and the area was evacuated promptly, presumably before a second pulse. A unique feature of the analysis of events was the use of a small, remotely controlled robot developed for handling irradiated fuel. By means of this device, the excursion site was located, meters were positioned and read, and valves were operated without exposures to personnel. 
A new plant to replace Recuplex had been authorized before the accident, and operations were not resumed until it became available. In the modern plant, vessels that are not subcritical by favorable geometry usually contain neutron absorbers, the system is adaptable to a variety of uses without improvisation, and equipment is easier to keep clean.

\section{Wood River Junction Plant, RI - July 24, 1964 ${ }^{30,57}$}

This accident was initiated when concentrated enriched-uranium solution was inadvertently poured into a $46-\mathrm{cm}$-diameter tank. The first of two excursions resulted in a lethal exposure and the second, about 2 hours later, was primarily responsible for two other significant radiation doses.

Startup difficulties in this plant for recovering highly enriched uranium from scrap led to an unusual accumulation of trichloroethane (TCE) solution of low uranium density. Small amounts of uranium were recovered by tedious hand agitation of the TCE with sodiumcarbonate solution. An easier process was improvised, in which the TCE was treated in the 46-cm-diameter tank that had been intended only for the makeup of sodium-carbonate solution used in the normal recovery process. Neither the plant superintendent nor one of three shift supervisors was aware of this practice. Meanwhile, solutions of unusually high ${ }^{235} \mathrm{U}$ density, resulting from cleanout of plugged equipment, had been stored in 11liter, 12.7-cm-diameter bottles identical to those that contained the contaminated TCE. Apparently, a bottle of the concentrated solution was mistaken for TCE and was poured into the sodium-carbonate solution being stirred in the makeup tank. The shock from a single pulse of $\sim 10^{17}$ fissions knocked the operator onto the floor and splashed part of the solution out of the tank. A flash of light was observed. The victim received an exposure estimated to be $10,000 \mathrm{rad}^{8}$ and died 49 hours later.

It appears that enough solution was ejected from the tank (the final content of the vessel was $2 \mathrm{~kg}$ of uranium in about 40 liters) so that the stirrer vortex was sufficient to maintain subcriticality. Two hours after the first excursion, however, two men entered the area, stopped the stirrer and restarted it some minutes later, after which they drained the tank. These two received radiation doses between 60 and $100 \mathrm{rad}$. Evidence of neutron exposure suggested a second less violent excursion while the stirrer was off, which was not detected because the radiation alarm continued to sound after the first excursion. The combined yield of both excursions was $1.3 \times 10^{17}$ fissions.

Before operation was resumed, there were extensive analyses of the process. These included penetrating reviews and modifications of operating and emergency procedures, criticality limits and controls, uranium accountability and material balance practices, health physics procedures and controls, and training. Favorable geometry equipment for recovering uranium from TCE, which had been planned previously, was put into operation. 


\section{UKAEA Windscale Works, Great Britain - August 24, 1970 $30,57,64$}

This excursion is reminiscent of the Los Alamos accident, but without severe consequence. Similarities are the unsuspected buildup of plutonium in an organic solvent layer and a transient change of geometry that led to criticality of short duration. The total fission yield was on the order of $10^{15}$ fissions, and exposures were negligible - less that $2 \mathrm{rad}$ for the two closest workers, who were protected somewhat by shielding.

The excursion, detected by the criticality alarm system, took place at the head end of a process for recovering plutonium by solvent extraction. Normally, aqueous solution having a density of $\sim 6 \mathrm{~g} \mathrm{Pu} / \mathrm{L}$ from a dissolver and a "conditioner" for feed adjustment was raised by vacuum into a transfer vessel, then flowed by gravity through a trap and into a tank that supplied metered solution to a favorable-geometry extraction column. When 40 liters of organic solvent from an unknown source entered the vacuum transfer vessel, the trap isolated the floating layer of solvent instead of permitting it to drain. So instead of serving the intended safety purpose, the trap allowed the solvent to accumulate plutonium in the transfer vessel, little by little, from aqueous batches pouring through it. At the final density of $55 \mathrm{~g} \mathrm{Pu} / \mathrm{L}$ in the solvent, it appears that an emulsion band between the solvent and aqueous solutions led to criticality during the brief period after the flow stopped and before the two phases of emulsion separated. This sequence of events was reconstructed and demonstrated by means of an inactive transparent replica of the transfer system.

Before the plant was returned to service, neutron monitors to detect plutonium accumulations were installed on all vessels without favorable geometry. Furthermore, the drain traps were modified to permit positive drainage and to facilitate washout procedures.

\section{The Idaho Chemical Processing Plant, Idaho Reactor Testing Area, ID - October 17, $1978^{30}$}

The most recent of eight process excursions occurred in a shielded cell of a plant for reprocessing irradiated fuel. The dissolved fuel, as dilute aqueous solution, was introduced into the first of a series of pulsed columns for extracting and purifying the highly enriched uranium.

Normally, in the first column the uranium is extracted into an organic stream which enters the second column for the removal of fission products by a stream of water. The water is buffered with aluminum nitrate to prevent significant takeup of uranium, then reintroduced along with feed to the first column to remove traces of uranium. Most of the uranium, in the organic stream, leaves the second column for further processing.

Abnormal operation occurred as a result of water leaking into the aluminum nitrate makeup tank, which was not detected because of malfunctioning instrumentation. As a result, the solution of aluminum nitrate entering the second column was too dilute to prevent appreciable uptake of uranium. Instead of leaving with the organic, the uranium recycled successively through the first and second columns building up to an estimated $10 \mathrm{~kg}$ in the second column. 
This was sufficient to cause an excursion of about $2.7 \times 10^{18}$ fissions extending over one-half hour until the reaction was terminated by improved mixing after feed was turned off.

Although there was insignificant personnel exposure and no damage of equipment, the plant underwent an extended and expensive shutdown. Operating procedures were revised, and there was increased emphasis on plant maintenance and operator training. Further, a highly instrumented plant protection system with automatic controls was installed.

\title{
3. Examples of Radioactive Contamination from Chemical Explosions
}

\author{
Explosion at Kyshtym, USSR - 1957
}

Chemical accidents, not just criticality accidents, have resulted in severe human exposure to nuclear radiation. A chemical explosion at the Kyshtym waste repository, which did not involve the potential for criticality, serves to illustrate this point. The explosion occurred in a concrete tank containing nitrate-acetate fission-product waste. A fault developed in the cooling system used to offset fission-product heating. As a result, in the mistaken belief that coolant was no longer necessary, its flow was stopped. The wastes then dried, leaving a highly explosive mixture of nitrate salts and acetate, which ignited as the temperature increased.

As a result of the accident, 10,180 people were evacuated throughout an area of roughly $1000 \mathrm{~km}^{2}$. There were no fatalities. After 25 years of surveillance, the greater part of this area had been repopulated. Health effects were summarized as follows. "In conclusion, we may note that observations on health, morbidity and mortality among the population subjected to the accidental release of radiation - with whole body exposure doses from 1 to $52 \mathrm{cSv}^{*}$ and irradiation of individual organs up to $150 \mathrm{cSv}$ - have revealed no significant deviations from the comparable values found among healthy unexposed individuals."

This incident provides a reminder that attention to criticality safety does not eliminate the need to guard against other types of radiation accidents.

\section{Explosion of Ion-Exchange Column, Hanford, WA $-1976^{67}$}

In the United States, chemical explosions capable of spreading contamination have been much less severe than that at Kyshtym. That, however, is no reason for complacency, for they have occurred and might happen where consequences could be more serious.

The 1976 explosion at Hanford was in a cation exchange column for americium recovery. The steel column ruptured, shattering windows of a glove box in which it was contained, injuring and contaminating an operator, and contaminating others nearby. The violent

\footnotetext{
${ }^{*}$ One cSv equals one rem; stated doses were received before evacuation.
} 
reaction was presumed to entail nitric acid and products of cation-resin degradation. The degradation resulted from exposure of the resin to radiation from $100 \mathrm{~g}$ of americium for more than five months.

The report of this accident refers to an earlier ion-exchange column explosion at another site, but no detail is given.

\section{B. General Observations}

Because of timely evacuations initiated by criticality alarms, exposures of personnel to criticality events in unshielded facilities were limited to the direct radiation from the initial pulse or two. The exposure limitations of eleven individuals from the two prolonged reactions are attributable to their evacuation following alarms. It may be concluded that lives were saved by immediate evacuation, showing the value of radiation-initiated alarms installed where the potential for an accidental excursion is significant. An American National Standard addresses this subject. ${ }^{46}$

The two fatalities were suffered by persons within a few feet of an excursion; significant exposures were received by others at distances extending to $15 \mathrm{~m}(50 \mathrm{ft})$. This observation may be generalized to a certain extent by Figure 1. This figure shows that personnel doses normalized to excursions of $10^{17}$ fissions and crudely adjusted to exposure times of $\sim 15$ sec correlate roughly with distances from the source. For the typical excursion of $10^{17}$ fissions, the distances resulting in early fatalities are similar to those of a moderate chemical explosion.

The relatively large number of plant accidents, six between 1958 and 1964, calls for some explanation. An increased demand for plutonium and enriched-uranium production without a corresponding reassessment of criticality control in existing processing facilities had some impact. Plants that had been designed for moderate capacity and were operating with minimal criticality safety guidance were called upon to increase throughput and perform a wider variety of tasks. Even though the potential for accidents had increased, a long accident-free period prior to 1958 made it difficult to justify an accelerated effort to improve criticality safety. On the other hand, the occurrence of a criticality accident provides an immediate incentive to improve criticality control. For example, the plutonium recovery plants at Los Alamos and Hanford were not modernized until the accidents occurred there. As might be expected, the cluster of accidents between 1958 and 1964 emphasized the need to improve nuclear criticality safety. Most importantly, additional experiments were performed to determine critical configurations for a larger range of materials and geometries. The resulting body of experimental data led to more definitive guidance and enhanced techniques for criticality control. This effort led to a significant reduction in the accident rate after 1964 in that only one accident has occurred since then. 
Figure 1

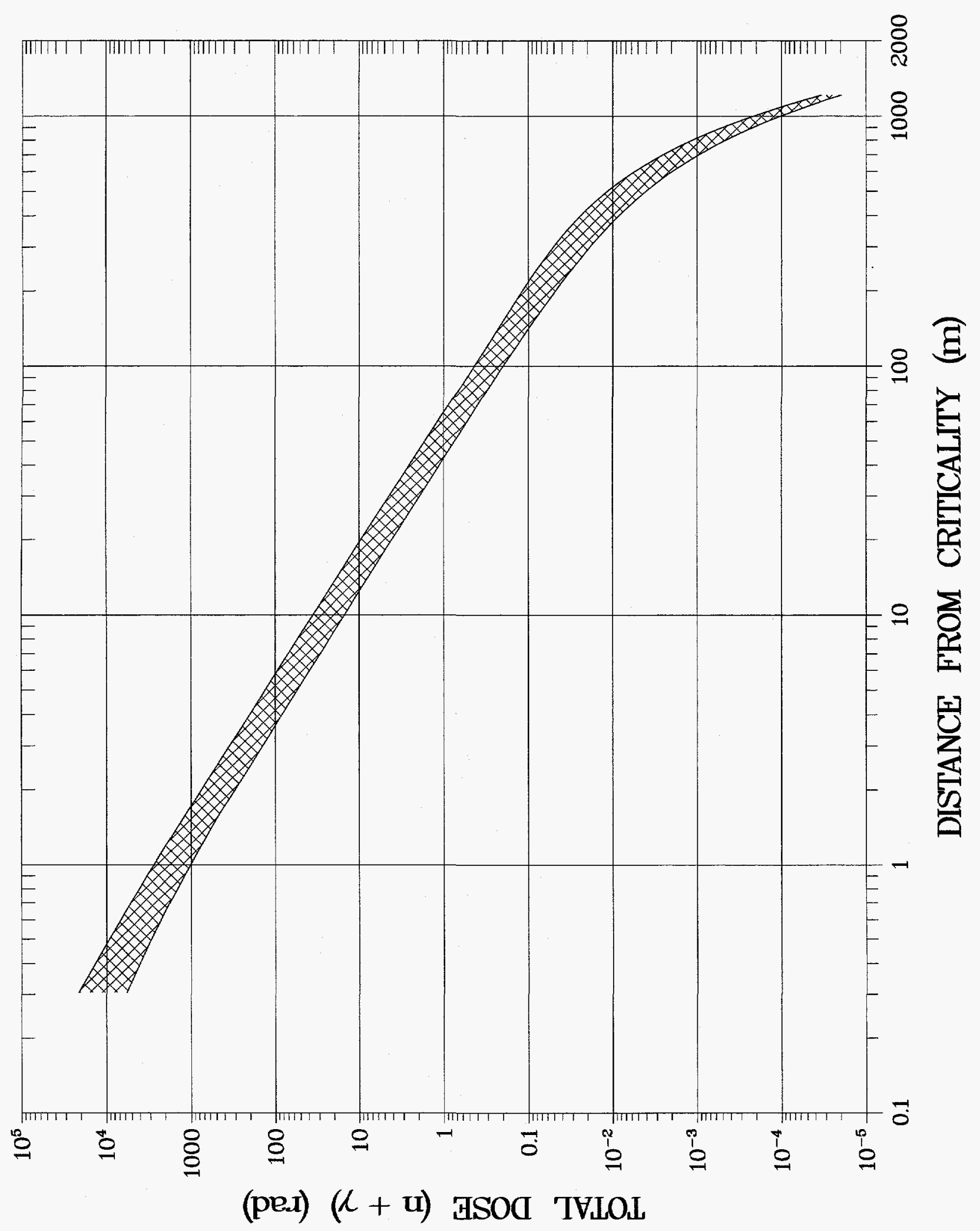

皮 鱼 क. ํํㅇ 政 드. $\circ$ 명 : 马 घี

능

$\exists$ 曲

ड

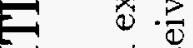

ए)

0
0
0
0 $\stackrel{\square}{\square}$

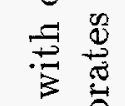
\& 茟 ถี

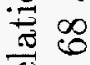
ن 过 풍 $\stackrel{\Xi}{*}$ 范 产萦 $-$ $\dot{90}$ 
The fact that all the accidental excursions involved solutions of plutonium or highly enriched uranium is not surprising. Small critical mass and the mobility and ease of solute exchange that make solutions so desirable in chemical processing, invite criticality in unexpected locations. By contrast, the movement of solids is more apparent, more easily controlled, and the amount of fissile material needed to achieve a critical configuration is much larger. Containers sufficiently larger than their solid contents can prevent criticality in the event that they fall together as a result of structural collapse.* As we shall see, it is more important that criticality control be effective for certain solids than for solutions, although the problems with solutions are much more subtle.

Typical accident experience with solutions of fissile material shows minimal damage to equipment and no exposure of the public to radiation. Disruptive pressures resulting in dispersion of radioactive contamination would require unusual circumstances, such as containment without pressure relief. Properties of solution excursions are illustrated further by an extensive series of kinetic experiments conducted at the Dijon Laboratory of the French Commissariat a $1^{6}$ Energie Atomique. ${ }^{70}$ Certain types of conceptual accidents with solid fissile material, notably with ${ }^{235} \mathrm{U}$ metal, are more likely to be violent. ${ }^{30}$ Fortunately, as noted above, it is not difficult to foresee the conditions, such as large pieces of metal falling together, that might lead to an extreme accident. Control of these conditions is usually straightforward and is emphasized in plant operations; for example, by limiting the location and movement of massive pieces in a single plane.

\footnotetext{
* One hundred twenty-five units, each consisting of $10 \mathrm{~kg}$ of enriched uranium metal in a convenient 20.3-cmdiameter x 24.1-cm-deep can, would remain subcritical if gathered together on a concrete floor. ${ }^{69}$
} 


\section{Chapter III}

\section{LIMITS FOR INDIVIDUAL UNITS}

\section{A. Subcritical Limits of Controlling Parameters}

Subcritical limits for individual units appear in American National Standard for Nuclear Criticality Safety in Operations with Fissionable Materials Outside Reactors, ANSI/ANS8.1, and American National Standard for Nuclear Criticality Control and Safety of Plutonium-Uranium Fuel Mixtures Outside Reactors, ANSI/ANS-8.12. ${ }^{71}$ The former source, $A N S I / A N S-8.1$, includes all such limits except those for the plutonium-natural uranium combinations of $A N S I / A N S-8.12$, which are appropiate for the fissionable material of mixed-oxide reactors.

The subcritical limits throughout $A N S I / A N S-8.1$ result from calculations validated by comparison with experimental data. The computational bias is incorporated in a subcritical margin of $\Delta \mathrm{k}_{\mathrm{eff}}=0.02$ below minimum indicated criticality. ${ }^{{ }^{2-74}}$ The subcritical limits apply to units with full water reflection. This small margin is effectively increased if reflection is limited, for example, to that of a container, a person nearby, objects more than one-meter distant, and parts of a room (i.e., incidental reflection). Regardless, contingencies that include the effects of more probable deviations must be considered in applying any of these limits. In other words, the following requirement of the Standard must be satisfied.

Process specifications shall incorporate margins to protect against uncertainties in process variables and against a limit being accidentally exceeded.

For subcritical limits in $A N S I / A N S-8.12$, the margin is $\Delta \mathrm{k}_{\text {eff }}=0.05$, and full water reflection is again specified. ${ }^{75}$ The greater margin demonstrates judgment as to the adequacy of the range of supporting experimental data and in no way reduces the need to consider contingencies. See Section F of this chapter for a discussion of typical contingencies. 


\section{B. Subcritical Limits for Systems of Fissile Nuclides}

\section{Introduction}

This section is an expansion of Section 5 of Standard ANSI/ANS-8.1, which bears the same title. The section gives the subcritical limits for various parameters, such as the mass or volume of fissile material, any one of which is sufficient for implementing criticality control. Subcritical limits, as discussed in Section A of this chapter, are implied. The subcritical limits of Tables 1 through 5 are taken directly from Standard ANSI/ANS-8.1.

\section{Hydrogen-Moderated Systems}

\section{Aqueous Solutions ${ }^{72-74,76}$}

The subcritical limits of Tables 1 and 2 apply to solutions reflected by the equivalent of an unlimited thickness of water. Masses and volumes apply to spheres and so are conservative for other shapes. The limits expressed for cylinder and slab dimensions apply, respectively, to the diameter of a uniform circular cylinder of unlimited length and to the thickness of a uniform slab of unlimited area. These dimensions are conservative for a cylinder of finite length or a slab of finite area. Areal density is defined as the product of the thickness of a uniform slab and the density of fissile material within the slab; hence, it is the mass of fissile material per unit area of the slab.

For plutonium in which the content of ${ }^{240} \mathrm{Pu}$ exceeds that of ${ }^{241} \mathrm{Pu}$, the mass, density, and areal density limits of Table 1 apply to the sum of ${ }^{239} \mathrm{Pu}$ and ${ }^{241} \mathrm{Pu}$. It should be noted that the content of ${ }^{240} \mathrm{Pu}$ exceeds that of ${ }^{241} \mathrm{Pu}$ in typical materials encountered in a reactor fuel cycle. The limits of Tables 1 and 2 are appropriate for many commonly encountered reflector conditions. An example of a reflector other than thick water is the metal-water combination of a cooling jacket and a steel wall of moderate thickness. Sometimes water-flooding may be a reasonable assumed contingency, but, where this is not the case, the adoption of values for complete water reflection allows for unknown neutron reflecting properties of nearby concrete walls, floors, neighboring water lines and process vessels, and transient personnel. Closely fitting reflectors of thick beryllium, beryllium oxide, heavy water, concrete, lead, or graphite are examples of exceptions for which the listed limits are not appropriate. Composite reflectors, e.g., thick steel outside a thin hydrogenous reflector, may be very effective, thus requiring explicit evaluation. 


\section{Organic Mixtures and Uniform Slurries}

The limits of Tables 1 and 2 may be used for effectively homogeneous hydrogen-moderated mixtures, e.g., organic solutions and macroscopically uniform slurries, provided the atomic ratio of hydrogen-to-fissile-material does not exceed that of a water solution having the same density of fissile material. ${ }^{*}$ Note that experiments at Hanford ${ }^{77}$ show nearly identical critical numbers of reactor fuel pins latticed in water and in organic (dodecane) moderator at the same value of $\mathrm{H} / \mathrm{Pu}$.

This provision is satisfied by most common mixtures, such as oxides combined with organic material. For plutonium, an additional restriction is that the nitrogen-to-plutonium atomic ratio be at least 4.0 throughout.

\section{Nonuniform Slurries}

Single-parameter limits may be assigned to certain nonuniform slurries, provided the restrictions for uniform slurries are satisfied at all locations within the slurry. In that case, the subcritical mass limits for ${ }^{233} \mathrm{U},{ }^{235} \mathrm{U}$, and ${ }^{239} \mathrm{Pu}$ are $0.52,0.70$, and $0.45 \mathrm{~kg}$, respectively. ${ }^{78}$ For vertical cylinders or slabs on edge, where density gradients arise entirely from gravitational settling (i.e., a gradient along the cylinder axis or parallel to the slab face), the limits of Table 1 on cylinder diameter and slab thickness may be used. The areal density limits of that table are valid for a horizontal slab subject only to gravitational settling, provided the restrictions for uniform slurries are met throughout. Where there are variations in the areal density, the maximum value shall not exceed the limit.

\footnotetext{
${ }^{*}$ Quantities characteristic of solutions appear in Table 7 of Reference 11.
} 
Table 1

Single-Parameter Subcritical Limits for Uranium and Plutonium Solutions, Reflected by an Effectively Infinite Thickness of Water

\begin{tabular}{|c|c|c|c|c|c|c|c|}
\hline \multirow[b]{2}{*}{$\begin{array}{l}\text { Fissile } \\
\text { Solute }\end{array}$} & \multicolumn{7}{|c|}{ Subcritical Limit } \\
\hline & $\begin{array}{c}\text { Mass of } \\
\text { Fissile } \\
\text { Nuclide } \\
(\mathrm{kg})\end{array}$ & $\begin{array}{c}\text { Diameter } \\
\text { of } \\
\text { Cylinder } \\
\text { of } \\
\text { Solution } \\
(\mathrm{cm}) \\
\end{array}$ & $\begin{array}{l}\text { Thickness } \\
\text { of Slab } \\
\text { of } \\
\text { Solution } \\
\text { (cm) }\end{array}$ & $\begin{array}{c}\text { Volume } \\
\text { of } \\
\text { Solution } \\
\text { (L) }\end{array}$ & $\begin{array}{c}\text { Density } \\
\text { of } \\
\text { Fissile } \\
\text { Nuclide } \\
\text { (g/L) }\end{array}$ & $\begin{array}{c}\text { Atomic } \\
\text { Ratio }^{a} \text { of } \\
\text { Hydrogen } \\
\text { to } \\
\text { Fissile } \\
\text { Nuclide }\end{array}$ & $\begin{array}{c}\text { Areal } \\
\text { Density } \\
\text { of } \\
\text { Fissile } \\
\text { Nuclide } \\
\left(\mathrm{g} / \mathrm{cm}^{2}\right)\end{array}$ \\
\hline${ }^{233} \mathrm{UO}_{2} \mathrm{~F}_{2}$ & 0.54 & 10.5 & 2.5 & 2.8 & 10.8 & 2390 & 0.35 \\
\hline${ }^{233} \mathrm{UO}_{2}\left(\mathrm{NO}_{3}\right)_{2}$ & 0.55 & 11.7 & 3.1 & 3.6 & 10.8 & 2390 & 0.35 \\
\hline${ }^{235} \mathrm{UO}_{2} \mathrm{~F}_{2}$ & 0.76 & 13.7 & 4.4 & 5.5 & 11.6 & 2250 & 0.40 \\
\hline${ }^{235} \mathrm{UO}_{2}\left(\mathrm{NO}_{3}\right)_{2}$ & 0.78 & 14.4 & 4.9 & 6.2 & 11.6 & 2250 & 0.40 \\
\hline${ }^{239} \mathrm{Pu}\left(\mathrm{NO}_{3}\right)_{4}$ & 0.48 & 15.4 & 5.5 & 7.3 & 7.3 & 3630 & 0.25 \\
\hline
\end{tabular}

Table 2

Subcritical Limits for Solutions of $\mathrm{Pu}\left(\mathrm{NO}_{3}\right)_{4}$ Containing ${ }^{240} \mathrm{Pu}$, Reflected by an Effectively Infinite Thickness of Water

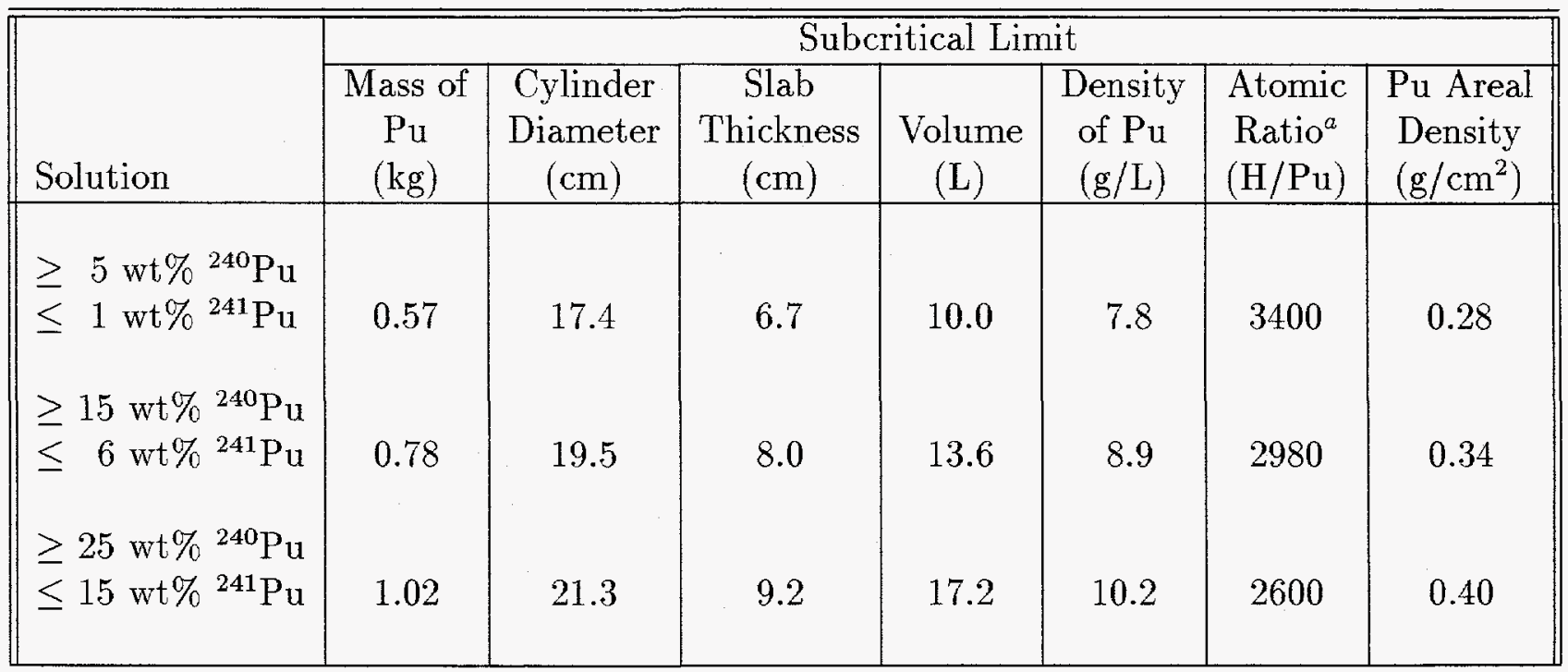

${ }^{a}$ Lower limit. 


\section{Metal Units}

Single-parameter subcritical limits ${ }^{4,79-80}$ for units of water-reflected fissile metal appear in Table 3. The mass limits and the ${ }^{235} \mathrm{U}$ enrichment limit for uranium metal apply to a unit without reentrant void that can be occupied by water or other moderator. These limits may be extended to a group of small pieces having the same total mass, provided there can be no moderator between the pieces. The limits for ${ }^{233} \mathrm{U}$ and ${ }^{235} \mathrm{U}$ of Table 3 may be applied to uranium containing ${ }^{234} \mathrm{U},{ }^{236} \mathrm{U}$, and ${ }^{238} \mathrm{U}$, provided the masses of ${ }^{234} \mathrm{U}$ and ${ }^{236} \mathrm{U}$ are included with that of ${ }^{233} \mathrm{U}$ or ${ }^{235} \mathrm{U}$.

\section{Oxide Units}

The single-parameter limits of Tables 4 and 5 apply to oxides that have less than $1.5 \mathrm{wt} \%$ water. ${ }^{4}$ The 1.5 wt\% water is chosen because absolutely dry oxide can seldom be guaranteed. Table 4 holds for oxides compacted to as much as the stated maximum density. As footnote 10 of Reference 4 points out, it is possible for this density to be exceeded in a highly compacted oxide. Table 5 applies to uncompacted oxides at no more than one-half maximum density.

\section{Table 3}

Single-Parameter Subcritical Limits for Metal Units, Reflected by an Effectively Infinite Thickness of Water

\begin{tabular}{||c|c|c|c|c||}
\hline \hline & \multicolumn{4}{|c|}{ Subcritical Limit } \\
\cline { 2 - 5 } Nuclide & $\begin{array}{c}\text { Mass of } \\
\text { Fissile } \\
\text { Nuclide } \\
\text { (kg) }\end{array}$ & $\begin{array}{c}\text { Cylinder } \\
\text { Diameter } \\
\text { (cm) }\end{array}$ & $\begin{array}{c}\text { Slab } \\
\text { Thickness } \\
\text { (cm) }\end{array}$ & $\begin{array}{c}\text { Uranium } \\
\text { Enrichment } \\
\left(\text { wt\% }{ }^{235} \mathrm{U}\right)\end{array}$ \\
\hline${ }^{233} \mathrm{U}$ & 6.0 & 4.5 & 0.38 & - \\
${ }^{235} \mathrm{U}$ & 20.1 & 7.3 & 1.30 & 5.0 \\
${ }^{239} \mathrm{Pu}$ & 5.0 & 4.4 & 0.65 & - \\
\hline
\end{tabular}


Table 4

Subcritical Limits for Oxides Containing No More Than 1.5 wt\% Water, at Full Density, Reflected by an Effectively Infinite Thickness of Water

\begin{tabular}{||c|c|c|c|c|c||}
\hline \hline & \multicolumn{5}{|c|}{ Subcritical Limit } \\
\cline { 2 - 5 } Compound & $\begin{array}{c}\text { Mass of fissile } \\
\text { nuclide, } \\
(\mathrm{kg})\end{array}$ & $\begin{array}{c}\text { Mass of } \\
\text { oxide, } \\
(\mathrm{kg})\end{array}$ & $\begin{array}{c}\text { Cylinder } \\
\text { diameter, } \\
(\mathrm{cm})\end{array}$ & $\begin{array}{c}\text { Slab } \\
\text { thickness, } \\
(\mathrm{cm})\end{array}$ & $\begin{array}{c}\text { Maximum dry bulk } \\
\text { density for which } \\
\text { limits are valid }\left(\mathrm{g} / \mathrm{cm}^{3}\right)\end{array}$ \\
\hline${ }^{233} \mathrm{UO}_{2}$ & 10.1 & 11.7 & 7.2 & 0.8 & 10.75 \\
${ }^{233} \mathrm{U}_{3} \mathrm{O}_{8}$ & 13.4 & 16.0 & 9.0 & 1.1 & 8.15 \\
${ }^{233} \mathrm{UO}_{3}$ & 15.2 & 18.7 & 9.9 & 1.3 & 7.16 \\
${ }^{235} \mathrm{UO}_{2}$ & 32.3 & 37.2 & 11.6 & 2.9 & 10.84 \\
${ }^{235} \mathrm{U}_{3} \mathrm{O}_{8}$ & 44.0 & 52.8 & 14.6 & 4.0 & 8.21 \\
${ }^{235} \mathrm{UO}_{3}$ & 51.2 & 62.6 & 16.2 & 4.6 & 7.22 \\
${ }^{239} \mathrm{PuO}_{2}$ & 10.2 & 11.5 & 7.2 & 1.4 & 11.49 \\
\hline
\end{tabular}

These values include the mass of any associated water up to the limiting value of 1.5 wt $\%$. 
Table 5

Subcritical Limits for Oxides Containing No More Than

1.5 wt\% Water, at No More Than Half Density,

Reflected by an Effectively Infinite Thickness of Water

\begin{tabular}{||c|c|c|c|c||}
\hline \hline & \multicolumn{3}{|c|}{ Subcritical limit } \\
\cline { 2 - 5 } Compound & $\begin{array}{c}\text { Mass of } \\
\text { Fissile } \\
\text { Nuclide } \\
(\mathrm{kg})\end{array}$ & $\begin{array}{c}\text { Mass of } \\
\text { Oxide } \\
(\mathrm{kg})\end{array}$ & $\begin{array}{c}\text { Cylinder } \\
\text { Diameter } \\
(\mathrm{cm})\end{array}$ & $\begin{array}{c}\text { Slab } \\
\text { Thickness } \\
(\mathrm{cm})\end{array}$ \\
\hline${ }^{233} \mathrm{UO}_{2}$ & 23.4 & 27.0 & 11.9 & 1.6 \\
${ }^{233} \mathrm{U}_{3} \mathrm{O}_{8}$ & 30.5 & 36.6 & 14.8 & 2.2 \\
${ }^{233} \mathrm{UO}_{3}$ & 34.7 & 42.4 & 16.3 & 2.6 \\
${ }^{235} \mathrm{UO}_{2}$ & 88.0 & 102.0 & 20.4 & 5.8 \\
${ }^{235} \mathrm{U}_{3} \mathrm{O}_{8}$ & 122.0 & 146.0 & 26.0 & 8.0 \\
${ }^{235} \mathrm{UO}_{3}$ & 142.0 & 174.0 & 28.8 & 9.3 \\
${ }^{239} \mathrm{PuO}_{2}$ & 27.0 & 30.0 & 12.6 & 2.8 \\
\hline
\end{tabular}

$\bar{a}$ These are half the maximum bulk densities of Table 4 .

${ }^{b}$ These values include the mass of any associated water up to the limiting value of $1.5 \mathrm{wt} \%$. 


\section{Fissile Density Dependent Limits}

\section{Solutions and Metal-Water Mixtures}

The overall acceptable limit for a solution parameter applies to the minimum value over the solution density range. If the solution density range is controlled to exclude the value for which the parameter is minimum, an increased limit may be valid. From Figures 2-13, acceptable limits for restricted density ranges may be established. Curves of critical and subcritical values as functions of the density of ${ }^{233} \mathrm{U},{ }^{235} \mathrm{U}$ or ${ }^{239} \mathrm{Pu}$ are given for

- spherical mass in Figures 2, 6, and 10;

- spherical volume in Figures 3, 7, and 11;

- infinite cylinder diameter in Figures 4, 8, and 12;

- infinite slab thickness in Figures 5, 9, and 13.

The curves labeled $k=1.0$ (to avoid cluttering figures, $k$ appears instead of $k_{\text {eff }}$ ) represent calculated critical conditions for water reflected metal-water mixtures. The Figures also display experimental results for solutions. Critical parameters for experimental results are consistently larger than the corresponding values for the metal-water mixtures. The Appendix describes the Monte Carlo computational techniques that were used, and it documents the calculational method used to obtain the results. Curves at $\mathrm{k}=0.9$ and $\mathrm{k}=0.8$, calculated by the same means are included in each figure to show adjustments that would correspond to desired margins in $\Delta \mathrm{k}$.

By means of the curves for different values of $\mathrm{k}$, subcritical margins that allow for assumed contingencies can be selected. These margins, of course, go beyond the computational bias incorporated in the subcritical limits that have been discussed. If, for example, the dominant contingency could increase $\mathrm{k}$ to 1.02 , a point on or near the curve for $\mathrm{k}=0.9$ may be acceptably conservative.

The 15-cm-thick (effectively infinite) water reflector used for the curves is the most effective reflector material commonly encountered outside reactors. As stated earlier, some reflector materials, when closely fitting and of sufficient thicknesses, are more effective than ordinary water. Thicknesses of these materials equivalent to 15 -cm-thick water about fissile metal are listed in Tables 6 and 7. Unlike water, these materials, including closely fitting concrete, are rarely encountered, never accidentally, and call for special evaluation if incorporated into a design. Water is indeed one of the most effective reflectors in thicknesses of $7.5 \mathrm{~cm}$ or less. In general, like water, the effectiveness of hydrocarbons as reflectors saturates at thicknesses of about $10 \mathrm{~cm} .^{81}$ 
Table 6

Thickness of Reflectors Required for the Criticality of a $21.24-\mathrm{kg}^{235} \mathrm{U}$ Metal Sphere at $18.81 \mathrm{~g} / \mathrm{cm}^{3}$

\begin{tabular}{|c|c|c|}
\hline $\begin{array}{l}\text { Reflector } \\
\text { Material }\end{array}$ & $\begin{array}{l}\text { Density } \\
\left(\mathrm{g} / \mathrm{cm}^{3}\right)\end{array}$ & $\begin{array}{c}\text { Thickness } \\
(\mathrm{cm})\end{array}$ \\
\hline Water & 1.00 & 15.0 \\
\hline Iron & 7.86 & 17.6 \\
\hline Heavy Water & 1.10 & 7.2 \\
\hline Carbon & 1.90 & 8.4 \\
\hline Beryllium & 1.80 & 3.8 \\
\hline Plexiglas $^{a}$ & 1.20 & 5.1 \\
\hline
\end{tabular}

Table 7

Thickness of Reflectors Required for the Criticality of a $5.32-\mathrm{kg}{ }^{239} \mathrm{Pu}$ Metal Sphere at $19.85 \mathrm{~g} / \mathrm{cm}^{3}$

\begin{tabular}{|c|c|c|}
\hline $\begin{array}{l}\text { Reflector } \\
\text { Material }\end{array}$ & $\begin{array}{l}\text { Density } \\
\left(\mathrm{g} / \mathrm{cm}^{3}\right)\end{array}$ & $\begin{array}{l}\text { Thickness } \\
(\mathrm{cm})\end{array}$ \\
\hline Water & 1.00 & 15.0 \\
\hline Iron & 7.86 & 16.2 \\
\hline Heavy Water & 1.10 & 7.6 \\
\hline Carbon & 1.90 & 8.1 \\
\hline Beryllium & 1.80 & 3.2 \\
\hline Plexiglas $^{a}$ & 1.20 & 6.1 \\
\hline
\end{tabular}

${ }^{a}$ Methacrylate plastic, $\mathrm{C}_{5} \mathrm{H}_{8} \mathrm{O}_{2}$. 
The upper dashed curves of Figures 2 to 13 display critical values, provided the only reflection is by a thin aluminum or steel container. This reflection condition is seldom encountered in processing plants because it is nearly always augmented by reflection from external objects (incidental reflection). ${ }^{*}$ The purpose of these curves is to provide a reference for showing the effect of assuming full water reflection when it does not actually occur. It may be noted that this effect corresponds roughly to a shift in $\mathrm{k}$ of 0.1 .

The metal-water curves, of course, apply conservatively to solutions. An appropriate adjustment between curves at $\mathrm{k}=1.0$ and $\mathrm{k}=0.9$ can establish subcritical limits. The curves at $\mathrm{k}=0.9$ and $\mathrm{k}=0.8$ can be used to adjust safety margins for operating contingencies to which general subcritical limits would not apply. Because of this flexibility, the figures do not include specific values of subcritical limits similar to the single-parameter limits of Section A of this chapter. The following may be pertinent if there should be interest in curves that appear in Nuclear Safety Guide, Revision 2 for a 2.5 -cm thick water reflector. It is seen that the subcritical limits for this reflector very nearly coincide with the $\mathrm{k}=1$ curves with thick water reflection in each figure.

\footnotetext{
${ }^{*}$ Except as a limit, a minimally reflected infinite critical slab (Figs. 5, 9, and 13) would be fictional. If truly of infinite extent, it could not escape full reflection.
} 
Figure 2

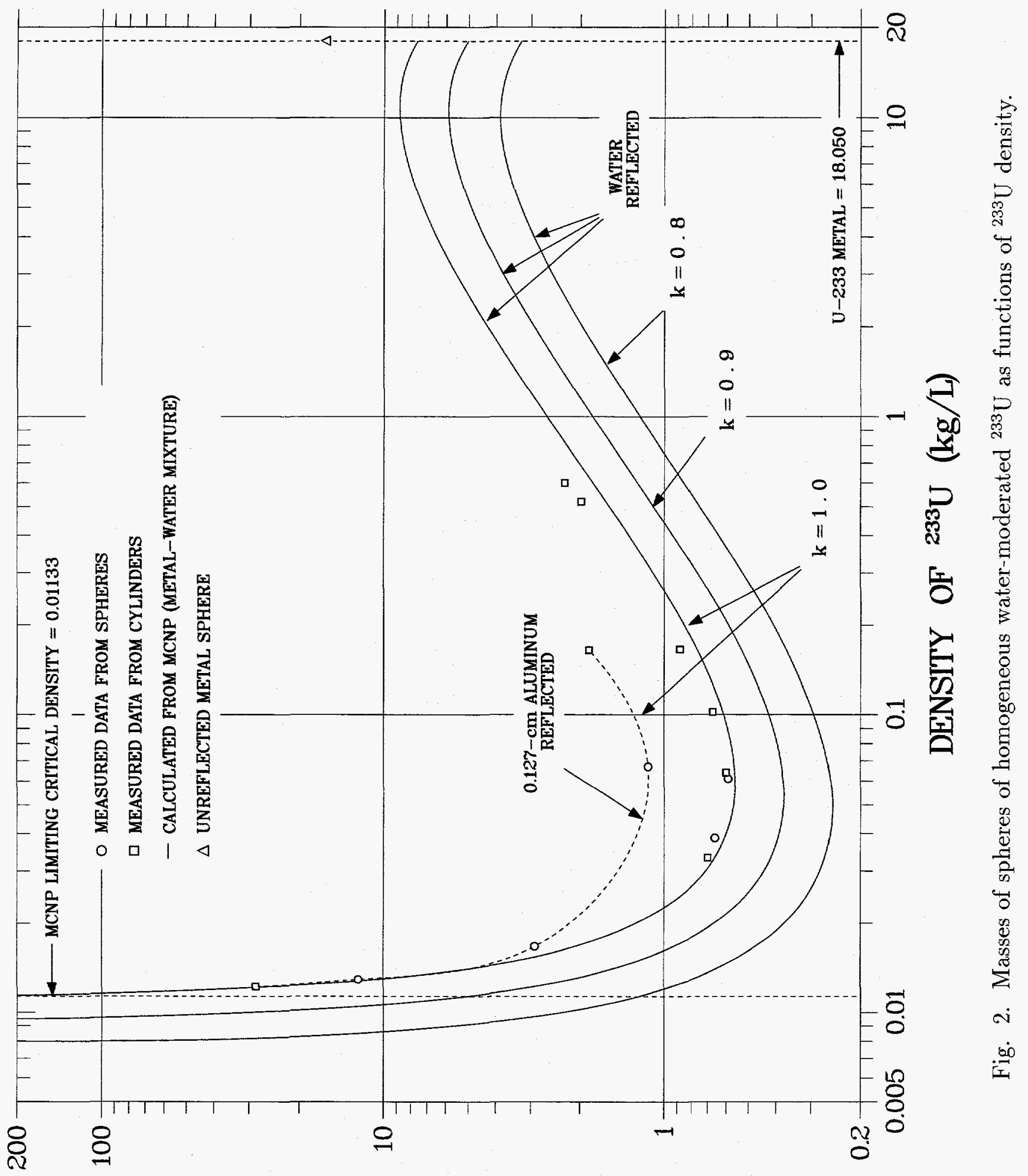

(ฮу) $\bigcap_{\mathcal{E E z}}$ 으 SSVW 


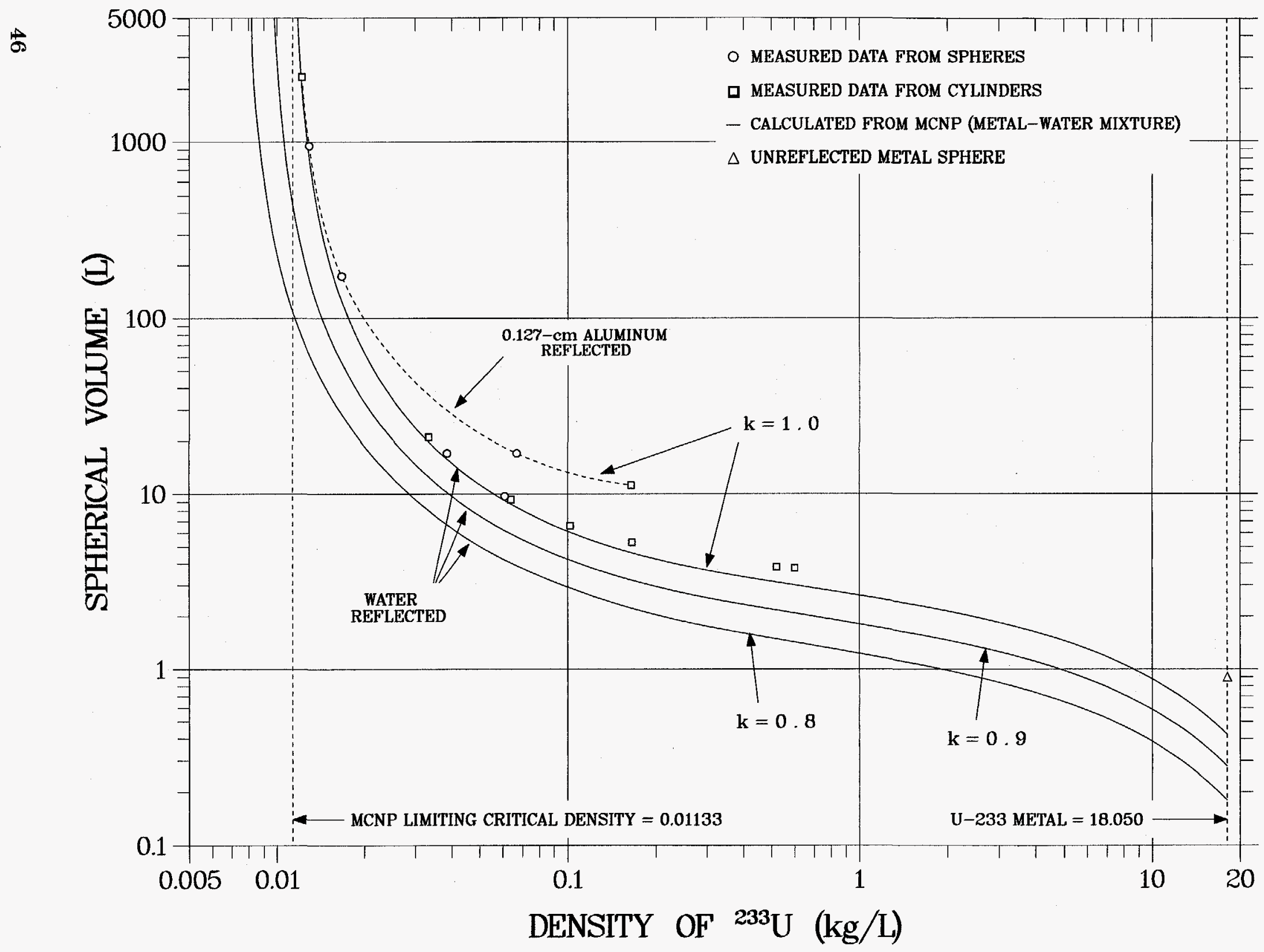

Fig. 3. Volumes of spheres of homogeneous water-moderated ${ }^{233} \mathrm{U}$ as functions of ${ }^{233} \mathrm{U}$ density. 


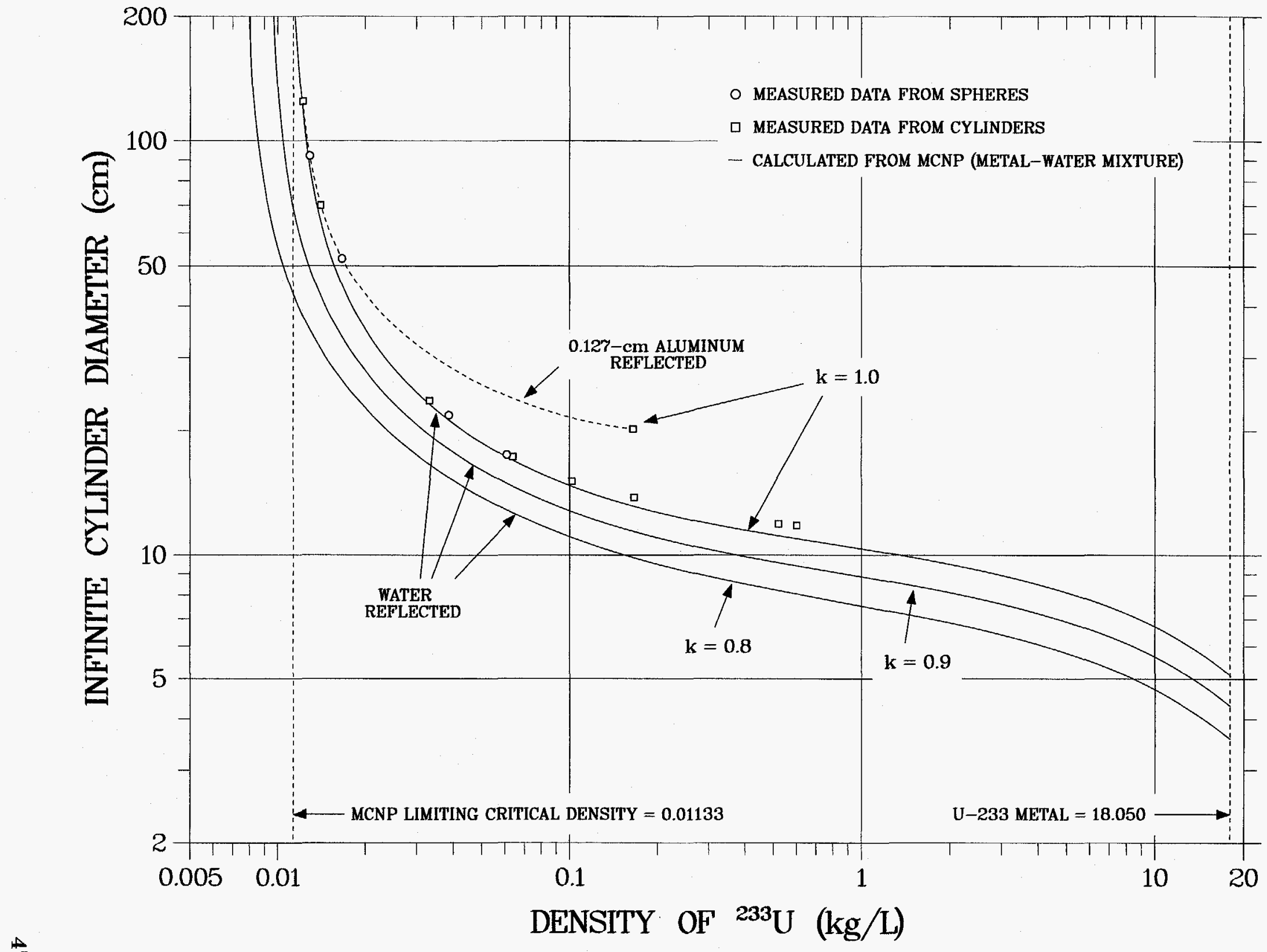

Fig. 4. Diameters of infinite cylinders of homogeneous water-moderated ${ }^{233} \mathrm{U}$ as functions of ${ }^{233} \mathrm{U}$ density. 
$\stackrel{\infty}{\infty}$

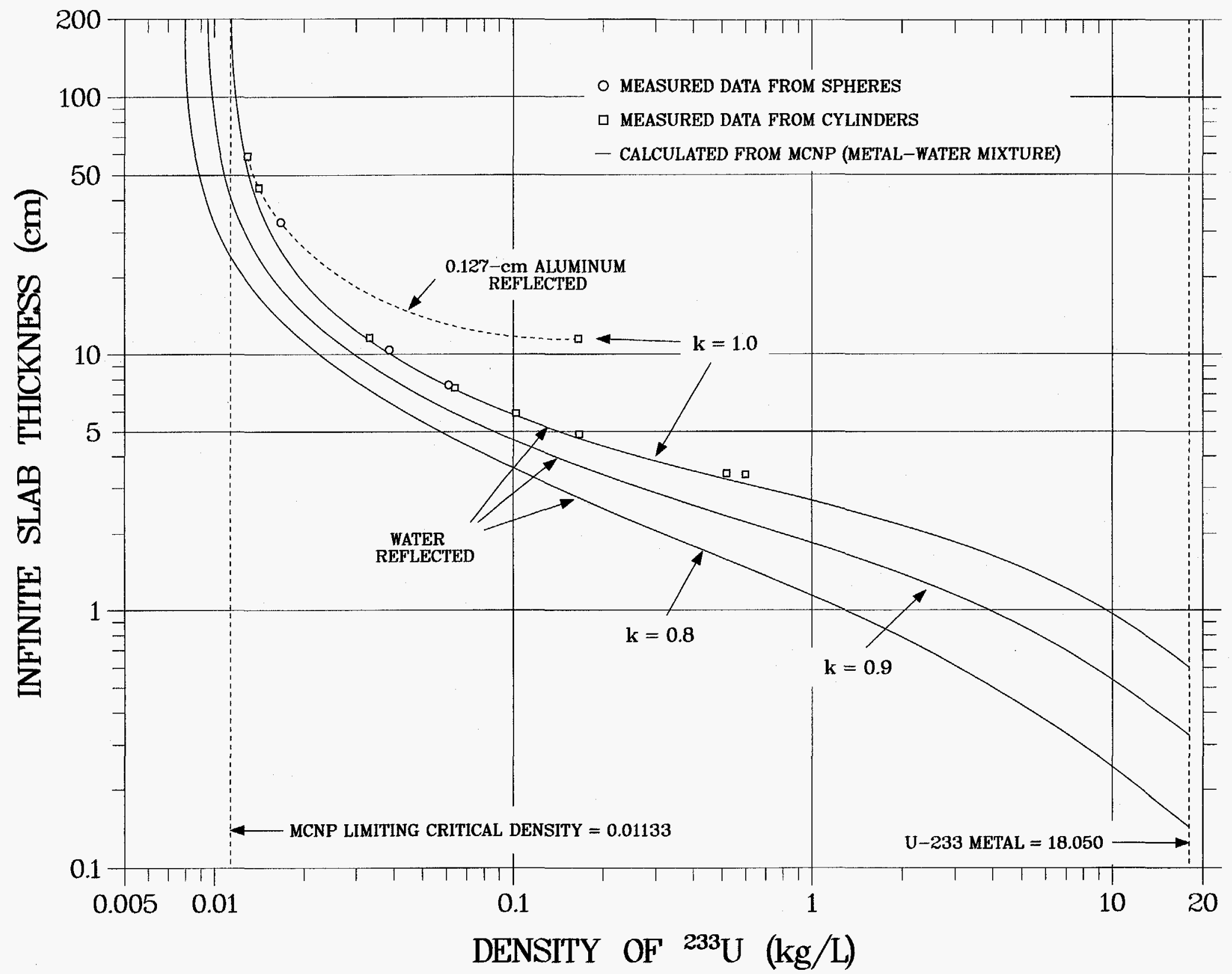

Fig. 5. Thicknesses of infinite slabs of homogeneous water-moderated ${ }^{233} \mathrm{U}$ as functions of ${ }^{233} \mathrm{U}$ density. 


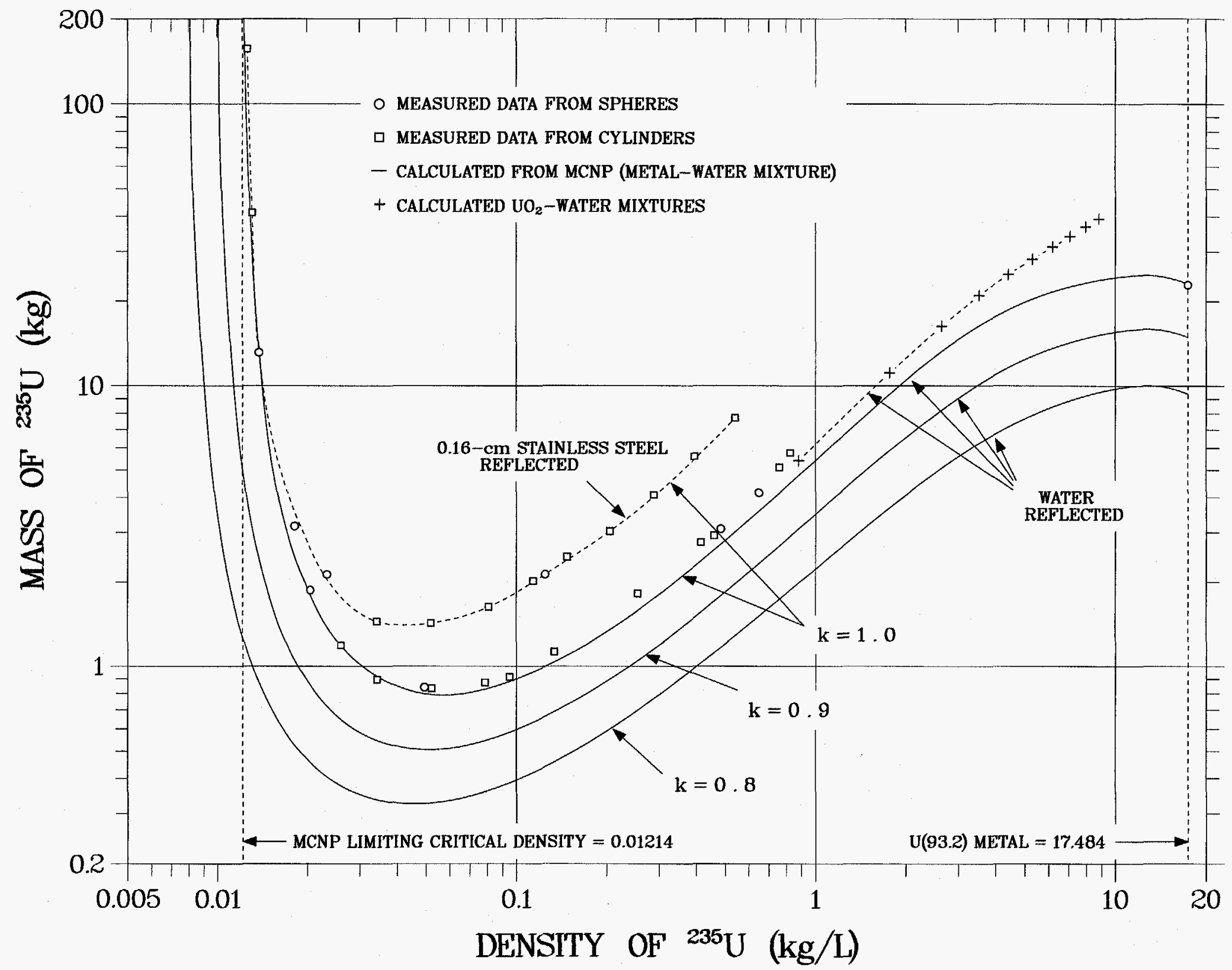

Fig. 6. Masses of spheres of homogeneous water-moderated U(93.2) as functions of ${ }^{235} \mathrm{U}$ density. 
Figure 7

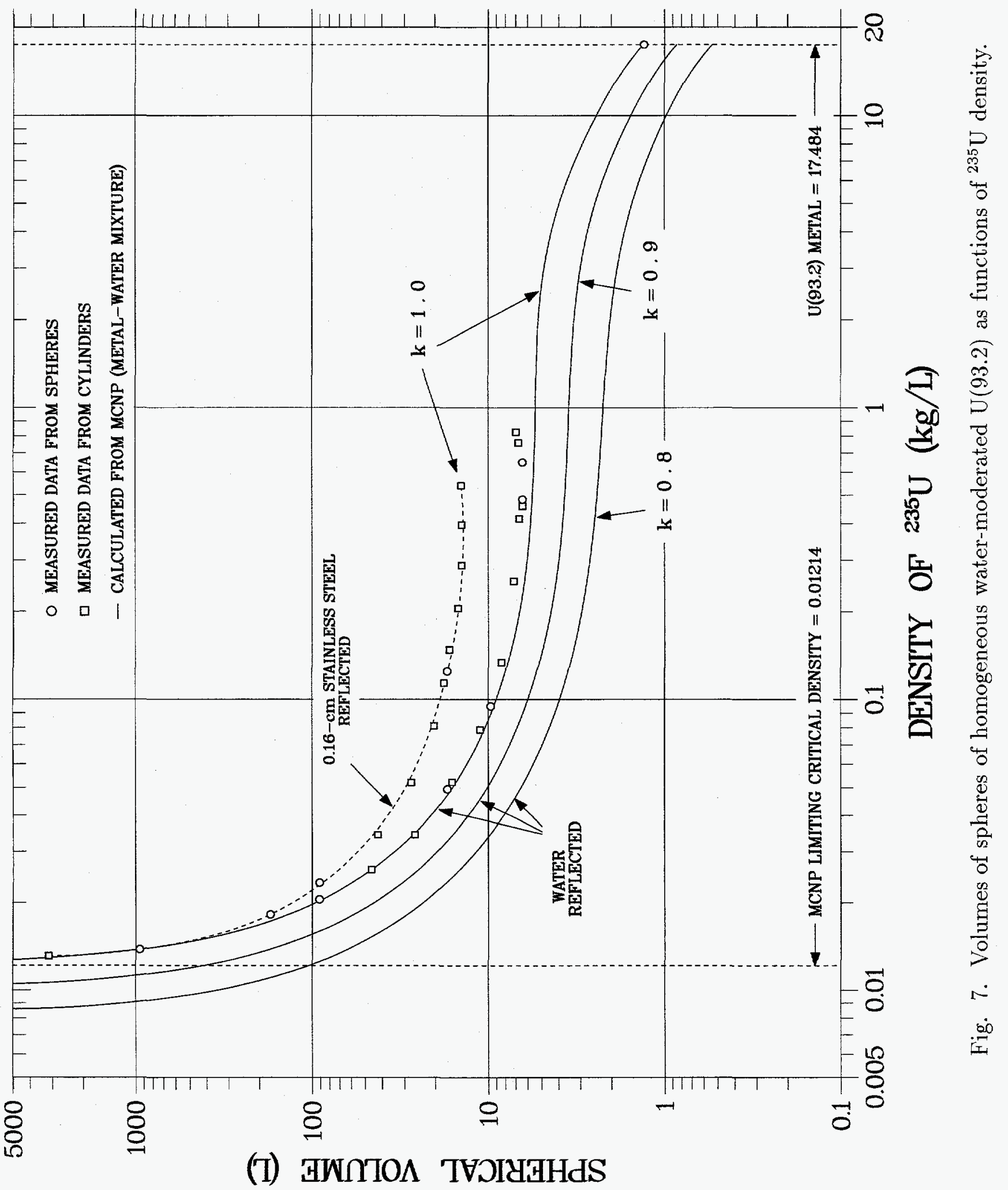


Figure 8

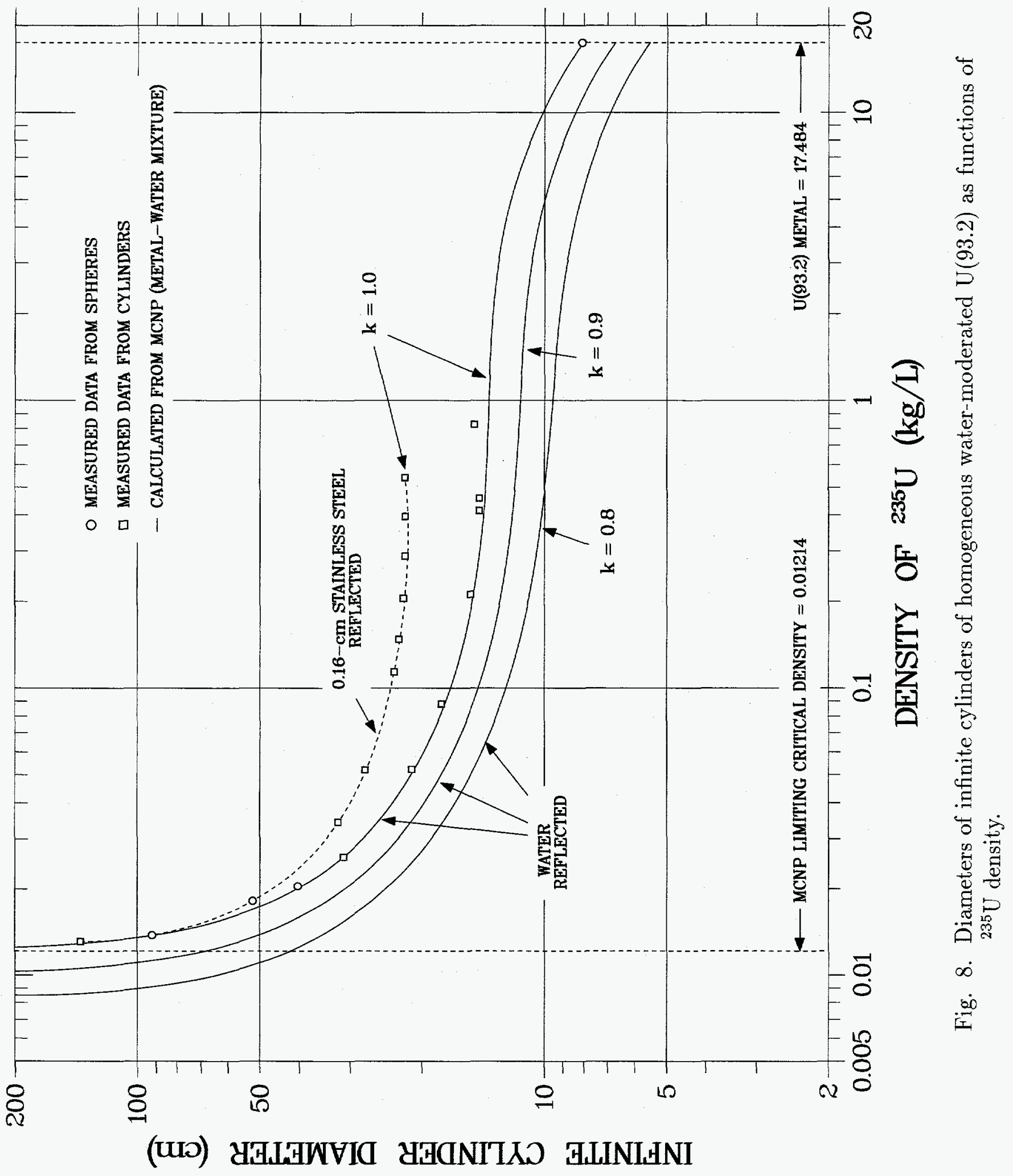


Figure 9

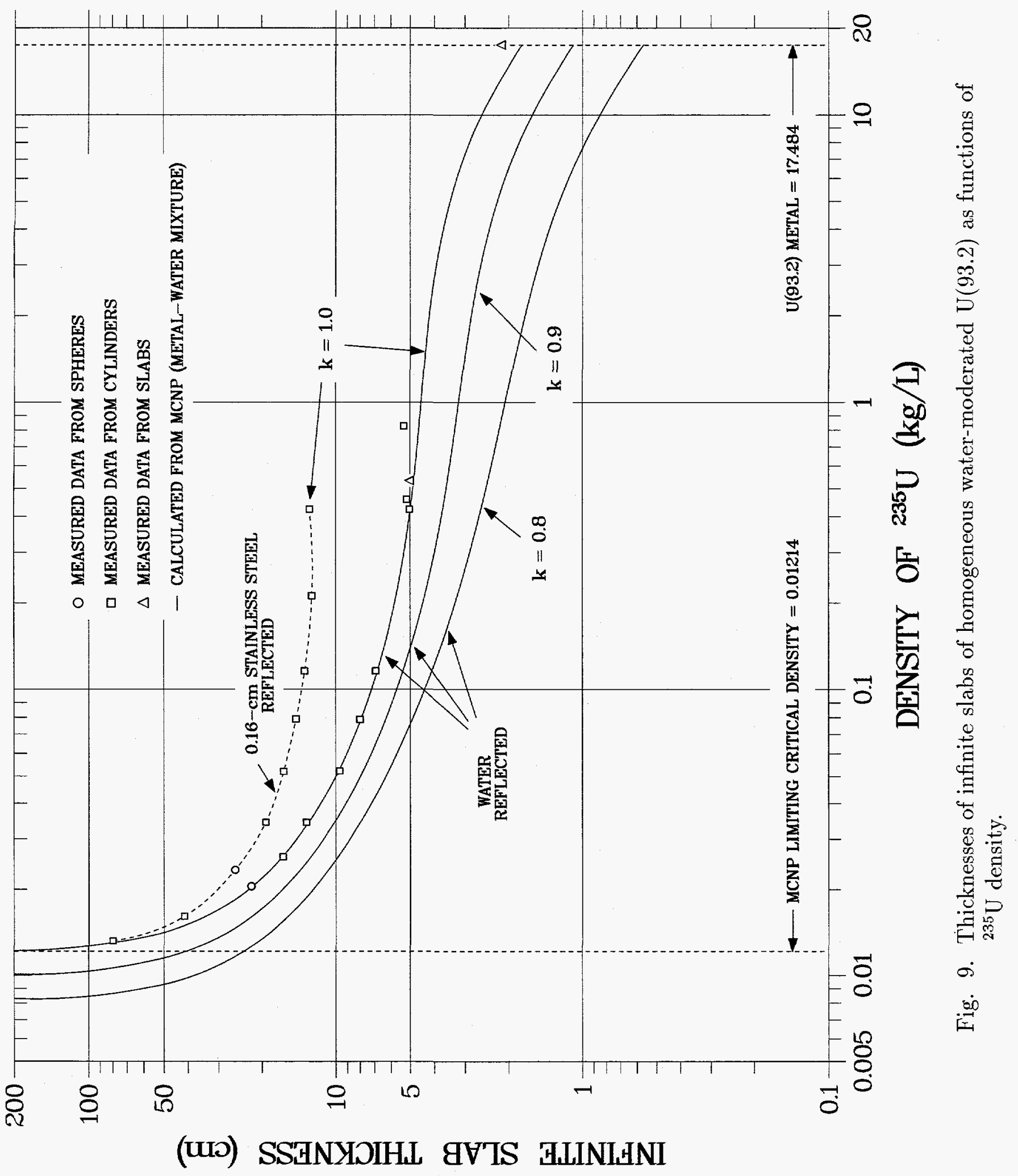


Figure 10

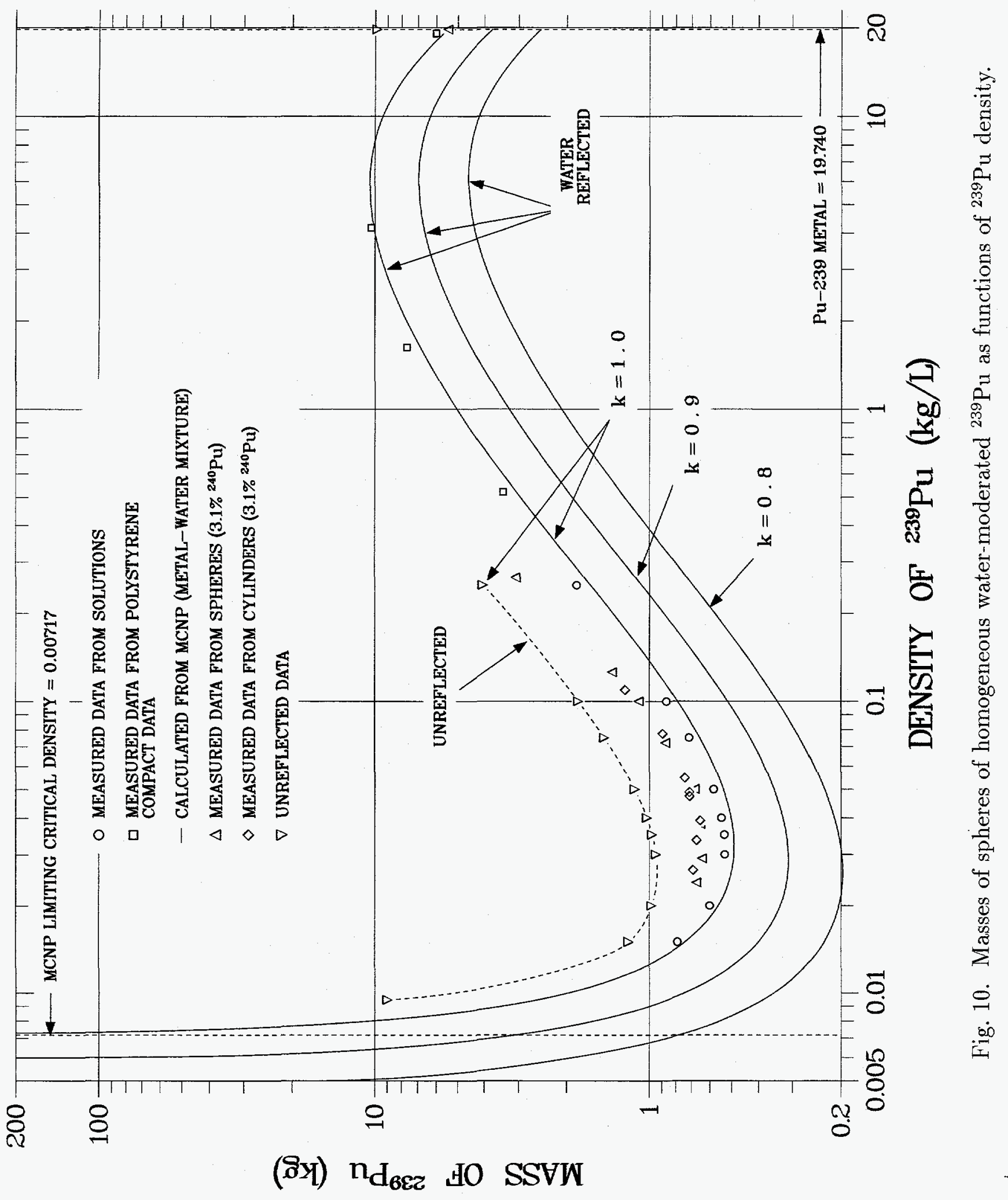




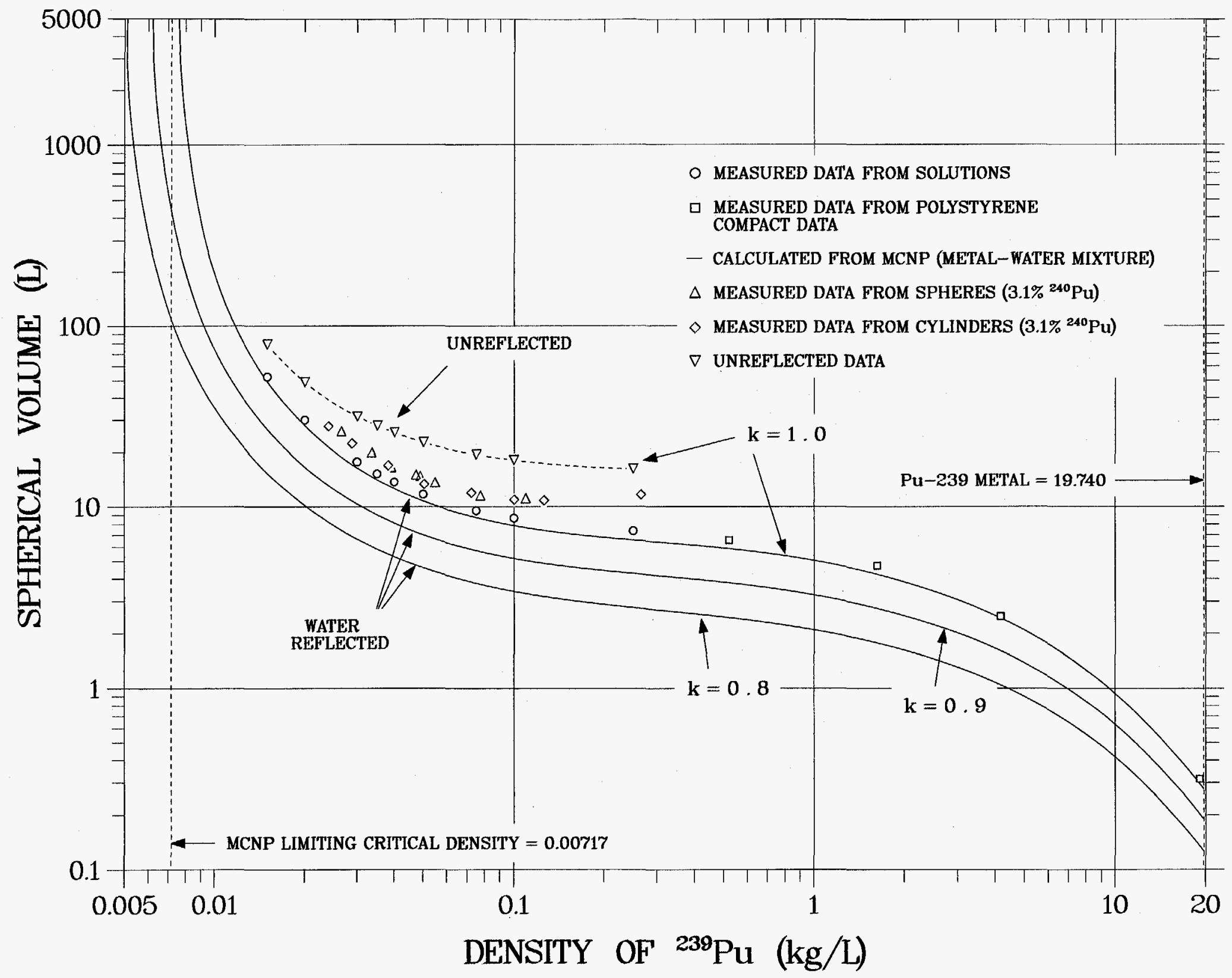

Fig. 11. Volumes of spheres of homogeneous water-moderated ${ }^{239} \mathrm{Pu}$ as functions of ${ }^{239} \mathrm{Pu}$ density. 
Figure 12

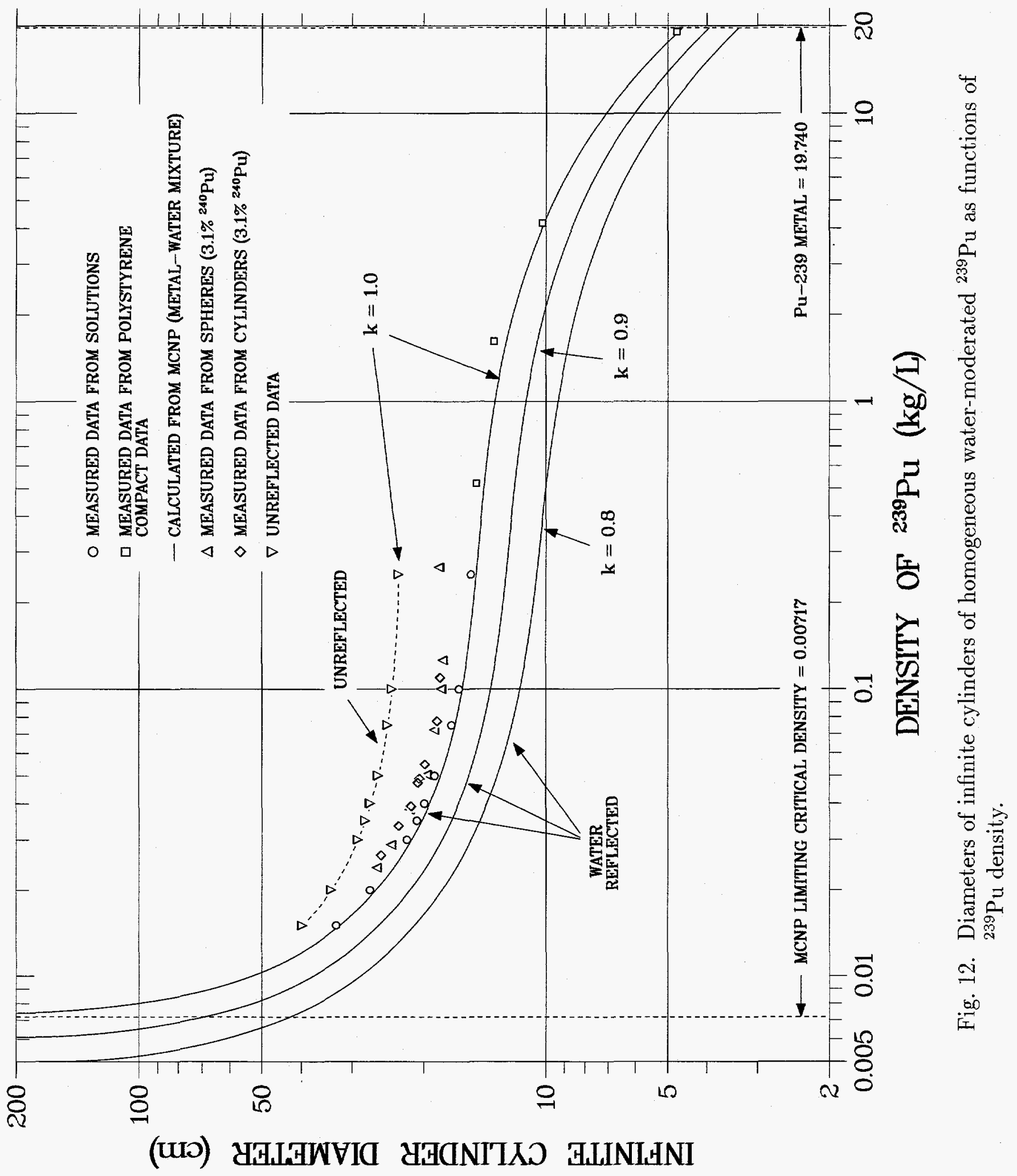




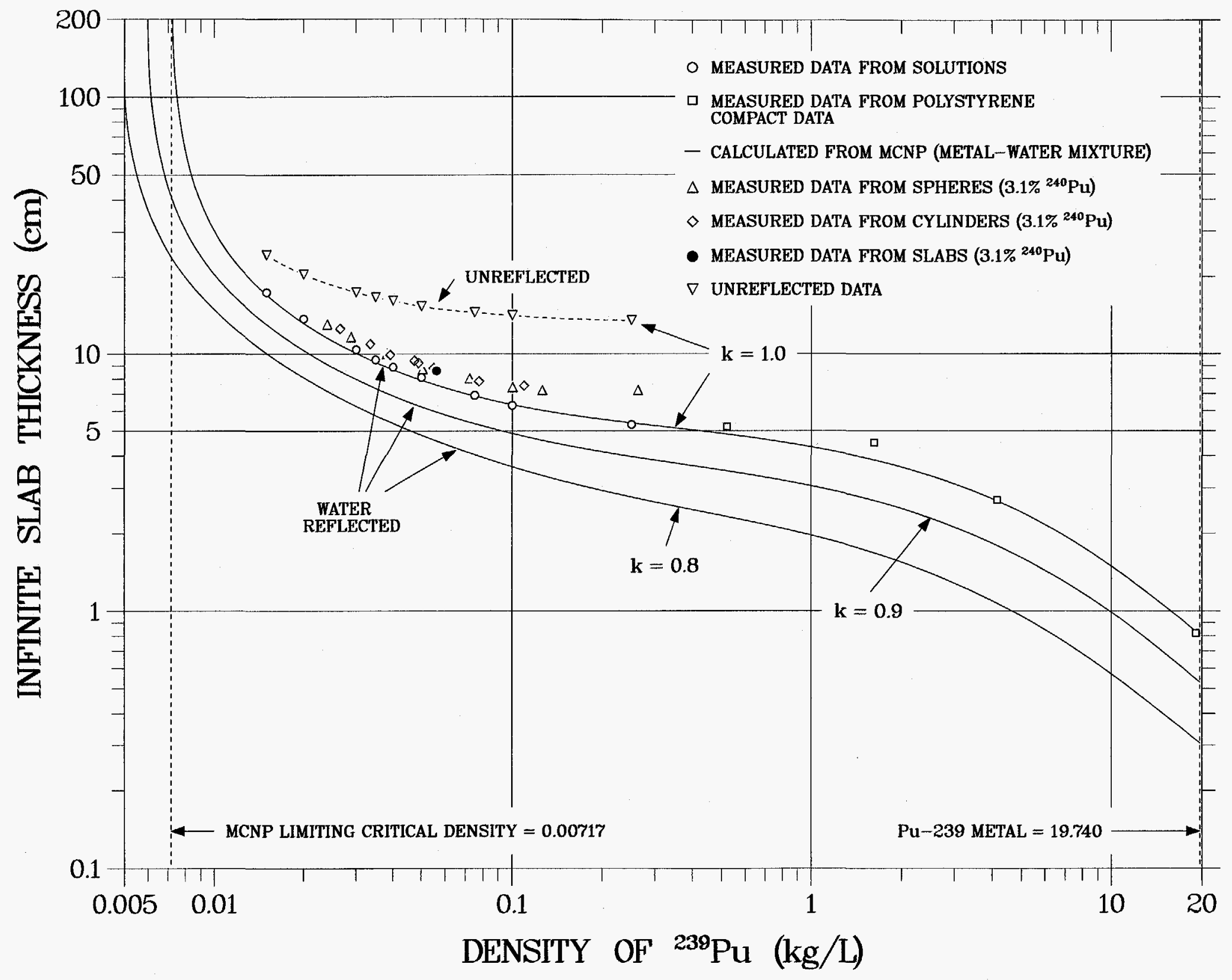

Fig. 13. Thicknesses of infinite slabs of homogeneous water-moderated ${ }^{239} \mathrm{Pu}$ as functions of ${ }^{239} \mathrm{Pu}$ density. 


\section{Low-Enriched Uranium}

Application of the ${ }^{235} \mathrm{U}$ limits of Table 1 and Figures 6 through 9 to uranium at low enrichments would result in safe but very uneconomic criticality safety criteria. Strict administrative controls to establish the enrichment and to maintain material identification are mandatory in order to take advantage of realistic limits for uranium of low enrichment. It should be noted that criticality is not possible for uranium metal containing less than approximately $5 \mathrm{wt} \%{ }^{235} \mathrm{U}^{82-83}$

Table 8 gives more realistic subcritical limits for uranium enriched to $10 \mathrm{wt} \%$ or less ${ }^{235} \mathrm{U}^{4}$ The limits in Table 8 with footnote "a" must be decreased if the uranium density for a saturated solution can be exceeded, as by precipitation.

The subcritical masses presented in Table 8 for solutions of low-enriched uranium compounds are not applicable when applied to lattices such as exist in power reactors. This is a consequence of the absorbing characteristics of ${ }^{238} U$ for neutrons having energies of a few electron volts, a property called resonance absorption. ${ }^{23}$ When the uranium is latticed, as in a reactor, there is a greater probability of immediate neutron energy degradation from the high energy at which neutrons are produced by fission to less than that at which ${ }^{238} \mathrm{U}$ is strongly absorbing. These neutrons "escape" the ${ }^{238} \mathrm{U}$ resonance absorption and the probability of the escape is a measurable and calculable property of such lattices. The maximum ${ }^{235} \mathrm{U}$ enrichment of the uranium at which latticing can reduce the critical mass is estimated to be about $6 \mathrm{wt} \%{ }^{235} \mathrm{U}$. As noted above, the critical mass of uranium below this enrichment can be lower for a heterogeneous system than for a homogeneous system. Therefore, subcritical limits of a lattice are smaller than for homogeneous uranium of the same enrichment. If the particles constituting a mixture are uniformly distributed and are larger than 127 microns (i.e., not capable of being passed through a 120-mesh screen), the mixture should be considered as heterogeneous unless demonstrated otherwise. ${ }^{84-85}$

Subcritical limits on masses and dimensions of lattices in water of $U(\leq 5)^{*}$ metal or oxide rods of any diameter or lattice spacing surrounded by a thick water reflector have been calculated. ${ }^{86-87}$ These limits can be applied to other heterogeneous arrangements of uranium in water. Limits derived for rods of optimum diameter latticed at the most reactive spacing can be applied conservatively to other sizes, shapes, or distributions. Experiments $^{88-89}$ indicate that a random arrangement is less reactive than is a uniform array of rods at optimum spacing; the actual spacings in the random array may be distributed about the most reactive spacing.

Subcritical limits for uranium and uranium oxide in heterogeneous mixtures ${ }^{86-87}$ are given in Table 9. The limits are applicable regardless of the size or shape of the metal or oxide pieces; they apply only if the environment does not return neutrons more effectively than water (see Table 6). For comparison with lattices, limits for homogeneous uranium oxide water mixtures from the reference are included in Table 9.

${ }^{*}$ Read as uranium enriched to less than or equal to $5 \mathrm{wt} \%$ in ${ }^{235} \mathrm{U}$. 
Table 8

Subcritical Limits for Solutions of Low-Enriched Uranium, Thick Water Reflector

\begin{tabular}{||l|c|c|c|c|c|c||}
\hline & & \multicolumn{6}{|c|}{ Subcritical Limit } \\
\cline { 3 - 7 } Solution & $\begin{array}{c}\text { Enrichment } \\
\left(\mathrm{wt} \%{ }^{235} \mathrm{U}\right)\end{array}$ & $\begin{array}{c}\text { Mass } \\
\left(\mathrm{kg}{ }^{235} \mathrm{U}\right)\end{array}$ & $\begin{array}{c}\text { Volume } \\
(\mathrm{L})\end{array}$ & $\begin{array}{c}\text { Cylinder } \\
\text { Diameter } \\
(\mathrm{cm})\end{array}$ & $\begin{array}{c}\text { Slab } \\
\text { Thickness } \\
(\mathrm{cm})\end{array}$ & $\begin{array}{c}\text { Density } \\
\text { of U } \\
(\mathrm{g} / \mathrm{L})\end{array}$ \\
\hline & & & & & & \\
$\mathrm{UO}_{2} \mathrm{~F}_{2}$ & 1.45 & - & - & - & - & $1190.0^{a}$ \\
& 2.0 & $8.00^{b}$ & $340.0^{b}$ & $63.0^{b}$ & $36.5^{b}$ & $770.0^{c}$ \\
& 3.0 & 2.75 & $77.0^{b}$ & $37.4^{b}$ & $20.0^{b}$ & $470.0^{c}$ \\
& 4.0 & 1.98 & $42.7^{b}$ & $30.2^{b}$ & $15.1^{b}$ & $335.0^{c}$ \\
& 5.0 & 1.64 & 30.6 & 26.6 & 12.6 & $261.0^{c}$ \\
& 10.0 & 1.07 & 14.8 & 20.1 & 8.3 & $123.0^{c}$ \\
& & & & & & \\
$\mathrm{UO}_{2}\left(\mathrm{NO}_{3}\right)_{2}$ & 2.88 & - & - & - & - & $594.9^{a}$ \\
& 4.0 & $6.50^{b}$ & $273.0^{b}$ & $58.6^{b}$ & $33.7^{b}$ & $375.0^{c}$ \\
& 5.0 & 3.30 & $111.0^{b}$ & $42.7^{b}$ & $23.4^{b}$ & $283.0^{c}$ \\
& 10.0 & 1.47 & 26.7 & 25.2 & 11.9 & $128.0^{c}$ \\
& & & & & & \\
\hline
\end{tabular}

${ }^{a}$ Density below which criticality is unattainable.

${ }^{b}$ This value is for a saturated solution; the minimum occurs at a greater density of the salt.

c Saturated solution, assuming that a molarity of 5 for $\mathrm{UO}_{2} \mathrm{~F}_{2}$ and 2.5 for $\mathrm{UO}_{2}\left(\mathrm{NO}_{3}\right)_{2}$ is not exceeded; at larger molarities, the above limits are not valid. 
Table 9

Subcritical Limits for Low-Enriched Uranium as Oxide-Water and Metal-Water Lattices, Thick Water Reflector

\begin{tabular}{||l|c|c|c|c|c||}
\hline \hline \multirow{4}{*}{ Material } & & \multicolumn{4}{|c||}{ Subcritical Limit } \\
\cline { 2 - 6 } & $\begin{array}{c}\text { Enrichment } \\
\text { (wt\% }{ }^{235} \mathrm{U}\end{array}$ & $\begin{array}{c}\text { Mass } \\
\left(\mathrm{kg}^{235} \mathrm{U}\right)\end{array}$ & $\begin{array}{c}\text { Volume of } \\
\text { Lattice } \\
(\mathrm{L})\end{array}$ & $\begin{array}{c}\text { Cylinder } \\
\text { Diameter } \\
(\mathrm{cm})\end{array}$ & $\begin{array}{c}\text { Slab } \\
\text { Thickness } \\
(\mathrm{cm})\end{array}$ \\
\hline Oxide & 1.0 & 19.50 & 480.0 & 72.0 & 41.0 \\
& 2.0 & 3.37 & 60.3 & 34.0 & 17.4 \\
& 3.0 & 2.12 & 33.4 & 27.4 & 13.0 \\
Latticed & 4.0 & 1.59 & 24.0 & 24.5 & 11.2 \\
Metal & 5.0 & 1.36 & 19.5 & 22.3 & 9.8 \\
& 1.0 & 13.10 & 234.0 & 55.5 & 31.6 \\
& 2.0 & 2.94 & 43.0 & 30.1 & 15.0 \\
& 3.0 & 2.03 & 25.8 & 24.9 & 11.5 \\
Homogeneous & 4.0 & 1.54 & 18.3 & 21.7 & 9.8 \\
Oxide & 5.0 & 1.29 & 14.5 & 20.0 & 8.2 \\
& 2.0 & 5.55 & 109.0 & 41.9 & 22.4 \\
& 3.0 & 2.84 & 49.4 & 31.4 & 15.5 \\
& 4.0 & 2.00 & 33.5 & 26.9 & 12.6 \\
& 5.0 & 1.58 & 25.2 & 24.6 & 11.1 \\
& & & & & \\
\hline
\end{tabular}


It is unclear from available data whether natural uranium metal rods can become critical in water if they are of the appropriate diameter and spacing. The minimum ${ }^{235} \mathrm{U}$ enrichment of critical homogeneous aqueous mixtures is about $1 \mathrm{wt} \%{ }^{*}$ Table 10 gives the ${ }^{235} \mathrm{U}$ enrichments at or below which several compounds will be subcritical as homogeneous aqueous mixtures or solution.

Table 10

Subcritical ${ }^{235} \mathrm{U}$ Enrichment Limits for Uranium

Mixed Homogeneously with Water

\begin{tabular}{||c|c||}
\hline \hline Compound & $\begin{array}{c}\text { Subcritical Limit } \\
\left(\mathrm{wt} \%{ }^{235} \mathrm{U}\right)\end{array}$ \\
\hline Uranium metal & 0.93 \\
$\mathrm{UO}_{2}, \mathrm{UO}_{3}, \mathrm{U}_{3} \mathrm{O}_{8}$, or $\mathrm{UO}_{2} \mathrm{~F}_{2}$ & 0.96 \\
$\mathrm{UO}_{2}\left(\mathrm{NO}_{3}\right)_{2}$ & 1.96 \\
\hline
\end{tabular}

${ }^{*}$ See Fig. 22 of Ref. 11. 


\section{Mixtures of Nuclides}

\section{Mixtures of ${ }^{233} \mathrm{U}$, Carbon, Water, and Thorium}

When the ${ }^{233} \mathrm{U}$-Th reactor fuel cycle was considered more seriously than at present, Thomas made a computational criticality survey of combinations that might be encountered in fuel processing. ${ }^{90}$ Thomas covered mixtures of ${ }^{233} \mathrm{UO}_{2}, \mathrm{ThO}_{2}$, carbon and water over a range of ${ }^{233} \mathrm{U}$ densities and at $\mathrm{Th} / \mathrm{U}$ ratios of 0,1 , and 4 . Water-reflected critical spherical masses and radii of infinite cylinders are given as functions of ${ }^{233} \mathrm{U}$ density.

\section{2. ${ }^{235} \mathrm{U}$-Water-Graphite Mixtures}

During the life of the Rover propulsion-reactor project, the need to process graphitemoderated fuel led to a computational criticality survey of U(93) metal-water-graphite mixtures. This survey, reported by Stratton, ${ }^{81}$ gives critical sphere masses and volumes, diameters of infinite cylinders, and thicknesses of infinite slabs over ranges of $U$ density, $\mathrm{H} / \mathrm{U}$ ratio, and $\mathrm{C} / \mathrm{U}$ ratio, and two thicknesses of water reflector. Subsequently, calculated subcritical limits for U(93.5) metal-water-graphite systems were re-examined and appear in Table 11. 


\section{Table 11}

\section{Subcritical Limits for Spheres, Cylinders and Slabs}

of U(93.5) Metal-Water-Graphite Mixtures

\begin{tabular}{|c|c|c|c|c|c|c|c|c|c|}
\hline \multirow[b]{3}{*}{$\mathrm{H} / \mathrm{U}$} & \multirow[b]{3}{*}{$\begin{array}{c}\text { Density } \\
(\mathrm{kg} \mathrm{U} / \mathrm{L})\end{array}$} & \multicolumn{4}{|c|}{ 2.5-cm-Thick Water Reflector } & \multicolumn{4}{|c|}{ 30-cm-Thick Water Reflector } \\
\hline & & \multicolumn{2}{|c|}{ Sphere } & \multirow{2}{*}{$\begin{array}{c}\text { Cylinder } \\
\text { Diameter } \\
\text { (cm) }\end{array}$} & \multirow{2}{*}{$\begin{array}{c}\text { Slab } \\
\text { Thickness } \\
\text { (cm) }\end{array}$} & \multicolumn{2}{|c|}{ Sphere } & \multirow{2}{*}{$\begin{array}{c}\text { Cylinder } \\
\text { Diameter } \\
(\mathrm{cm})\end{array}$} & \multirow{2}{*}{$\begin{array}{c}\text { Slab } \\
\text { Thickness } \\
\text { (cm) }\end{array}$} \\
\hline & & $\begin{array}{l}\operatorname{Mass}^{a} \\
(\mathrm{~kg} \mathrm{U})\end{array}$ & $\begin{array}{l}\text { Volume } \\
\text { (L) }\end{array}$ & & & $\begin{array}{l}\operatorname{Mass}^{a} \\
(\mathrm{~kg} \mathrm{U})\end{array}$ & $\begin{array}{l}\text { Volume } \\
(\mathrm{L})\end{array}$ & & \\
\hline \multicolumn{10}{|c|}{$\mathrm{C} / \mathrm{U}=0$} \\
\hline 0 & 18.8 & 29.5 & 1.56 & 9.43 & 3.80 & 21.0 & 1.00 & 7.16 & 1.31 \\
\hline 5 & 4.09 & 22.2 & 5.44 & 14.7 & 6.83 & 13.2 & 3.24 & 11.1 & 2.96 \\
\hline 50 & 0.508 & 3.55 & 6.99 & 16.2 & 7.80 & 2.22 & 4.37 & 12.6 & 4.18 \\
\hline 300 & 0.0867 & 0.991 & 11.4 & 19.5 & 10.0 & 0.705 & 8.14 & 16.4 & 6.96 \\
\hline 1500 & 0.0174 & 2.75 & 158. & 49.4 & 29.2 & 2.35 & 135. & 46.0 & 26.3 \\
\hline \multicolumn{10}{|c|}{$\mathrm{C} / \mathrm{U}=20$} \\
\hline 0 & 1.69 & 141. & 83.7 & 39.0 & 21.7 & 80.8 & 47.7 & 29.6 & 12.0 \\
\hline 5 & 1.28 & 46.2 & 36.1 & 29.0 & 15.4 & 26.4 & 20.6 & 21.9 & 8.13 \\
\hline 50 & 0.399 & 4.22 & 10.5 & 18.8 & 9.33 & 2.61 & 6.55 & 14.7 & 5.15 \\
\hline 300 & 0.0828 & 1.02 & 12.3 & 20.0 & 10.3 & 0.730 & 8.81 & 16.9 & 7.21 \\
\hline 1500 & 0.0172 & 2.77 & 160. & 49.5 & 29.4 & 2.38 & 138. & 45.5 & 25.9 \\
\hline \multicolumn{10}{|c|}{$\mathrm{C} / \mathrm{U}=100$} \\
\hline 0 & 0.365 & 104. & 285. & 59.8 & 35.1 & 63.5 & 174. & 47.6 & 23.0 \\
\hline 5 & 0.341 & 54.0 & 158. & 48.7 & 28.0 & 32.4 & 95.0 & 38.3 & 17.7 \\
\hline 50 & 0.215 & 5.97 & 27.8 & 26.5 . & 14.0 & 3.70 & 17.2 & 20.9 & 8.48 \\
\hline 300 & 0.0703 & 1.15 & 16.3 & 22.1 & 11.6 & 0.822 & 11.7 & 18.7 & 8.23 \\
\hline 1500 & 0.0166 & 2.83 & 170. & 50.6 & 30.0 & 2.42 & 145. & 47.3 & 27.0 \\
\hline \multicolumn{10}{|c|}{$\mathrm{C} / \mathrm{U}=200$} \\
\hline 0 & 0.184 & 74.8 & 406. & 67.5 & 40.0 & 46.8 & 254. & 54.5 & 27.4 \\
\hline 5 & 0.178 & 45.3 & 254. & 57.5 & 33.6 & 28.1 & 157. & 46.1 & 22.5 \\
\hline 50 & 0.136 & 7.05 & 51.8 & 33.0 & 18.1 & 4.40 & 32.3 & 26.4 & 11.6 \\
\hline 300 & 0.0591 & 1.29 & 21.8 & 24.5 & 13.1 & 0.925 & 15.6 & 20.8 & 9.43 \\
\hline 1500 & 0.0159 & 2.91 & 183. & 51.8 & 30.9 & 2.49 & 156. & 50.8 & 27.7 \\
\hline \multicolumn{10}{|c|}{$\mathrm{C} / \mathrm{U}=500$} \\
\hline 0 & 0.0741 & 38.9 & 524. & 73.7 & 43.9 & 25.3 & 341. & 60.8 & 31.7 \\
\hline 5 & 0.0731 & 28.7 & 393. & 66.7 & 39.5 & 18.6 & 255. & 54.9 & 28.3 \\
\hline 50 & 0.0649 & 7.84 & 120. & 44.4 & 25.3 & 5.11 & 78.7 & 36.4 & 17.7 \\
\hline 300 & 0.0400 & 1.62 & 40.6 & 30.5 & 16.8 & 1.17 & 29.3 & 26.1 & 12.5 \\
\hline 1500 & 0.0141 & 3.13 & 222. & 55.5 & 33.2 & 2.69 & 191. & 51.4 & 30.0 \\
\hline \multicolumn{10}{|c|}{$\mathrm{C} / \mathrm{U}=1000$} \\
\hline 0 & 0.0371 & 21.4 & 576. & 76.1 & 45.4 & 14.4 & 390. & 63.9 & 34.1 \\
\hline 5 & 0.0369 & 18.0 & 488. & 71.9 & 42.7 & 12.1 & 330. & 60.4 & 32.0 \\
\hline 50 & 0.0347 & 7.46 & 215 . & 54.2 & 31.5 & 5.06 & 145. & 45.5 & 23.4 \\
\hline 300 & 0.0260 & 1.99 & 76.5 & 38.0 & 21.5 & 1.46 & 56.1 & 32.9 & 16.7 \\
\hline 1500 & 0.0119 & 3.50 & 295 . & 61.1 & 36.8 & 3.05 & 257. & 56.0 & 33.4 \\
\hline
\end{tabular}




\section{Plutonium-Uranium Mixtures}

\section{Aqueous Mixtures ${ }^{71,91}$}

Standard ANSI/ANS-8.12 gives subcritical limits for individual units of mixtures of plutonium and natural uranium. It is noted that the subcritical margin of these limits, $\Delta \mathrm{k}_{\mathrm{eff}}=0.05$, includes no allowance for contingencies. Consequently, in application, there must be sufficient overall margin to protect against the limit being exceeded accidently.

These subcritical limits appear in Figure 14 for mass, Figure 15 for volume, Figure 16 for cylinder diameter, and Figure 17 for slab thickness. Again, the equivalent of full water reflection is assumed. Solid lines apply to solutions and effectively homogeneous* aqueous mixtures. Dashed lines apply to optimum lattices of rods in water, and may be applied conservatively to other distributions of small pieces in water.

\footnotetext{
* Particles in a slurry should be uniformly distributed and have a diameter no larger than $0.127 \mathrm{~mm}(0.005 \mathrm{in}$.), i.e., are capable of being passed through a 120 -mesh screen. ${ }^{71}$
} 


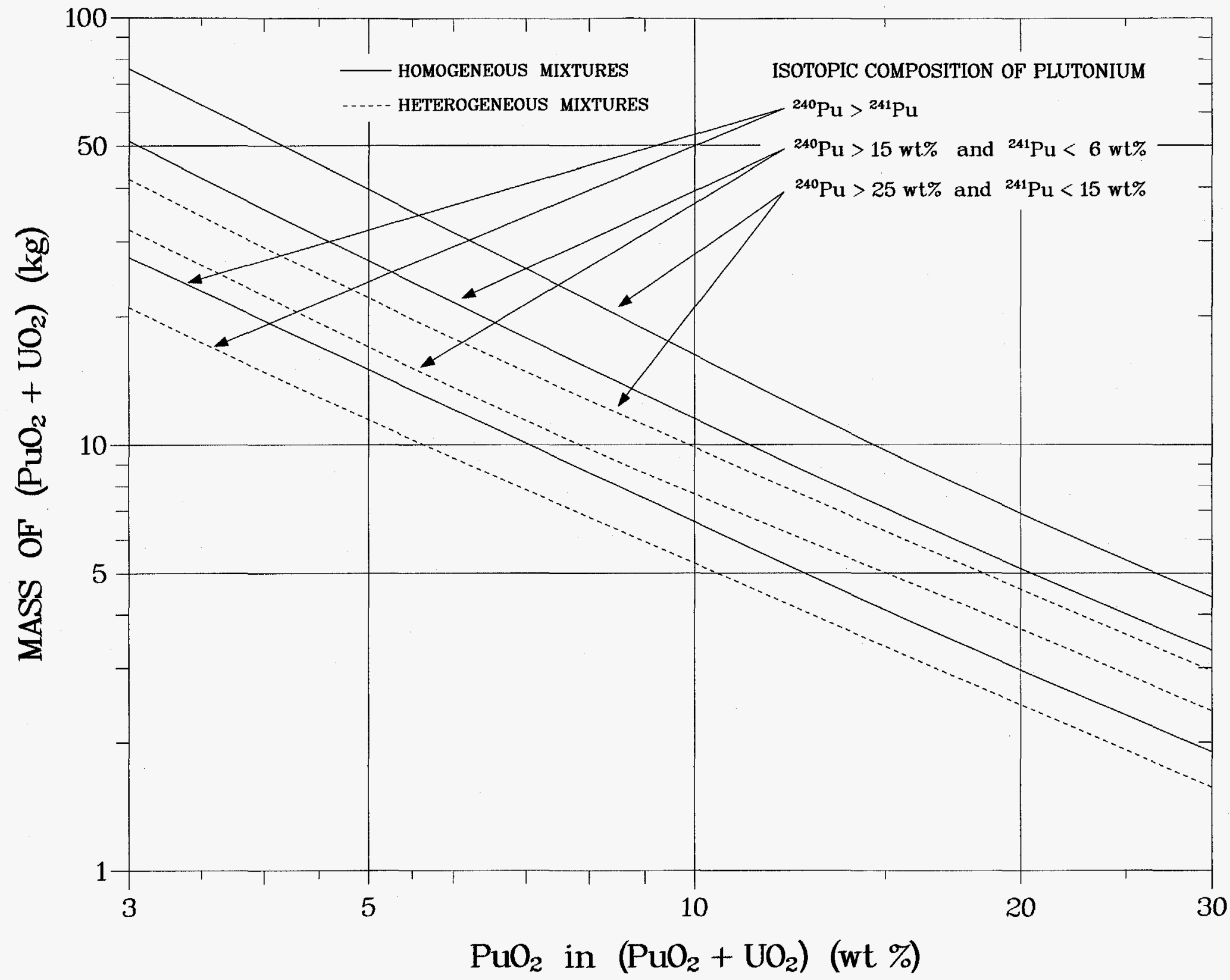

Fig. 14. Subcritical mass limits for water-reflected spheres of aqueous mixtures of $\mathrm{PuO}_{2}$ and $\mathrm{U}(0.7) \mathrm{O}_{2}$. 
Figure 15

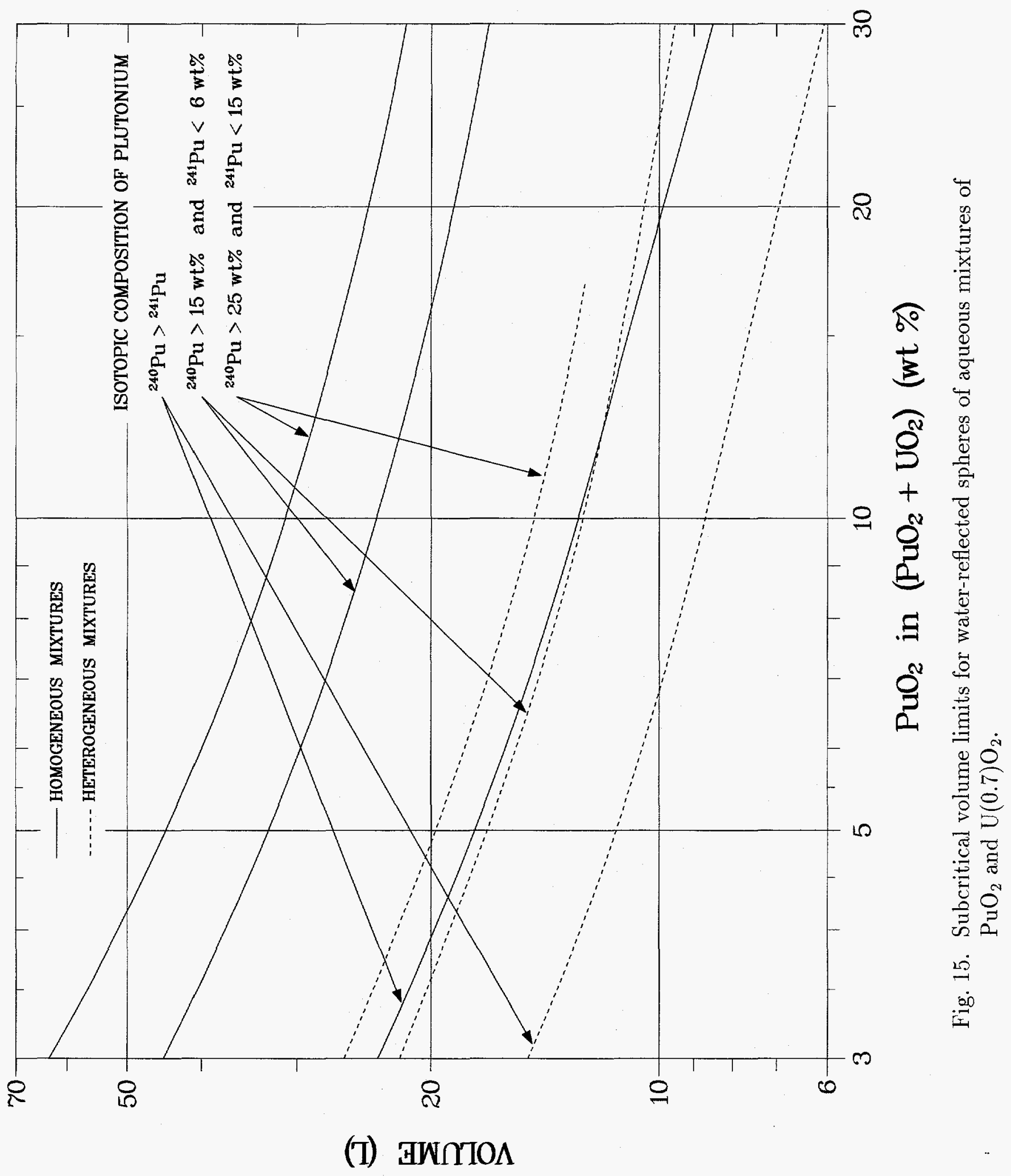


Figure 16

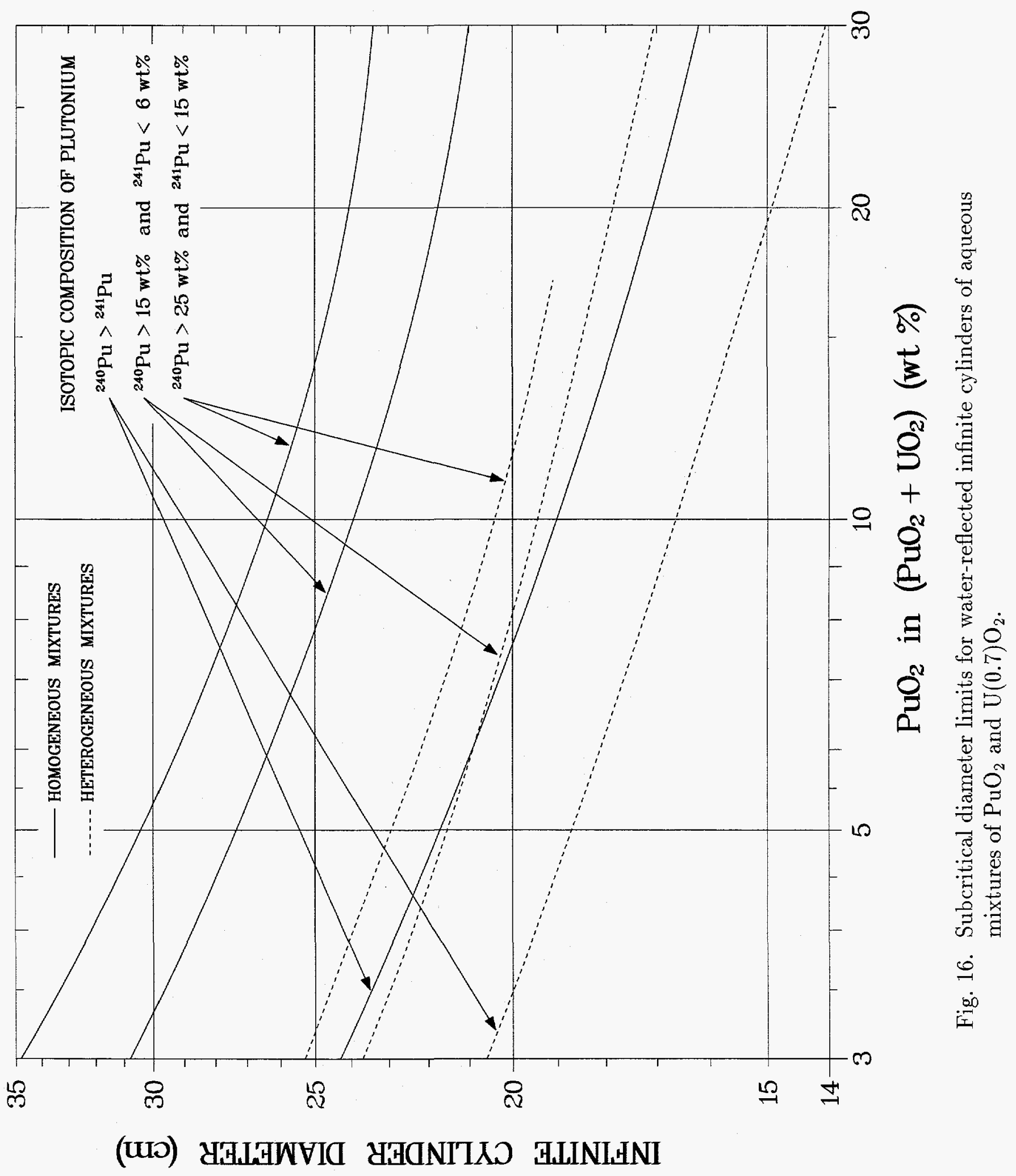


Figure 17

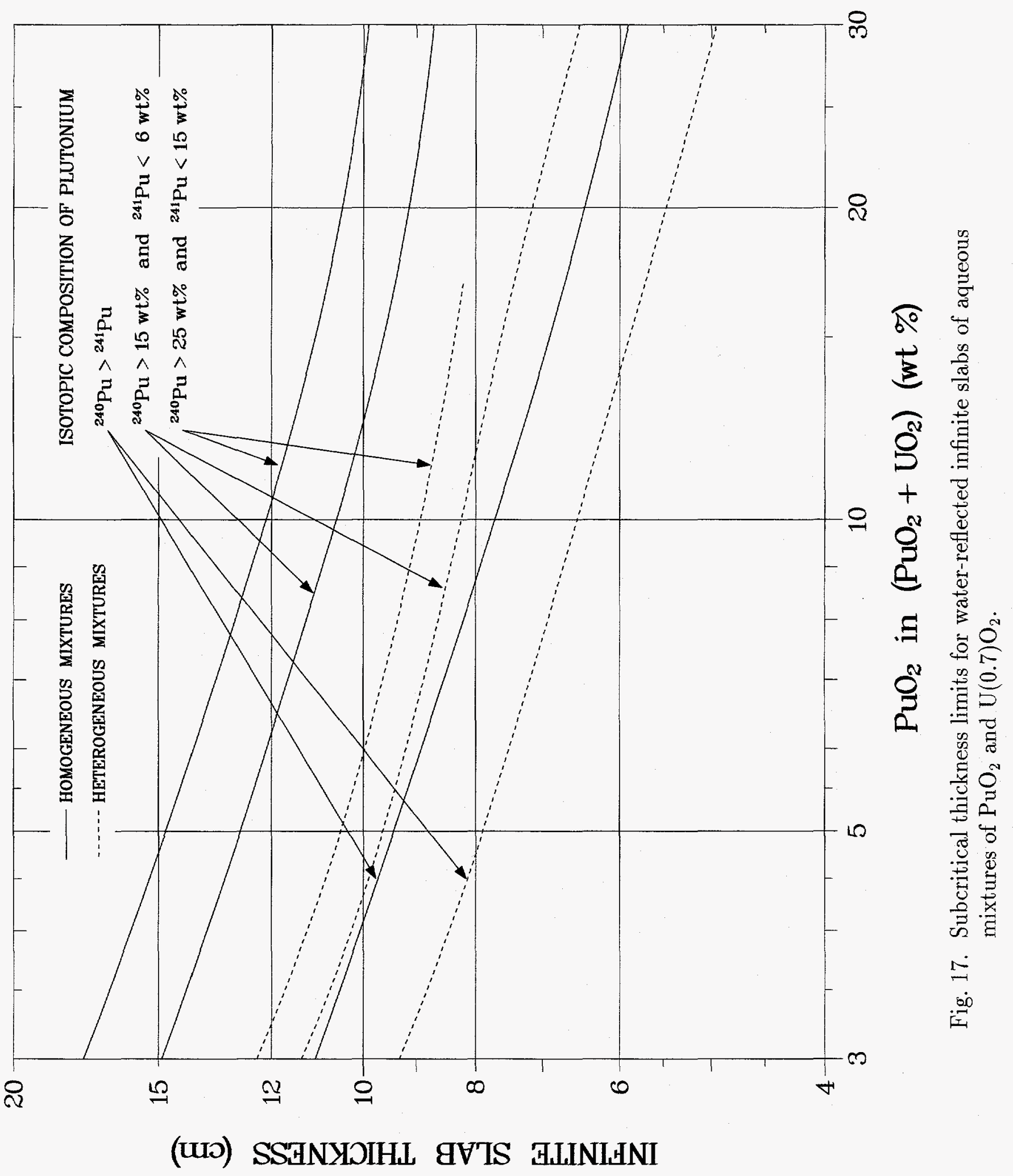




\section{Dry and Damp Mixed-Oxide Powders ${ }^{71}$}

The subcritical mass limits given in Table 12 apply to dry and damp mixed oxides of plutonium and natural uranium. Again, the limits for damp oxide are provided because completely dry oxide may be difficult to maintain. These are for $\mathrm{H} /(\mathrm{Pu}+\mathrm{U}) \leq 0.45(1.48 \mathrm{wt} \%$ water). Also, limits are provided for oxides of half-theoretical density.

Table 12

Subcritical Mass Limits for Single Units of Mixed Oxides of Plutonium and Natural Uranium, Thick Water Reflector ${ }^{a}$

\begin{tabular}{|c|c|c|c|}
\hline \multirow[b]{2}{*}{ Material } & \multirow[b]{2}{*}{$\begin{array}{c}\mathrm{PuO}_{2} \text { in } \\
\left(\mathrm{PuO}_{2}+\mathrm{UO}_{2}\right) \\
(\mathrm{wt} \%)\end{array}$} & \multicolumn{2}{|c|}{ Subcritical Limit } \\
\hline & & $\begin{array}{l}\text { Mass of } \\
\mathrm{Pu} \\
(\mathrm{kg})\end{array}$ & $\begin{array}{c}\text { Mass of } \\
\text { Oxides } \\
(\mathrm{kg})\end{array}$ \\
\hline \multirow{4}{*}{$\begin{array}{l}\text { Dry mixed oxides at } \\
\text { density } \leq 11.0 \mathrm{~g} / \mathrm{cm}^{3}\end{array}$} & 3 & $-^{b}$ & ${ }^{b}$ \\
\hline & 8 & 122.0 & 1729.0 \\
\hline & 15 & 47.0 & 355.0 \\
\hline & 30 & 26.1 & 98.6 \\
\hline Damp mixed oxides at & 3 & 236.0 & 8919.0 \\
\hline density $\leq 9.4 \mathrm{~g} / \mathrm{cm}^{3}$ & 8 & 49.4 & 700.0 \\
\hline \multirow[t]{2}{*}{$\mathrm{H} /(\mathrm{Pu}+\mathrm{U}) \leq 0.45$} & 15 & 32.9 & 249.0 \\
\hline & 30 & 23.3 & 88.1 \\
\hline Damp mixed oxides at & 3 & 885.0 & $33,447.0$ \\
\hline half density ${ }^{c} \leq 4.7 \mathrm{~g} / \mathrm{cm}^{3}$ & 8 & 161.0 & 2282.0 \\
\hline \multirow[t]{2}{*}{$\mathrm{H} /(\mathrm{Pu}+\mathrm{U}) \leq 0.45$} & 15 & 102.0 & 771.0 \\
\hline & 30 & 67.9 & 256.6 \\
\hline
\end{tabular}

a Masses given are for the $\mathrm{Pu}$ contained in the mixed oxide, and for the permissible quantity of $\mathrm{PuO}_{2}+\mathrm{UO}_{2}$. The limits apply to mixed oxides of ${ }^{239} \mathrm{Pu}$ and natural uranium $\left({ }^{235} \mathrm{U} \leq 0.72 \mathrm{wt} \%\right)$.

${ }^{b}$ Subcritical in any amount

c CAUTION: Application of these limits requires that the total oxide density be less than $4.7 \mathrm{~g} / \mathrm{cm}^{3}$. 
Subcritical Plutonium Content for Unlimited Quantities of Plutonium and Natural Uranium Mixtures ${ }^{71}$

Either of two conditions results in subcriticality for unlimited quantities of plutoniumnatural uranium mixtures. One condition is sufficient dilution of plutonium by uranium for $\mathrm{k}_{\infty} \leq 1$. Material for which $\mathrm{k}_{\infty}$ (Ref. 9) is less than unity will be subcritical regardless of the mass, volume, shape, or reflector condition. Table 13 gives subcritical limits of $\mathrm{Pu}$ in $(\mathrm{Pu}+\mathrm{U})$ for unlimited quantities of dry and aqueous oxide mixtures and nitrate solutions. For example, a homogeneous mixture of $\mathrm{PuO}_{2}$ and $\mathrm{UO}_{2}$ in water cannot achieve criticality if the plutonium content does not exceed $0.13 \mathrm{wt} \%$ of the total $(\mathrm{Pu}+\mathrm{U})$. Table 13 is not applicable to $(\mathrm{Pu}+\mathrm{U})$ metal and water mixtures.

Table 13

Subcritical Limits for Plutonium in Plutonium and Natural Uranium Mixtures of Unlimited Mass

\begin{tabular}{||l|c||}
\hline \multicolumn{1}{|c||}{ Mixture of $\mathrm{Pu}+\mathrm{U}$} & $\begin{array}{c}{ }_{\mathrm{wt}} \mathrm{Pu} \\
\text { in }(\mathrm{Pu}+\mathrm{U})\end{array}$ \\
\hline Dry oxides, $\mathrm{H} /(\mathrm{Pu}+\mathrm{U})=0$ & 4.4 \\
Damp oxides, $\mathrm{H} /(\mathrm{Pu}+\mathrm{U}) \leq 0.45$ & 1.8 \\
Oxides in water & 0.13 \\
Nitrate solution & 0.65 \\
\hline
\end{tabular}


The second condition is the dilution of plutonium by sufficient water that neutron absorption by hydrogen will maintain $k_{\infty}<1$. Guidance for uniform aqueous mixtures of the oxides of natural uranium and plutonium is provided in Table 14 for three isotopic compositions of plutonium. The particle size limitation stated earlier applies; i.e., less than $0.127 \mathrm{~mm}$. The limits are given for four compositions of plutonium expressed as wt $\mathrm{PuO}_{2}$ in the oxides and are specified for each of three controllable parameters.

These parameters are the mass of plutonium per unit volume, the minimum $\mathrm{H} / \mathrm{Pu}$ atomic ratio, and the mass of combined oxides per unit volume. When there is less than $3 \mathrm{wt} \%$ $\mathrm{PuO}_{2}$ in the oxides, the subcritical limit of $6.8 \mathrm{~g} \mathrm{Pu} / \mathrm{L}$ in Table 14 must be reduced because of the increased relative importance of ${ }^{235} \mathrm{U}$ as the proportion of uranium increases. Oxides having compositions between 0.13 and $3 \mathrm{wt} \% \mathrm{PuO}_{2}$ must be treated as special cases. If the $\mathrm{Pu}$ in $(\mathrm{Pu}+\mathrm{U})$ composition of the oxides is less than $0.13 \mathrm{wt} \%$, criticality is not possible, as noted in Table 13. 
Table 14

Limiting Subcritical Densities of Unlimited Volumes of Uniform Aqueous Mixtures ${ }^{a}$ of $\mathrm{PuO}_{2}$ and $\mathrm{UO}_{2}\left({ }^{235} \mathrm{U} \leq \mathbf{0 . 7 2} \mathrm{wt} \%\right)$

\begin{tabular}{||c|c|c|c|c||}
\hline \hline $\begin{array}{c}\mathrm{PuO}_{2} \text { in } \\
\left(\mathrm{Put}_{2}+\mathrm{UO}_{2}\right)\end{array}$ & $\begin{array}{c}\mathrm{Pu} \\
\text { Isotopic } \\
\text { Content }^{b}\end{array}$ & $\begin{array}{c}\mathrm{H} / \mathrm{Pu} \\
\text { Atomic } \\
\text { Ratio }^{c}\end{array}$ & $\begin{array}{c}\mathrm{Pu} \\
\text { Density } \\
(\mathrm{g} / \mathrm{L})\end{array}$ & $\begin{array}{c}\left(\mathrm{PuO}_{2}+\mathrm{UO}_{2}\right) \\
\text { Density } \\
(\mathrm{g} / \mathrm{L})\end{array}$ \\
\hline \multirow{3}{*}{3} & I & 3780 & $6.8^{d}$ & 257. \\
& II & 3203 & 8.1 & 305. \\
& III & 2780 & 9.3 & 351. \\
& I & 3780 & 6.9 & 97. \\
& II & 3210 & 8.2 & 116. \\
& III & 2780 & 9.4 & 134. \\
& I & 3780 & 7.0 & 52.9 \\
& II & 3237 & 8.2 & 61.7 \\
& III & 2818 & 9.4 & 71.0 \\
& & & & \\
& I & 3780 & 7.0 & 26.5 \\
& II & 3253 & 8.1 & 30.7 \\
& III & 2848 & 9.3 & 35.2 \\
& & & & \\
\hline
\end{tabular}

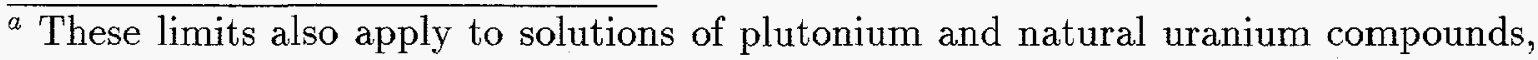
provided all specified conditions are satisfied.

${ }^{b}$ Plutonium isotopic content:

$$
\begin{aligned}
& \mathrm{I} \rightarrow{ }^{240} \mathrm{Pu}>{ }^{241} \mathrm{Pu} \\
& \mathrm{II} \rightarrow{ }^{240} \mathrm{Pu} \geq 15 \mathrm{wt} \% \text { and }{ }^{241} \mathrm{Pu} \leq 6 \mathrm{wt} \% \\
& \mathrm{III} \rightarrow{ }^{240} \mathrm{Pu} \geq 25 \text { wt } \% \text { and }{ }^{241} \mathrm{Pu} \leq 15 \mathrm{wt} \%
\end{aligned}
$$

${ }^{c}$ Lower limit.

$d$ This density limit is not applicable to oxide mixtures in which the $\mathrm{PuO}_{2} /\left(\mathrm{PuO}_{2}+\mathrm{UO}_{2}\right)$ ratio is less than $3 \mathrm{wt} \%$. 


\section{E. Special Geometries}

\section{Annular Cylinders}

Experiments at Oak Ridge ${ }^{92-93}$ and Valduc, France, ${ }^{94}$ on the criticality of solutions in annuli provide the basis for potential applications described in Section C of Chapter IV, Storage of Solutions. All annuli consisted of the space between two coaxial cylinders, with the central cylinder lined with cadmium and filled with water. The Oak Ridge experiments established critical heights of $\mathrm{U}(93) \mathrm{O}_{2} \mathrm{~F}_{2}$ solutions at $\mathrm{H} /{ }^{235} \mathrm{U}=50.4$ or 309 in annuli of various thicknesses and ranging from $25.4-\mathrm{cm}$ to $76.2-\mathrm{cm}-0 . \mathrm{d}$. These experiments were carried out with and without an external water reflector.

At Valduc, critical heights of plutonium solutions in water-reflected $50 \mathrm{~cm}$ o.d. annuli were determined. One set of data applies to $l{ }^{-}{ }^{240} \mathrm{Pu}$ solution at densities from 130 to $190 \mathrm{~g}$ ${ }^{239} \mathrm{Pu} / \mathrm{L}$ in an annulus of $30-\mathrm{cm}-$ i.d. Another set applies to solutions of $\mathrm{Pu}$ containing $19 \mathrm{wt} \%{ }^{240} \mathrm{Pu}$, at about 50 to $165 \mathrm{~g}{ }^{239} \mathrm{Pu} / \mathrm{L}$, in a 20 -cm-i.d. annulus.

Critical experiments at Los Alamos on a tall 76-cm-o.d. and 57-cm-i.d. tank with various reflectors ${ }^{95}$ were in support of upgraded fuel processing equipment at the Idaho Chemical Processing Plant.

Attention is called to the publication, Criticality Experiments with Mixed PlutoniumUranium Nitrate Solution at Plutonium Fractions of 0.2, 0.5, and 1.0 in Annular Cylindrical Geometry. ${ }^{96}$ The 21 -inch-o.d. by 10 -inch-i.d. annulus was reflected externally by water. Various inserts included bottles of solution surrounded by a variety of absorbers.

\section{Pipe Intersections}

Subcritical manifolds, consisting of pipe (arms) intersecting a larger diameter pipe (a column), are described in American National Standard Nuclear Criticality Safety Criteria for Steel-Pipe Intersections Containing Aqueous Solutions of Fissile Material, ANSI/ANS8.9. ${ }^{97}$ This Standard applies to ${ }^{233} \mathrm{U}$ solutions in 4-inch maximum pipe, ${ }^{235} \mathrm{U}$ or ${ }^{239} \mathrm{Pu}$ solutions in branched columns of 6 -inch or less Schedule-10 or heavier pipe, and U(5) solutions in columns as large as 10 -inch pipe. Reflector conditions applied to locations within a small enclosure with concrete walls, or complete water immersion. The Standard considers only single columns with intersections, and states, "Multiple columns or columns in the vicinity of other fissionable materials ... shall be investigated by experiment or by a. validated computational technique." 
Critical experiments with intersecting cylinders, at Rocky Flats and Oak Ridge, were involved in the validation of calculations providing data for ANSI/ANS-8.9. The Rocky Flats measurements all were with $\mathrm{U}(93.1) \mathrm{O}_{2}\left(\mathrm{NO}_{3}\right)_{2}$ solution in $17.8 \mathrm{-cm}$ square columns with as many as 12 arms in three layers. ${ }^{98}$ At Oak Ridge, concentrated $\mathrm{U}(5.0) \mathrm{O}_{2} \mathrm{~F}_{2}$ solution was in a $30^{\circ}$ aluminum "Y" (both legs 27.9-cm-i.d.), or in Plexiglas "crosses" (26.7-cm and 27.3-cm-i.d.). ${ }^{99}$ Results of earlier Oak Ridge measurements ${ }^{92}$ with U(93) solution in a cross and "Y" (both 12.3-cm-i.d.) apparently were not used for validation. Any validation of calculations going beyond the Standard should be based on data from these experiments.

The Monte Carlo calculations ${ }^{100}$ with 123-group cross sections that provided data for the Standard, averaged $k_{\text {eff }}=0.9994 \pm 0.0027$ for the Rocky Flats critical experiments and $0.9999 \pm 0.0022$ for the Oak Ridge U(5) experiments. Calculations for ${ }^{233} \mathrm{U}$ and ${ }^{239} \mathrm{Pu}$ relied upon data for simple cylinders. The geometries that appear in the Standard were adjusted to $\mathrm{k}_{\mathrm{eff}}=\mathbf{0 . 8 5}$ for reflection by concrete walls and $\mathrm{k}_{\text {eff }}=0.90$ for water immersion. 


\section{F. Factors Affecting Limits of Individual Units}

\section{Abnormal Conditions}

Appearing in Appendix A of Standard ANSI/ANS-8.1, and reproduced below, are examples of abnormal variations in process conditions. Such variations should be considered in establishing limits for criticality control. Contingencies, the dominant items, usually lead to practical limits with subcritical margins significantly greater than in the stated subcritical limits. The examples of contingencies, and other abnormal conditions to be considered, follow.*

- A change in intended shape or dimensions resulting from bulging, corrosion, or bursting of a container, or failure to meet specifications in fabrication.

- An increase in the mass of fissionable material in a location as the result of operational error, improper labeling, equipment failure, or failure of analytical techniques.

- A change in the ratio of moderator to fissionable material resulting from

1. Inaccuracies in instruments or chemical analyses,

2. Evaporating or displacing moderator,

3. Precipitating fissionable material from solutions,

4. Diluting concentrated solutions with additional moderator.

- A change in the fraction of the neutron population lost by absorption resulting from

1. Loss of solid absorber by corrosion or by leaching,

2. Loss of moderator,

3. Redistribution of absorber and fissionable material by precipitation of one but not the other from solution,

4. Redistribution of solid absorber within a matrix of moderator or solution by clumping,

5. Failure to add the intended amount of absorber to a solution or failure to add it with the intended distribution,

6. Failure of analytical techniques to yield correct ... concentrations.

\footnotetext{
*A group of examples applicable to multiple units has been deleted.
} 
- A change in the amount of neutron reflection resulting from

1. An increase in reflector thickness by adding ... material (e.g., water or personnel),

2. A change in reflector composition such as loss of absorber (e.g., by corrosion of an outer casing of absorber).

The remainder of this section discusses the influence on criticality limits of conditions that may be normal in processes but are not included in any Standard.

\section{Extended Subcritical Limits}

\section{Reduced Density of Fissile Cores}

For a highly enriched uranium metal core in the equivalent of a thick water reflector, the critical mass varies as the core density $(\rho)$ to the -1.4 power. ${ }^{11}$ This relationship also applies to cores of plutonium metal and of the uranium compounds listed in Table 4. Under rare circumstances, subcritical masses of Tables 3 and 4 may be increased in accordance with $\left(\rho / \rho_{o}\right)^{\mathbf{- 1 . 4}}$ when $\rho$ is less than the normal density $\rho_{o}$. Conditions that must be satisfied are that $\rho$ differs from $\rho_{o}$ only as a result of free space, that no moisture or other moderating material can enter the core, and that the unit cannot be compressed, for example, by compaction as a result of vibration.

\section{Dilution of ${ }^{235} \mathbf{U}$ Metal Core}

The relation discussed above does not apply when the density of fissile metal, $\rho$, is reduced by uniformly replacing a volume fraction of the metal $(\mathrm{F})$, with an inert element. The volume fraction of the remaining fissile metal $(1-F)$ equals $\rho / \rho_{0}$ as defined above. If the diluting element has an atomic number $\mathrm{Z}$ within the range $11 \leq \mathrm{Z} \leq 83$, the subcritical mass for ${ }^{235} \mathrm{U}$ in Table 3 may be increased ${ }^{101}$ by the factor $(1-\mathrm{F})^{-1.0}$, i.e., $\left(\rho / \rho_{0}\right)^{-1.0}$. This factor cannot be used if a moderating material is introduced into the mixture. This relation is a lower envelope for the diluting elements in ${ }^{235} \mathrm{U}$ with a natural uranium reflector and so would be conservative with a water reflector. With natural uranium as a diluting element, the measured factor $(1-F)^{-0.7}$ increases with large $F .^{102}$ 


\section{Neutron Absorbers in Solutions of Fissile Material}

As discussed in Chapter I, criticality in solutions of fissile material may be prevented by the proper addition of either solid or soluble neutron absorbers. In either case, it is important that intended distributions and densities of the absorbers be maintained. Examples of some elements that can be used as neutron absorbers are boron, chlorine, cadmium, and gadolinium.

\section{Solid Neutron Absorbers}

American National Standard Use of Borosilicate-Glass Raschig Rings as a Neutron Absorber in Solutions of Fissile Material, ANSI/ANS-8.5, provides guidance on the use of borosilicateglass Raschig rings as neutron absorbers for criticality control in plants processing fissile material. It specifies subcritical density limits for uranium and plutonium in vessels of unlimited size when packed with borosilicate-glass rings. The recommended limits are summarized in Table 15. Several examples of systems that go beyond the limits of Table 15, including plutonium-uranium solution mixtures, are mentioned in Chapter V.

Possible use of tanks loaded with borosilicate-glass Raschig rings for solution storage is discussed in Section C of Chapter IV and an example is provided in Chapter V. Also in Chapter $\mathrm{V}$ is an example of boron introduced heterogeneously as boron-loaded stainless steel rings.

Although not usually thought an absorber, the borosilicate-glass pipe commonly used for solution storage columns reduces the effectiveness of a surrounding water reflector, as does steel pipe. The specified minimum wall thickness of nominally 6 -inch-diameter Pyrex pipe is $0.71 \mathrm{~cm}$. Assuming this value and that thick water is the only external reflector to be considered, the value of the limit on cylinder diameter (from Table 1) may be increased to $18.5 \mathrm{~cm}$ for ${ }^{235} \mathrm{U}$. The value for ${ }^{239} \mathrm{Pu}$ may be increased to $20.7 \mathrm{~cm}$ provided the nitrogen to plutonium atomic ratio is no less than 4 . It may be noted that the $15.8 \mathrm{~cm}(6.20$ inch) maximum inside diameter of nominally 6 -inch-diameter Pyrex pipe is well below these limits. 
Table 15

Maximum Permissible Densities of Solutions ${ }^{a}$ of Fissile Material in Vessels of Unlimited Size Packed With Borosilicate-Glass Raschig Rings

\begin{tabular}{|c|c|c|c|}
\hline \multirow[b]{2}{*}{ Isotopic Composition } & \multicolumn{3}{|c|}{$\begin{array}{c}\text { Maximum Density }{ }^{b} \text { in Vessels } \\
\text { With Minimum Glass Content of: }\end{array}$} \\
\hline & 24 vol $\%$ & $28 \mathrm{vol} \%$ & 32 vol $\%$ \\
\hline $\begin{array}{r}\text { 1. } 0.0 \mathrm{wt} \%<{ }^{233} \mathrm{U} \leq 100 \mathrm{wt} \% \\
(\mathrm{~g} \mathrm{U} / \mathrm{L})\end{array}$ & $150^{c}$ & $180^{\circ}$ & $200^{c}$ \\
\hline $\begin{array}{l}\text { 2. } 5.0 \mathrm{wt} \%<{ }^{235} \mathrm{U} \leq 100 \mathrm{wt} \% \\
{ }^{233} \mathrm{U} \leq 1 \mathrm{wt} \% \\
(\mathrm{~g} \mathrm{U} / \mathrm{L})\end{array}$ & 270 & 330 & 400 \\
\hline $\begin{array}{l}\text { 3. } 0.7 \mathrm{wt} \% \leq{ }^{235} \mathrm{U} \leq 5.0 \mathrm{wt} \% \\
{ }^{233} \mathrm{U}=0 \mathrm{wt} \% \\
(\mathrm{~g} \mathrm{U} / \mathrm{L})\end{array}$ & unrestricted & unrestricted & unrestricted \\
\hline $\begin{array}{l}\text { 4. }{ }^{239} \mathrm{Pu} \geq 50 \mathrm{wt} \%,{ }^{241} \mathrm{Pu} \leq 15 \mathrm{wt} \% \\
\text { and }{ }^{240} \mathrm{Pu}>{ }^{241} \mathrm{Pu}\end{array}$ & & & \\
\hline a. $\leq 5 \mathrm{wt} \%{ }^{240} \mathrm{Pu}$ & 115 & 140 & 180 \\
\hline b. $>5$ wt $\%{ }^{240} \mathrm{Pu} \quad(\mathrm{g} \mathrm{Pu} / \mathrm{L})$ & 140 & 170 & 220 \\
\hline
\end{tabular}

${ }^{a}$ The density of the hydrogen in the solution shall be not less than $75 \mathrm{~g} / \mathrm{L}$ and not greater than $115 \mathrm{~g} / \mathrm{L}$.

${ }^{b}$ Any fissile material deposited as solids shall be included.

c These limits also apply to mixtures of ${ }^{233} \mathrm{U}$ and other uranium isotopes, including ${ }^{235} \mathrm{U}$, provided the ${ }^{233} \mathrm{U}$ content is greater than $1 \mathrm{wt} \%$ of all the uranium. 


\section{Soluble Neutron Absorbers}

Any use of a soluble absorber for criticality prevention requires confirmation that the absorber be uniformly distributed in the fissile solution and that it cannot precipitate.

Calculations based on experiments carried out at Hanford, ${ }^{103-104}$ provide densities of gadolinium in plutonium solutions required for $k_{\infty}$ to be less than unity.

Boron content in aqueous uranium solutions required to reduce $k_{\infty}$ to less than unity also have been calculated. The calculations were substantiated by experiments ${ }^{105-106}$ with enrichments not exceeding $5 \mathrm{wt} \%{ }^{235} \mathrm{U}$. Figure 18 gives the minimum $\mathrm{B} /{ }^{235} \mathrm{U}$ atomic ratio required to result in $\mathrm{k}_{\infty}$ less than unity for any moderation and for any ${ }^{235} \mathrm{U}$ enrichment up to $5 \mathrm{wt} \%$.

Calculations ${ }^{81}$ based on experiment ${ }^{107}$ indicate that the presence of one atom of boron for each atom of ${ }^{235} \mathrm{U}$ will maintain large volumes of solution subcritical for ${ }^{235} \mathrm{U}$ densities less than $400 \mathrm{~g} / \mathrm{L}$. A boron-to- ${ }^{235} \mathrm{U}$ atomic ratio of 1.5 is sufficient to maintain subcriticality up to a ${ }^{235} \mathrm{U}$ density of $1000 \mathrm{~g} / \mathrm{L}$.

Hanford critical experiments in support of the design of dissolvers at the Idaho Chemical Processing Plant ${ }^{108}$ established the effect of cadmium nitrate dissolved in $\mathrm{U}(85) \mathrm{O}_{2}\left(\mathrm{NO}_{3}\right)_{2}$ solution or its water reflector. 


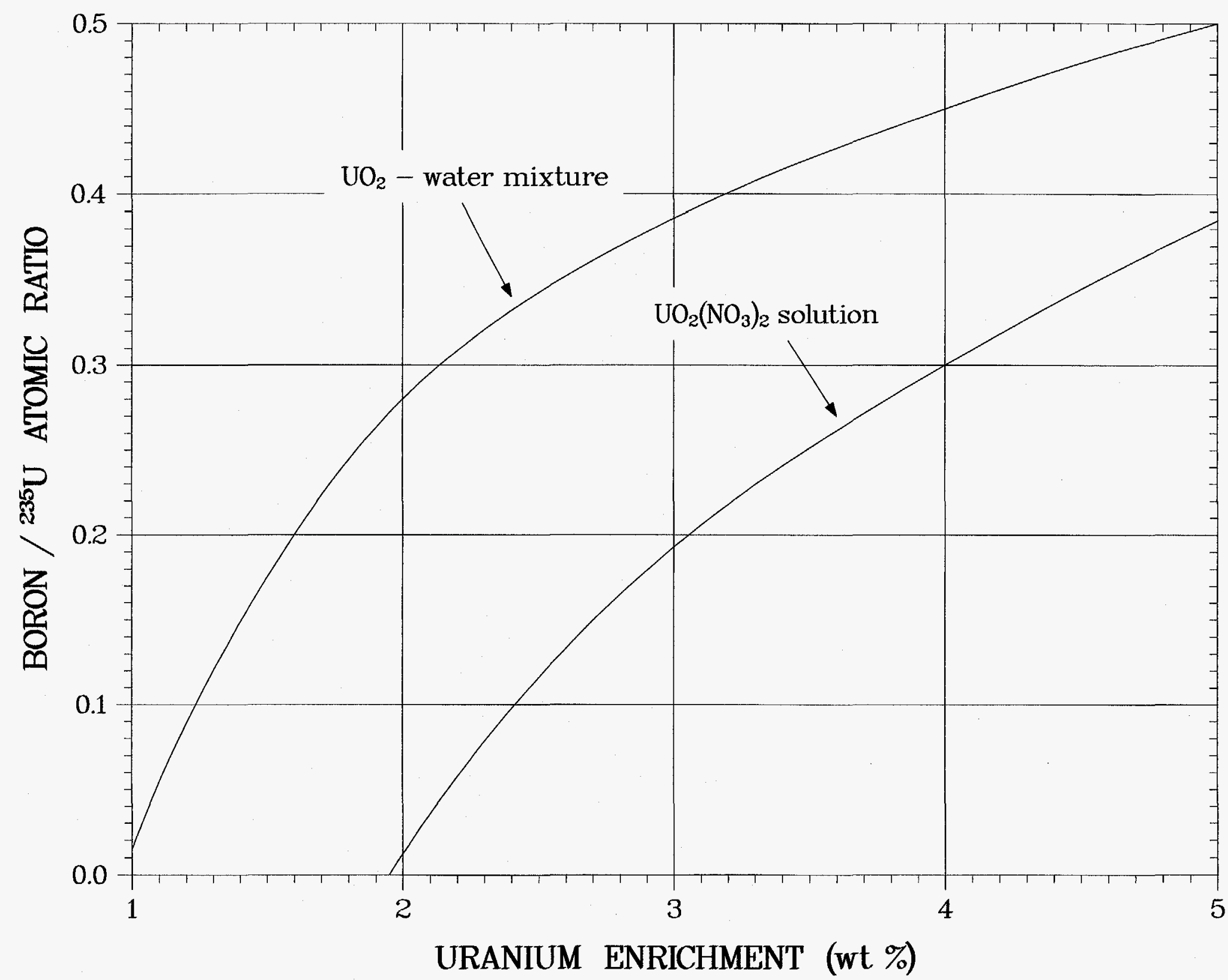

$\stackrel{7}{3}$
$\stackrel{00}{0}$
$\stackrel{0}{0}$
$\stackrel{\infty}{\infty}$

Fig. 18. Boron-to- ${ }^{235} \mathrm{U}$ atomic ratio for subcriticality of solutions of $\mathrm{UO}_{2}\left(\mathrm{NO}_{3}\right)_{2}$ and $\mathrm{UO}_{3}$-water mixtures for uranium containing no more than $5 \mathrm{wt} \%{ }^{235} \mathrm{U}$. 


\section{Concrete as a Reflector}

As noted before, concrete as a neutron reflector is significant because its effectiveness may exceed that of water. ${ }^{109-111}$ Although the composition of concrete is variable, changes in its effectiveness as a reflector are minor within the typical density range of 2.1 to $2.4 \mathrm{~g} / \mathrm{cm}^{3}$ and as the water content ranges from 3 to $10 \mathrm{wt} \%$. As a reflector, water is more effective for thicknesses less than $10 \mathrm{~cm}$ whereas concrete is more effective for thicknesses greater than $10 \mathrm{~cm}$. Consequently, for closely fitting concrete $10 \mathrm{~cm}$ or less in thickness, the single unit limits specified in Chapter III for thick water reflection may be used.

Closely fitting concrete greater than $10 \mathrm{~cm}$ in thickness requires a reduction of the thick water reflector limits. The limits should be multiplied by the following factors:

- 0.90 for mass and volume,

- 0.80 for diameter of infinite cylinder, and

- $0.44 \rho^{-0.155}$ for thickness of infinite slab, where $\rho$ is the fissile material density in $\mathrm{g} / \mathrm{cm}^{3}$.

A vessel often may be located in a concrete cell or in the vicinity of a concrete wall. Guidance is available for the location and dimensions of spherical and cylindrical vessels depending on the density of the fissile material in solution. ${ }^{109}$ For fissile material densities not exceeding $0.5 \mathrm{~g} / \mathrm{cm}^{3}$, the thick water reflector limits may be used, provided a surface separation between the vessel and concrete walls or floor is not less than 0.5 times the vessel diameter. For higher densities, the minimal surface separation should be 0.6 times the diameter. 


\section{Chapter IV}

\section{MULTIPLE UNITS}

\section{A. Neutron Interaction}

\section{Surface-Density, Density-Analog, and Solid-Angle Methods}

The approximate methods for the calculation of interacting fissile units described in this section were conceived before accurate experimental or computational information existed. ${ }^{112-113}$ These methods can still serve to separate hypothetical arrays which are clearly subcritical from those that may be supercritical. Models may also serve to identify borderline cases that require investigation by more reliable methods. The solid-angle method, and in some cases the surface-density method, may be particularly useful for estimating the acceptable interaction of vessels within processing plants where information on uniform arrays is inapplicable. The density-analog method was developed to crudely represent regular three-dimensional arrays of fissile units.

\section{Surface-Density ${ }^{114-116}$}

This interaction method considers the average surface density of an array of fissile units projected onto an appropriate plane such as a floor or wall. An acceptable value for this surface density is related to the surface density of a subcritical infinite slab of the fissile material by an empirical expression that depends upon the magnitude of an individual unit. For example, Figure 2 of Reference 115 shows such relationships for planar (twodimensional) arrays of ${ }^{235} \mathrm{U}$ metal spheres and cubes, and of elongated cylinders of uranium solutions at two different ${ }^{235} \mathrm{U}$ densities.

For arrays that are not cubic, the surface density is not unique, but depends upon the plane of projection. The plane giving the maximum value, which is most restrictive, usually will be apparent, e.g., the base of an array of vertical cylinders.

Although there may be cases where application of the surface-density method makes a Monte Carlo calculation unnecessary, the method is by no means universally applicable. There is, for example, no experimental basis for analyzing a planar array of horizontal cylinders such as used for solution storage. 


\section{Density-Analog ${ }^{113,117-118}$}

The initial density-analog approach was an attempt to apply to a cubic array a relation similar to that relating the critical mass and density of a single unit. For an isolated unit, the critical mass is proportional to the density to the $-2(1-\gamma)$ power where $\gamma$ is zero for an unreflected unit and 0.2 to 0.4 for full water reflection. Early crude subcritical measurements suggested that for arrays, $\gamma$ could be replaced by $f$, the "fraction critical" of an isolated unit as defined in the discussion of the surface-density model.

More refined measurements of arrays show that this model is much too conservative for arrays of significant size. As a result, Thomas ${ }^{114-115}$ has devised an improved density-analog model that is actually based more nearly on consideration of surface density than overall density. An expression from this version appears in Nuclear Safety Guide, Revision 2, but it is not pursued here because tabulations of data from experiments and Monte Carlo calculations are more reliable.

\section{Solid-Angle}

This method was developed ${ }^{112}$ as a quick, empirical means of evaluating interaction among small numbers of moderated fissile units. It is based on data from experiments with solutions. The technique has been extended in practice to arrays containing large numbers of units. Application of the method to units characterized by a fast neutron spectrum would result in nonconservative spacing if it were not for a required minimum spacing of $0.3 \mathrm{~m}$ between units. Thus, guidance for the storage of these units can best be obtained from American National Standard Guide for Nuclear Criticality Safety in the Storage of Fissile Materials, ANSI/ANS-8.7.119

Application of the solid-angle method may be convenient for special cases such as judging the safety of crowded equipment on a plant floor.

\section{Other Methods}

Models and methods shown to be consistent with requirements of Standard ANSI/ANS-8.7 may be used to establish nuclear criticality safety limits. It is emphasized that the concept of the method, its parameter dependence, and its area of applicability must be clearly understood. Appropriately, users should document, for themselves and for others, their ability to apply the method.

A method, well-described and extensively correlated with the results of critical experiments, is Clark's albedo method. ${ }^{120}$ Various tables and graphs of parameters have been published $^{121-122}$ which facilitate these hand calculations.

Another semi-empirical scheme for evaluating the interaction of fissile units, the interaction parameter method, is reported by Thomas and Scriven of the United Kingdom. ${ }^{123}$ 


\section{B. Storage of Metal and Compounds}

\section{Introduction}

In addressing the criticality safety of fissile material storage, consideration must be given to the purpose of the storage area. It may be a staging area providing temporary storage for materials in process, it may be an area for transient materials in transport, or it may be an area for long-term storage. Each use presents different problems. The number of units, their mass, surroundings, the necessary accessibility, and the desired margin of subcriticality determine the spacing between units.

Storage specifications of this section are based on descriptions of critical uniform nearcubic arrays that became available after the approximate methods of Section $\mathrm{A}$ of this chapter were developed. These descriptions are either experimental, ${ }^{69,124-125}$ from $\mathrm{NB}_{n}^{2}$ extrapolations of experimental data, or from validated Monte Carlo calculations. ${ }^{126-127}$

American National Standard Guide for Nuclear Criticality Safety in the Storage of Fissile Materials, ANSI/ANS-8.7, presents subcritical mass limits for spherical units of fissile material assembled in uniform cubic arrays reflected by thick water or its equivalent. The tabulated arrays have a neutron multiplication factor not exceeding 0.95. Although it does not answer all questions, this Standard is directly applicable to many storage problems.

The materials to which the Standard is directly applicable are ${ }^{233} \mathrm{U}$, uranium containing $30 \mathrm{wt} \%{ }^{235} \mathrm{U}$ or more, and plutonium as metals and as dry and wet oxides. The water content of the oxides varies between about 1.4 and $40 \mathrm{wt} \%$ (e.g., $0.4 \leq \mathrm{H} / \mathrm{U}$ or $\mathrm{H} / \mathrm{Pu} \leq 20$ ). For each species of fissile material, allowable masses of units are tabulated for cubic arrays of four to ten units on an edge and a range of cubic cell sizes. The limits are also conservatively applicable to units not spherical in shape and to arrays that are not cubic. It should be clear that cubic arrays for which data are tabulated in the Standard and the arrays in this section do not represent most practical storage arrangements because of need for access to interior units.

The Standard does not provide for the introduction of hydrogenous material into the space between units. If such moderation is present, the effect must be evaluated by a validated computational technique. The effect on array reactivity due to the introduction of water, as for example from fire protection systems, is strongly dependent on the form of the fissile material, and on the mass and spacing of the units. There is, however, an adequate margin in the limits to accommodate incidental moderation such as would result from enclosing the units in plastic bags that introduce no more than $10 \mathrm{~g}$ of polyethylene per kilogram of fissile material. As Reference 128 shows, there is extreme sensitivity to hydrogenous moderation between units, which becomes even greater if the density of units is decreased. Because this effect can easily override the margin $\Delta \mathrm{k}_{\text {eff }}=0.05$, interstitial moderation would become an important contingency. 
Guidance for increasing the subcritical margin of an array of Standard $A N S I / A N S-8.7$ beyond the existing $\Delta \mathrm{k}_{\text {eff }}=0.05$ may be obtained from Figure 3 of Reference 127 . This figure gives values of $k_{\text {eff }}$ for an extensive range of subcritical reflected cubic arrays of spherical units. All data in the range of $k_{\text {eff }}$ above about 0.75 satisfy the relation $\mathrm{k}_{\text {eff }}=\mathrm{r} / \mathrm{r}_{c}$, where $r$ is the radius of a unit in the subcritical array and $r_{c}$ is the radius that would make the array critical. As an example, a change of $\Delta \mathrm{k}_{\text {eff }}=0.1$ below $\mathrm{k}_{\text {eff }}=0.95$ corresponds to a decrease of $r / r_{c}$ from 0.95 to 0.85 . This change in radius is equivalent to a $28 \%$ decrease in mass.

The Standard provides factors for reducing the mass limits for arrays closely reflected by concrete. The limits are reduced to $75 \%$ of their tabulated values if the concrete thickness is between 5 and 8 inches and to $60 \%$ for greater thicknesses. Criteria are presented for pairs of arrays in concrete enclosures. (Slight neutron coupling of arrays separated by 50 -cm-thick concrete has been observed experimentally. ${ }^{129}$ Each unit of an array must remain subcritical if immersed in water. The possibility of double batching of the units in a storage cell should be considered when establishing safety limits and operating procedures. Administrative controls, appropriately-sized containers, and storage cell design may be useful for the prevention of double batching.

Consideration should be given to other normal and credible abnormal storage conditions that may affect the margin by which the array is subcritical. Typical examples ${ }^{4,23}$ of changes in operating conditions that should be considered are

- flooding, spraying, or the presence of water, oil, snow (i.e., low-density water), cardboard, wood, or other moderating materials;

- the introduction of additional units or reflectors;

- improper placement of units;

- loss of moderator and neutron absorber between units;

- collapse of a framework used to space units;

- a change in the density of fissile material during storage;

- the substitution of units containing more fissile material than permitted in operations as a result of operational error or improper labeling.

The Standard associates each unit with a cubic (or near-cubic) cell, but does not specify the means of establishing the cell. Although the cell can be visualized as an imaginary cuboidal volume, in practice it needs to be defined by hardware. For example, cells may be subdivisions of sturdy shelving, be maintained by compartments, or be defined by appropriately sized containers. Alternatively, the cell may be determined by a "birdcage" consisting, typically, of a container centered in a cell-size framework constructed of tubing or angle iron. Although the birdcage may be an open structure, it must be capable of 
assuring separation of the containers. Birdcages may be on shelving or simply distributed or stacked on a floor. An alternative to shelving, suitable for long-term storage, may be an array of tubes extending through a concrete matrix as reported from the Y-12 Plant. ${ }^{130}$ As a technical practice, the Standard states "Storage of fissile materials shall be such as to obviate concern with accidental nuclear criticality in event of fire, flood, earthquake or other natural calamities."

\section{Commingling of Dissimilar Units}

The Standard allows for commingling of dissimilar units in an array under the following conditions. If cell size is maintained by a container or birdcage about each unit, a criticality indicator CI may be assigned to each container or birdcage with its unit such that $\mathrm{CI}=100 / \mathrm{N}$, where $\mathrm{N}$ is the number of cells in an appropriate allowable array. ${ }^{131}$ Then, dissimilar units in containers may be commingled, provided the summation of CIs of all cells within the resultant array does not exceed 100 .

\section{Alternative Representation of Storage Arrays}

Figures 19 through 23 are graphic representations of selected tables in Standard ANSI/ANS8.7 for enriched uranium and plutonium. Graphs for ${ }^{233} \mathrm{U}$ are not included because of the generally small available quantity of this material. These figures simplify the interpolation of allowable numbers of units to non-cubic three-dimensional arrays and to cell sizes other than those tabulated.

It is considered more useful to give minimum cell dimensions in inches instead of millimeters. Further, equivalent cell volumes in US gallons are indicated in Figure 24. These include capacities of steel drums that may be used as containers of units. Often such drums are outer containers of units packaged for transportation. The graphs facilitate establishing values of $\mathrm{CI}$ for units in drums.

It must be emphasized that the conditions which pertain to Standard $A N S I / A N S-8.7$ apply to Figures 19 to 23. Specifically, the arrays are reflected, and no significant amount of interstitial moderating material is present. 
Figure 19

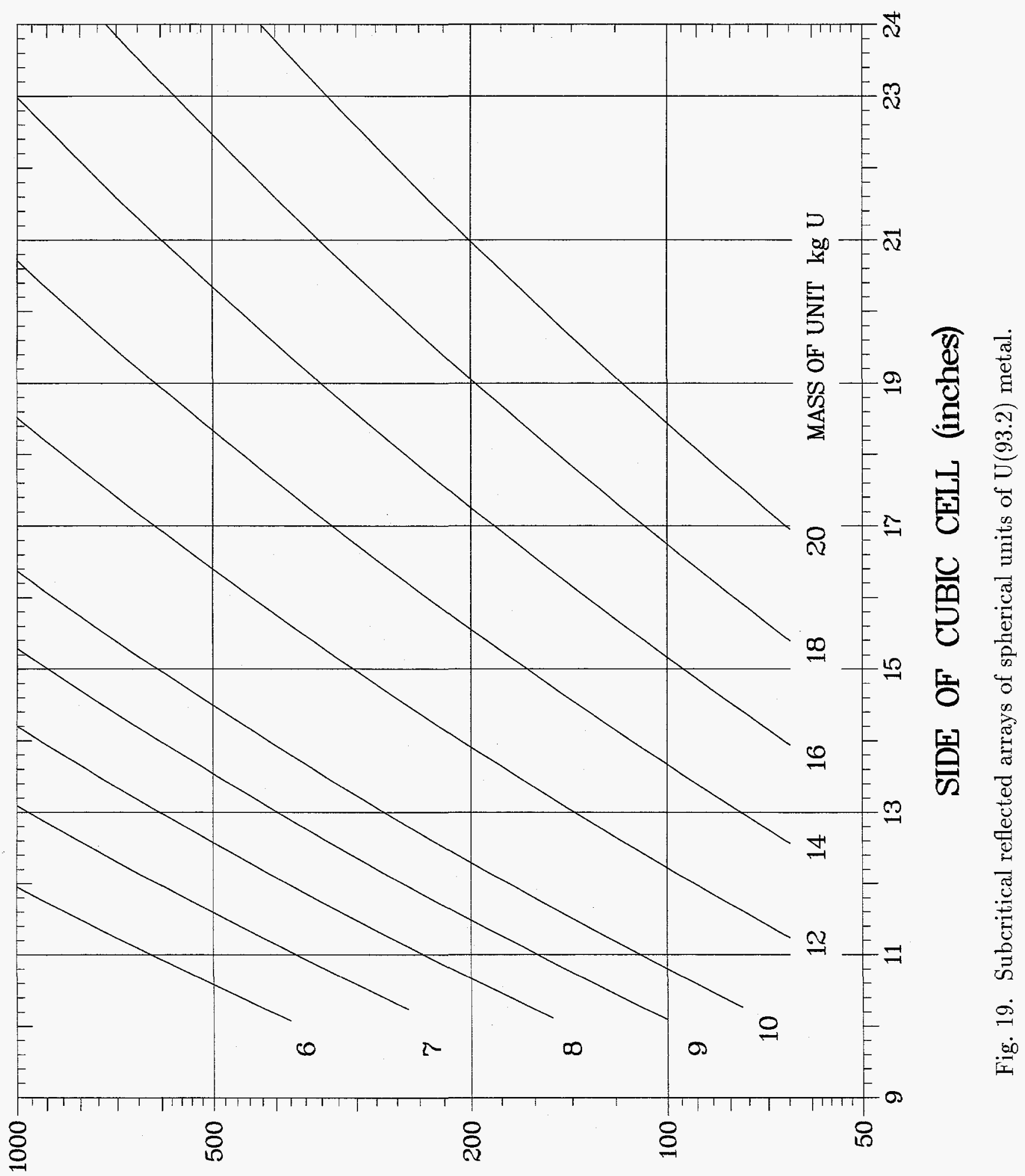

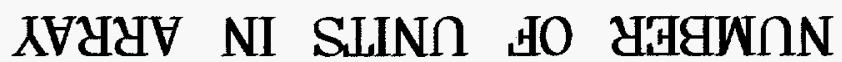




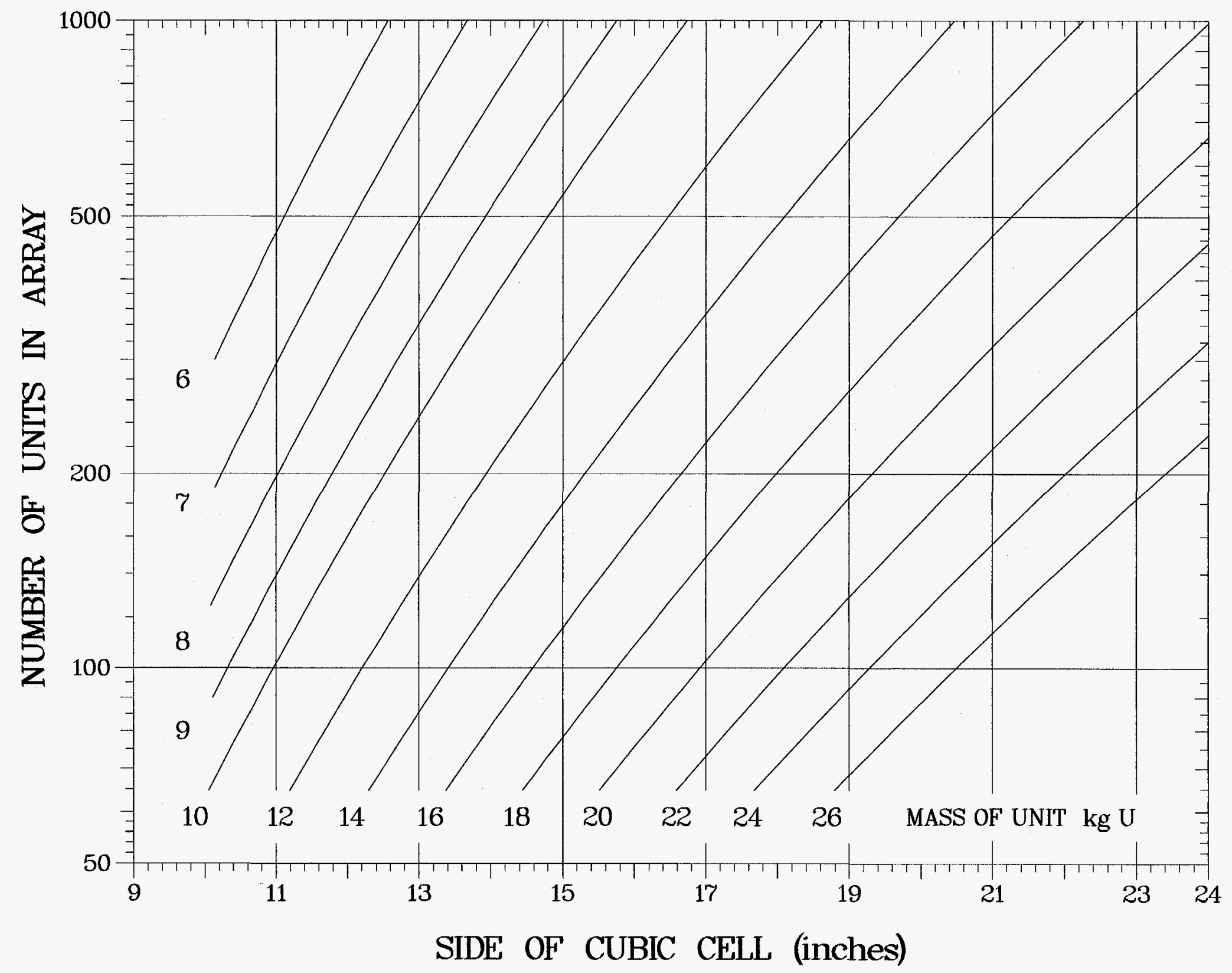

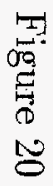

Fig. 20. Subcritical reflected arrays of spherical units of $U(93.2)$ oxide at $H / U \leq 0.40$. 
Figure 21

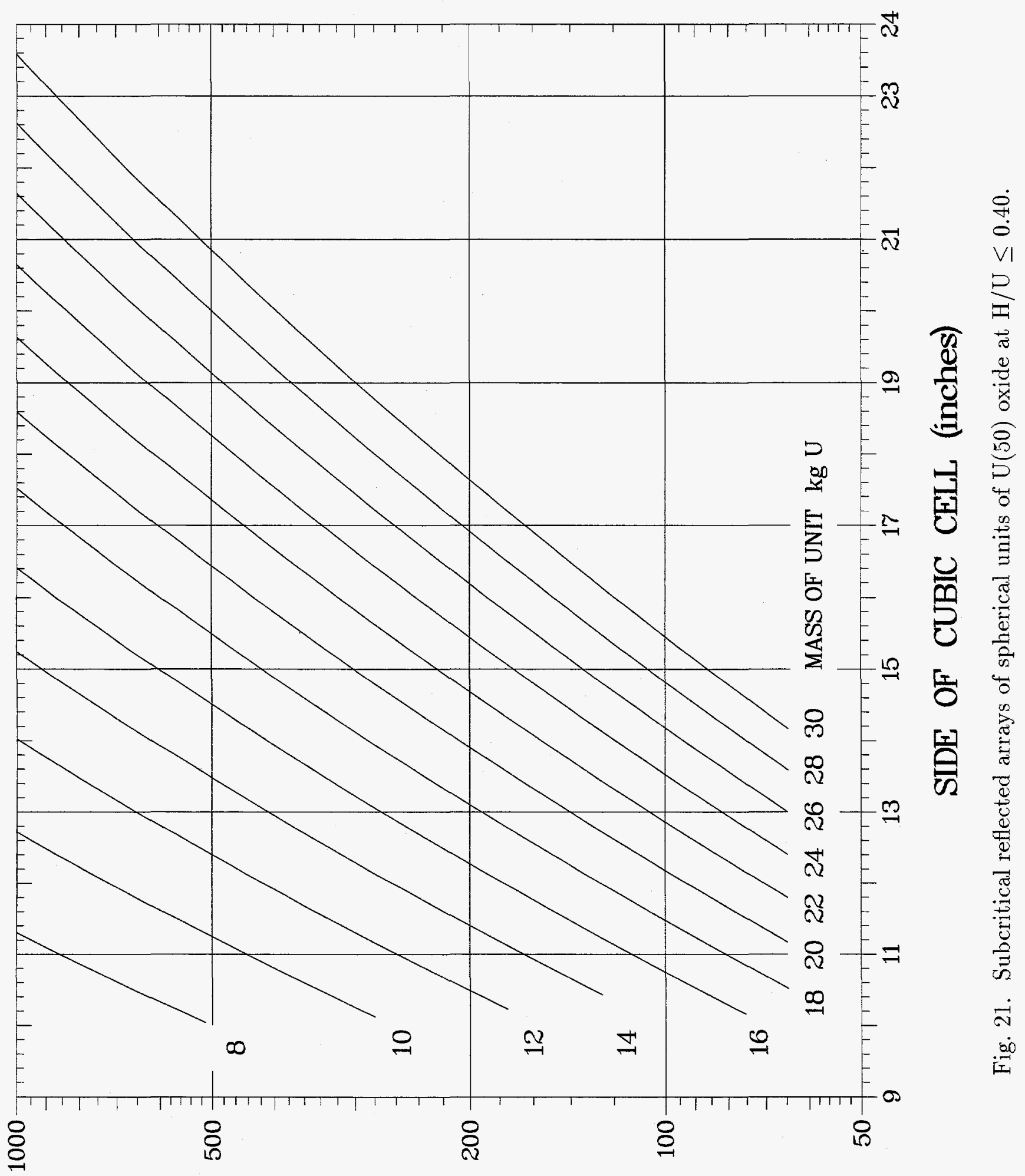

XVY4V NI SLIN 
Figure 22

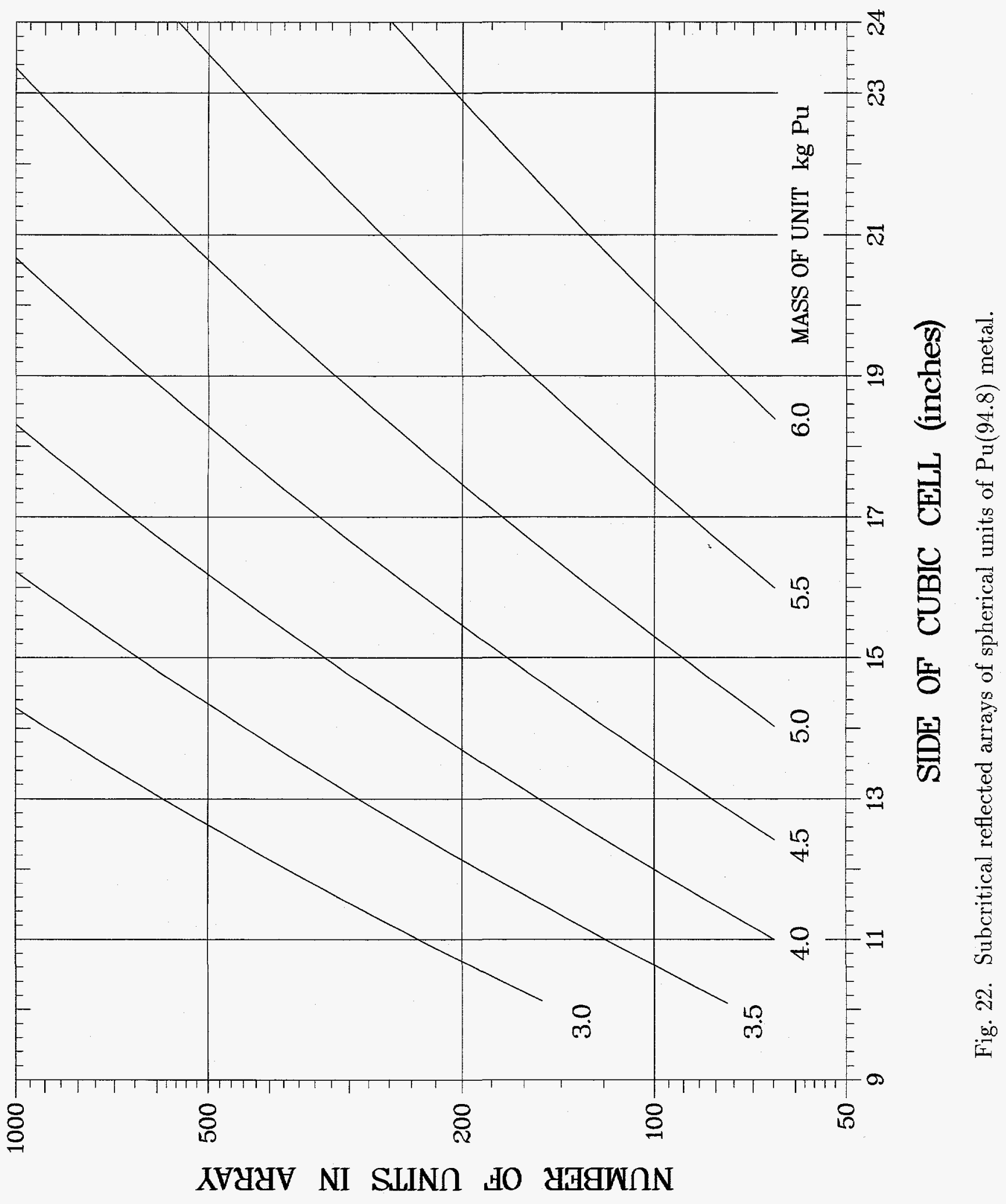




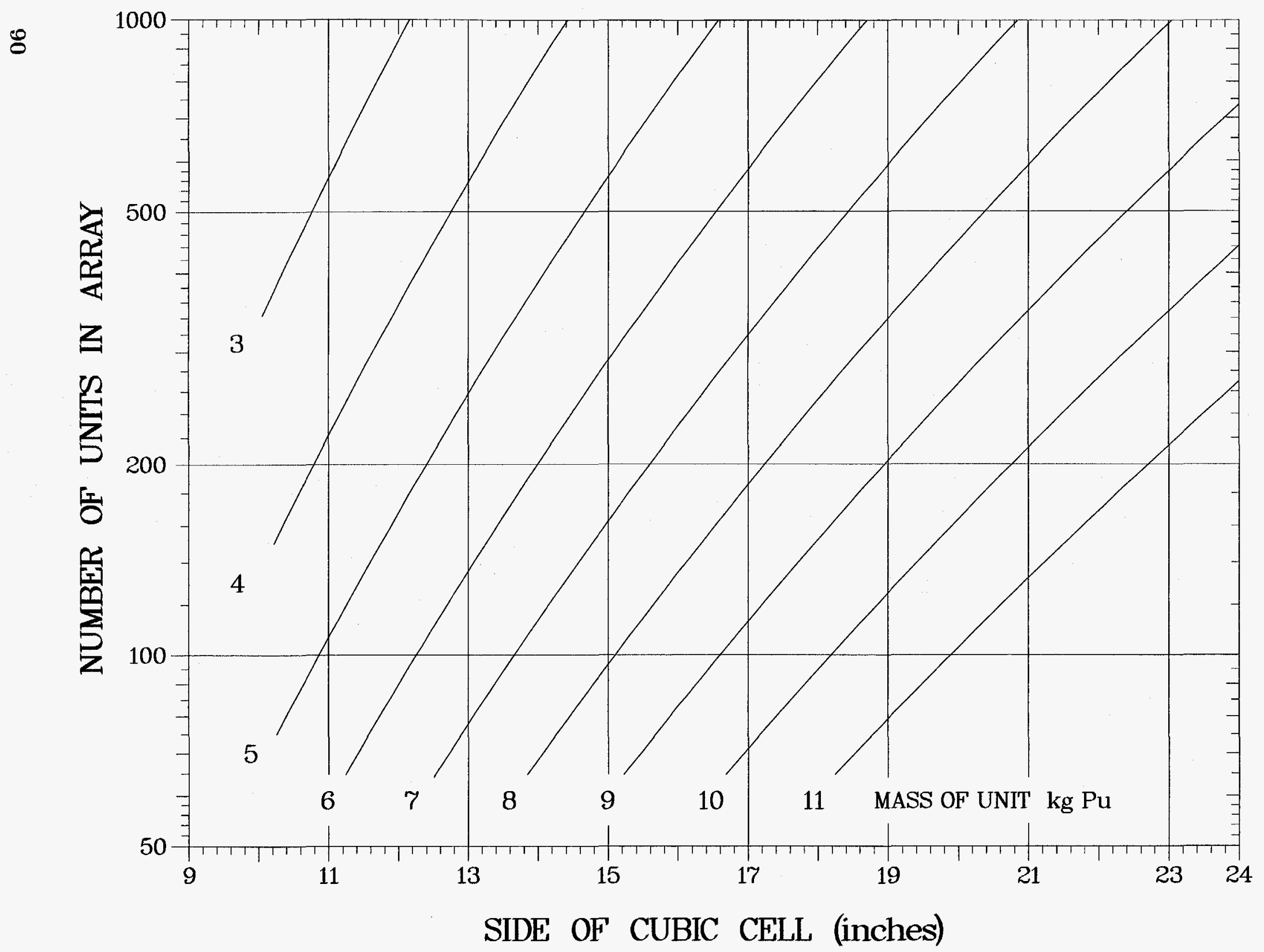

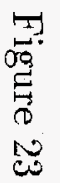

Fig. 23. Subcritical reflected arrays of spherical units of $\mathrm{Pu}(94.8)$ oxide at $\mathrm{H} / \mathrm{Pu} \leq 0.40$. 
Figure 24

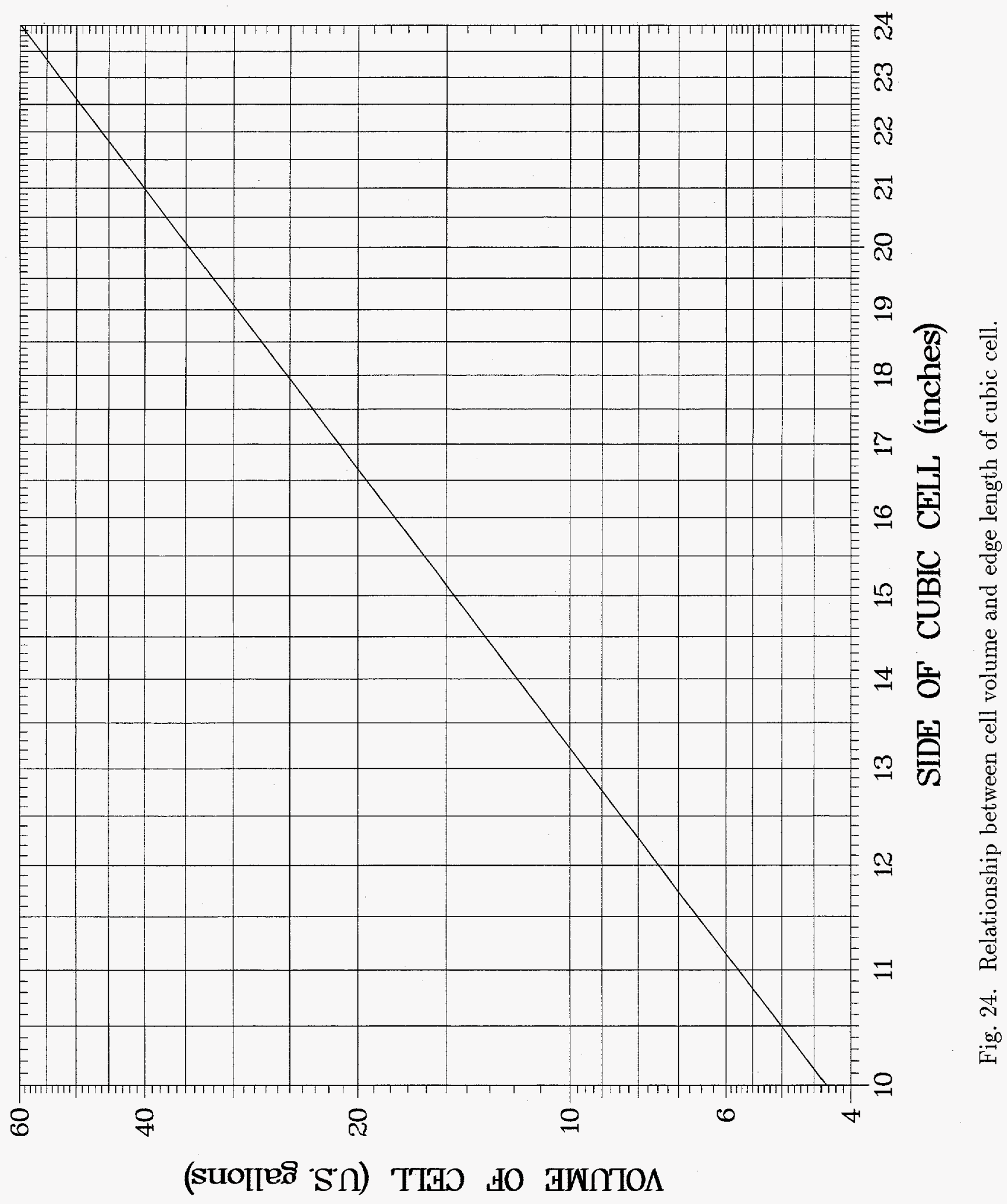




\section{Storage of Solutions}

\section{Tanks and Bottles}

Experimental data on critical near-cubic arrays of five-liter ${ }^{235} \mathrm{U}$ solution units ${ }^{126}$ suggest that it might be possible to include storage arrays of those units in the format of Standard $A N S I / A N S$-8.7. Such an approach would not be of much value, however, because there are more practical ways to store appreciable volumes of solution than in small containers. ${ }^{*}$ The absence of a general standard on solution storage may be, in part, because the choice among tanks with Raschig rings, banks of pipe or tubing, annular tanks, slab tanks, or even elongated polyethylene bottles depends on which fits best into the operational and physical features of each plant. Regardless, general solution-storage criteria are not available. Each of the available options will be considered, with the background experimental information, and something about adaptation to plant conditions. There is no study that uses a consistent set of criteria to evaluate the relative costs of these types of storage. Cost of solution storage can be quite high.

\section{Tanks with Raschig Rings ${ }^{31}$}

Storage of solutions in large tanks containing Raschig rings has the attractive feature of minimizing floor area. Offsetting this, however, are time-consuming and expensive inspections and tests called for in the Standard $A N S I / A N S-8.5$ as a result of the large surface area in contact with solution, which invites deposits, and the possibility of damage to the rings. ${ }^{134}$ Consequently tanks packed with Raschig rings are now used more commonly in auxiliary vessels where solution can be introduced only by accident than for actual storage.

The Raschig ring Standard ${ }^{31}$ is supported by critical experiments at Oak Ridge with $\mathrm{U}(93) \mathrm{O}_{2}\left(\mathrm{NO}_{3}\right)_{2}$ solution ${ }^{135}$ and ${ }^{233} \mathrm{UO}_{2}\left(\mathrm{NO}_{3}\right)_{2}$ solution. ${ }^{136}$ Experiments at Hanford included solutions of plutonium nitrate ${ }^{137}$ and mixtures of plutonium and uranium nitrate. ${ }^{138} \mathrm{~A}$ problem with computation is the difficulty of realistically modeling the random array of Raschig rings with Monte Carlo techniques. The possible use of vessels packed with Raschig rings for storing solutions is discussed further in Chapter V.

\footnotetext{
${ }^{*} \overline{\text { Because of the limited availability of }{ }^{233} \mathrm{U}}$ solution, storage in small containers may be practical. Guiding experimental data are available for critical arrays of 4.3 -liter ${ }^{132}$ and 3.0 -liter units of ${ }^{233} \mathrm{U}$ solution. ${ }^{133}$
} 


\section{Elongated Polyethylene Bottles}

The largest critical array of uranyl nitrate solution units, reported from Oak Ridge, ${ }^{139}$ is so impressive that its photograph has appeared widely, for example on p. 137 of Reference 11 and p. 607 of Reference 140. The solution is contained in 98 polyethylene bottles, each 13.7-cm-o.d. and of about 13-liter capacity. The wall thickness varies from $0.51 \mathrm{~cm}$ at the top to $1.14 \mathrm{~cm}$ near the base and the inside height is about $122 \mathrm{~cm}$.

These containers, designated "Type A" in the Oak Ridge report, have been used in several plants for transferring solution from one location to another and for at least temporary storage. A cart for transfer holds the container upright and spaces it from other objects. A fixture secures the container at an appropriate storage location, properly separated from other objects. This arrangement may be useful for regular uranium solution storage if the total inventory does not exceed $100 \mathrm{~L}$ or so.

Some type A containers have embrittled after a couple years of service and in one instance are being replaced by smaller cylinders with a more resistant polyethylene composition.

\section{Slab Tanks}

Thin slab tanks have been used to store solutions of both plutonium and enriched uranium. They have been used for both plutonium and enriched uranium solutions. Welded spacers prevent thickness increase as a result of hydrostatic pressure or relaxation of walls. Slab tanks have not been used in plants for large-scale storage partially because of the moderator-absorber between parallel tanks that would be required to reduce interaction in an array.

\section{Annular Cylinders}

Although experiments with cylindrical annuli ${ }^{92-93,96}$ were conceived as contributing to solution storage, this type of container has not been used for large-volume storage. At the Valduc facility in France, solution for CRAC experiments was stored in annular containers. ${ }^{94}$ 


\section{Solution Storage using Pipe or Tubing}

Parallel lengths of 6-inch pipe or tubing are used for storing very large volumes of fissile solutions at the Oak Ridge Y-12 Plant and at Los Alamos. Principally because of sensitivity to surroundings, generally applicable criteria for such storage do not exist. Therefore, each new application should be examined in detail by a validated method.

Apart from solution properties, significant considerations include spacing of units, distance from concrete walls and other massive or fissionable objects, provisions for handling solution leakage, and the possibility of water flooding. It should be noted that effects of even small depths of water can be significant. At neither Y-12 nor Los Alamos is flooding a contingency, although the influence of low-density water from fire-protection sprinklers is considered.

With solutions, control of fissile-material density and stability are important. The possibility and consequences of precipitation and settling must be considered.

Effective procedures for transfer of solution to and from storage arrays must be established.

\section{Y-12 Practice}

At the Y-12 Plant, solution volumes are thousands of liters even though practice is to concentrate dilute solutions. The practical upper limit of uranium density is $450 \mathrm{~g} /$ liter, and solutes are uranyl nitrate. Containers are lengths (up to 40 feet) of 6 -inch stainless-steel pipe, generally Schedule-40 or greater to allow for corrosion. 6-inch stainless-steel tubing, presently with one-quarter inch wall, is substituted in some cases. Pipes of smaller standard size are ruled out because of the large numbers that would be required.

In storage arrays, the minimum axial spacing of containers is 24 inches, and separation of axes from wall or floor is at least one-half of this. Each array consists of containers in a single planar configuration. Most arrays have horizontal containers, which are awkward to clean thoroughly. To simplify sparging, plans call for replacing all horizontal containers with vertical containers. There is allowance for the effect of sprinkler water having a density of $0.015 \mathrm{~g} / \mathrm{cm}^{3}$ between units, which is three times the expected value.

The floor of each storage room is lined with a stainless steel pan to accommodate solution in a subcritical slab in the event of severe leakage.

These conditions prove to be conservative throughout the Y-12 Plant, which might not be the case for an array consisting of more than one plane of containers, if water-flooding were a contingency, or if extremely concentrated solutions or mixtures were permitted. 


\section{Los Alamos Practice}

Los Alamos has been required to accommodate hundreds of liters of plutonium solution in a facility designed originally for research in which solution storage was expected to be minimal. As at Y-12, 6-inch pipe is the practical size for storage containers, but space limitations call for 10-foot lengths in more compact arrays than those at Y-12. This compact configuration is made possible by a stringent limitation on plutonium density.

Supported by Monte Carlo calculations, ${ }^{141}$ solutions with plutonium density not to exceed $20 \mathrm{~g} /$ liter are stored in 6 -inch Schedule-10 pipes with minimal axial spacings of 18 inches. Smaller spacings with intervening fixed neutron absorbers are used for dilute waste solutions held to determine whether further plutonium recovery is required.

As planned at Y-12, horizontal tanks are being replaced by vertical tanks for ease of cleaning. Deposits as a result of precipitation are more often encountered with plutonium solutions than with uranium.

Plutonium contamination is controlled by plastic wrappings of potential leakage points. This approach eliminates the need for the floor catch pans such as those in use at Y-12.

\section{Comments}

These examples show what can be done for large-volume solution storage when validated Monte Carlo calculations are available for guidance and confirmation. With smaller volumes, for which containers of diameter no greater than 5 inches are practical, generous spacing of vessels, or a readily observed limit on density of fissile material, may reduce or eliminate the need for Monte Carlo confirmation of safe conditions. Administrative controls on solution transfer, handling of leakage or spillage, and material accountability should contribute reassuringly to criticality safety. The possibility of precipitation and settling or deposit on surfaces would still be a consideration. 


\section{Transportation}

Transport of fissile material is addressed by regulations of the International Atomic Energy Agency (IAEA) ${ }^{142-143}$ the US Department of Transportation, ${ }^{144}$ the Nuclear Regulatory Commission (NRC) ${ }^{145}$ and the Department of Energy (DOE).${ }^{146}$

Requirements of transport regulation for criticality safety necessarily go beyond experimental data and computational results. Some requirements result from consensus among national and international authorities on judgmental matters. These matters include interaction of shipments, effects of accidents on packages, and design of specification containers. Approved US practice, also a matter of judgment, is even more limited than allowed by regulation, e.g., the general avoidance of shipment by common carrier. Since the requirements for transport of fissile material are more legalistic than technical, discussion of these requirements is beyond the scope of this document. 


\section{Chapter V}

\section{CRITICALITY SAFETY IN PROCESSING PLANTS}

\section{A. Plant Features with Criticality Potential}

Processing plants contain a multiplicity of work stations, and areas for both long-term and short-term storage. Criticality safety considerations go beyond the analysis of each of these in terms of subcritical individual units or storage arrays. The progression of fissile material through a plant involves transfers and special handling during which unusual conditions may be encountered. It is important that these operations be governed by procedures and be carried out by well-trained personnel.

Consider a plant for processing highly enriched uranium as solids, such as fabrication of weapon components or fuel elements for reactors. It is essential to avoid the effect of massive fissile units falling together or encountering other units as the result of an accident with transfer equipment. Minimum spacing between units can be maintained by the use of birdcages, provided there are appropriate procedures for loading and unloading them.

In a plant for scrap recovery or processing irradiated fuel, the operations involving fissile solutions must be carefully planned. It is noteworthy that all criticality accidents that have occurred in processing plants have involved solutions. Mishaps that have led to these accidents include solution leakage, precipitation, dissolution of solids, instrument failure, and transfer among vessels. Avoidance of these mishaps calls for continued cooperation of criticality safety and operating personnel.

In general, both physical and administrative criticality safety practices must be tailored to specific plant conditions. This requirement inevitably will require judgment. Special evaluation also may be required because there is no "standard" plant for which universal criticality safety recipes can be defined. 


\section{B. Administration}

Provisions of Standard ANSI/ANS-8.19, Administrative Practices for Nuclear Criticality Safety, are of major significance in processing plants. This Standard recognizes that criticality safety requirements must contribute to the physical and economic functions of a plant in a balanced manner. Accordingly, it places no requirement on the form of plant organization. Instead, requirements of the Standard are expressed in terms of management, operational supervisors, and a criticality safety staff provided by management.

The Standard emphasizes that effective criticality control, like other branches of safety, requires the positive support of management and implementation by supervisors with assistance of the criticality safety staff. It identifies associated responsibilities, calls for effective training of personnel and concise operating procedures, and has sections on process evaluation, material control, and planned response to criticality accidents.

\section{Training}

The training program for persons involved in operations with fissile material should make safety considerations, including criticality safety, an integral part of a program that provides necessary job skills. Standard ANSI/ANS-8.20, Nuclear Criticality Safety Training, applies to personnel associated with operations where there is the potential for a criticality accident. Provisions of the Standard are consistent with the precept that safety education will be most meaningful and readily assimilated if it is clearly relevant to operations. It follows that local supervision should participate in criticality safety training, or conduct it with the support of criticality safety specialists. Appropriate training of supervisory personnel is implied.

The Standard calls for training in the recognition of criticality alarms and the proper response to them. Training should be supported by discussion of selected criticality accidents. Stratton's history of nuclear accidents ${ }^{30}$ describes each in sufficient detail to be helpful for this purpose. Accounts of real accident experience in training talks can help keep the audience awake.

\section{Criticality Alarms and Response}

Criticality alarms have twice initiated lifesaving evacuation of areas in which accidents occurred. $^{30}$ The value of such systems is therefore clear in areas for processing significant amounts of fissile material. Guidance for the design, installation, and maintenance of such systems may be obtained from Standard ANSI/ANS-8.3, Criticality Accident Alarm System. This document directs that an accident alarm system must be considered for any 
area containing more than a threshold quantity of fissile material. The Standard calls for an easily recognized signal for immediate evacuation in case of an alarm. It recommends that the response of the alarm system to radiation be tested at least monthly, each signal generator be tested at least once every three months, and an evacuation drill be performed at least annually.

The existence of an alarm system carries with it certain responsibilities. The system must be maintained to provide confidence that it will function if needed, and to minimize the frequency of false alarms. False alarms can have a negative impact on safety by creating a potential for injury as a result of precipitous response. False alarms also tend to destroy confidence in the system. Unannounced drills are not endorsed.

The response to an alarm is to be governed by an emergency plan with elements given in the administrative Standard ANSI/ANS-8.19. Further features of an emergency plan are being considered.

Elements of the emergency plan include procedures for evacuation to specified assembly stations, actions after assembly, and treatment of injured and exposed persons in accordance with advance arrangements.

Personnel must be trained in their proper response to the alarm including the use of evacuation routes and designated assembly points. Emergency plans must be kept current; evolution of a plant can influence the procedures to be followed in the event of an alarm.

\section{E. Material Control}

One criticality accident occurred because a concentrated fissile solution in a polyethylene cylinder was mistaken for a dilute solution. ${ }^{30}$ This occurrence emphasizes the value of labeling or other positive identification of fissile material in helping to avoid routing errors within a plant. Also of value are posted limits at work stations and storage areas. If observed, for example, in the transfer of material along a glove-box line, posted limits can prevent inadvertent overloading of a box.

Labeling and posted limits cannot take the place of up-to-date procedures used by welltrained personnel, but should make errors less likely. Computerized accounting procedures, such as proposed for safeguards, should contribute further to the reduction of transfer errors.

Provisions for handling fissile material during inventories must be as carefully planned as for regular plant operation. This need is emphasized by the three criticality accidents that resulted from misdirection of solutions during inventory. ${ }^{30}$ 
An occasional requirement that should be anticipated is the emergency storage of fissile material that can accumulate as the result of interruptions of normal operations. Mishaps such as faulty processing or equipment failure may interrupt the flow of solutions, and accidents or other disruptions may prevent material from leaving the plant.

In a plant layout, the convenience of proper operations should be considered. To be avoided, for example, is transfer of material through a working area when another convenient route is available, and unnecessary processing of different fissionable materials in the same area. To illustrate, use of the same furnace for casting enriched and natural uranium, except during independent campaigns, could contribute to the confusion of feed items. An example of making mishaps inconvenient is to transfer fissile material on a single plane, as with special carts. Transfer by crane over other fissile material would be objectionable.

\section{F. Process Startup}

Before initial operation of a plant, or of a module that is new or revised, confirmation of the proper condition of its components is mandatory. Confirmation includes testing of instrumentation, valves, seals, transfer devices, and ventilation and fire-protection equipment. At this point, adequacy of training should be established. ${ }^{26}$

It is also important to reassess criticality safety before startup. The initial assessment can be influenced by evolutionary changes during construction. Even though the effect of each change has been considered, the as-constructed configuration should be examined.

At this stage, it is appropriate to reconsider matters of judgment about the adequacy of the experimental basis for evaluating the criticality safety of operation. Judgment is involved in decisions concerning the appropriateness of directly applicable experiments, of experiments used for validating calculations, or of additional safety margins applied when validation is questionable. Any doubt usually can be resolved by means of neutronmultiplication measurements as outlined in Standard ANSI/ANS-8.6, Safety in Conducting Subcritical Neutron-Multiplication Measurements in Situ. These measurements, conducted during stepwise introduction of fissile material, would identify safely subcritical conditions. In general, they would simply provide reassurance that normal operation is acceptable. They must not cause personnel to relax concerning accident potential. 


\section{G. Maintaining Safety Provisions}

During plant operation, continuous observation and periodic surveys are means of guarding against adverse effects of evolutionary change in conditions or practices. Has a vessel that could contain more than a critical volume been brought into a process area? Has equipment for fissile material been used for other material?. Should features of fire protection be reviewed because of changed plant content? Have precautions against the consequences of natural disasters such as earthquake, flood, or tornado been relaxed over time? The list of questions does not stop here. In fact, it depends on detailed plant features, regulations, and the policy of plant management. Thus, the wish for a universal check list would be futile.

\section{H. Examples of Plant Application}

\section{Dissolver for Water-Reactor Fuel}

The safe geometry of a 100-liter dissolver for chopped $\mathrm{U}(3.2) \mathrm{O}_{2}$ fuel elements is to be explored. The shape of the dissolver should be simple and it is to be surrounded by a steam jacket. Full water reflection should be assumed to allow for water in the steam jacket and for incidental reflection.

Table 9 shows a limiting value of $26.4 \mathrm{~cm}$ for the subcritical diameter of a long cylinder of heterogeneous oxide. ${ }^{86}$ This value is essentially the inside diameter of 10 -inch Schedule-5S pipe. The diameter limit for solution is significantly greater. Because a cylinder of this diameter has a capacity of 55 liters per meter of length, the height of a 100-liter dissolver would be about $1.8 \mathrm{~m}$. A design study will show whether this height meets functional requirements.

Should this long, small diameter prove to be undesirable, an alternative would be an annular tank surrounding a neutron-absorbing material to reduce neutron exchange within the configuration. If the absorbing material is water and the inside diameter is at least $30 \mathrm{~cm}$, the annular thickness can be approximated by a reflected infinite slab specified in Table 9 to be $12.6-\mathrm{cm}$ thick. If additional conservatism is desired, a thickness of $10 \mathrm{~cm}$ and an inside diameter of $40 \mathrm{~cm}$ may be assumed for the design study, the capacity of which is about 157 liters per meter. Accordingly, a vessel of 100-liter capacity would have near-equilateral external dimensions. Before adoption, the acceptability of the final design should be confirmed either by a validated calculation or by in situ neutron-multiplication measurements. ${ }^{29}$

Of course, this dissolver encompasses more than the simple container. In the first place, to accommodate irradiated fuel, it must be one component of a shielded fuel-handling system. The container must be modified for introduction of the chopped fuel, draining solution, and withdrawal of residual solids. Sparging to facilitate uniform dissolution also may prove 
desirable. The ultimate criticality safety evaluation must take into account auxiliaries and interaction with other components.

Further, there may be special requirements for campaigning fuels from different sources, for instance, the fuel up to $4 \mathrm{wt} \%{ }^{235} \mathrm{U}$ in the following example of plant application. If the possibility of handling fuel at somewhat more than $3.2 \mathrm{wt} \%{ }^{235} \mathrm{U}$ can be foreseen, it should be more effective to plan for it at this stage than to adapt to it later. Actually, the "conservative" annular thickness of $10 \mathrm{~cm}$ may prove to be suitable for fuel enrichments of nearly 5 wt\% ${ }^{235} \mathrm{U}$.

\section{Storage of Low-Enriched Uranium Solution}

Consider vessels for storing a variety of uranium solutions in which the ${ }^{235} \mathrm{U}$ enrichment will not exceed $4 \mathrm{wt} \%$ and the uranium density will remain below $750 \mathrm{~g} / \mathrm{L}$. A total capacity of 1890 liters ( $500 \mathrm{gal}$ ) is desired, and, because of the possibility of long-term storage and the difficulty of internal inspection, a single vessel packed with Raschig rings is not selected. The preferred arrangement is a planar bank of cylinders near a 12-m-long, 5-m-high concrete wall, with a narrow walkway between the cylinders and wall.

According to Table 8, the subcritical limit on cylinder diameter for U(4) solution is $30 \mathrm{~cm}$; the next smaller commercial pipe size is 10 -inch Schedule-5S (26.6-cm-i.d.). At a usable height of $4.6 \mathrm{~m}$, the capacity per cylinder is 250 liters and 8 cylinders would be required. Construction and operational convenience would be met by a one-meter center spacing of cylinders and would result in additional space at the ends of the bank of cylinders.

A walkway of $0.7 \mathrm{~m}$ separates the cylinders from the concrete wall and reduces the effect of the wall to that of incidental reflection on each vessel. Because the $30-\mathrm{cm}$ diameter limit is based on full water reflection, which is much more effective than incidental reflection, it is necessary to show that the effect of interaction among the cylinders is acceptable. According to validated KENO calculations, ${ }^{147} \mathrm{k}_{\mathrm{eff}}=0.725$ for a single cylinder having only $2.5-\mathrm{cm}$-thick water reflection, and $\mathrm{k}_{\text {eff }}=0.785$ for the linear array spaced from the concrete wall, showing that interaction is adequately small. Thus, it is appropriate to proceed with the design of this arrangement and with detailed exploration of contingencies.

The low values of $k_{\text {eff }}$ suggest the reasonableness of further investigation of a storage bank with significantly increased capacity. For example, a one-dimensional calculation of a 12 -inch Schedule-5S pipe $\left(31.5\right.$-cm-i.d.) instead of the $26.6-\mathrm{cm}$ pipe resulted in a $k_{\text {eff }}$ of 0.9 . The capacity of 8 cylinders at the $4.6 \mathrm{~m}$ height would be increased to 750 gallons. Of course, a careful computational study and analysis of contingencies would be required before adopting this approach. 


\section{Solution in Tanks Packed with Boron-Containing Raschig Rings}

In certain cases, as noted before, an alternative to geometrically subcritical tanks for solution storage is the use of large capacity tanks packed with borosilicate-glass Raschig rings. Typically, although one-quarter to one-third of the tank volume is sacrificed to the glass absorber, the tank may still accommodate large volumes of solution more efficiently than long, limited-diameter cylinders or thin slab-like containers. Other than for primary criticality control, Raschig rings in auxiliary tanks may protect against accidental criticality resulting from inadvertent diversion of fissile solution to those tanks.

American National Standard Use of Borosilicate-Glass Raschig Rings as a Neutron Absorber in Solutions of Fissile Material, ANSI/ANS-8.5, defines appropriate conditions for criticality control. Restrictions exclude the use of alkaline solutions, HF, and hot, concentrated $\mathrm{H}_{3} \mathrm{PO}_{4}$. Temperature and radiation fields also are limited. The Standard defines chemical and physical properties that are typified by Pyrex type 7740 and Kimbal type KG-33 and limits the ring size to $3.81-\mathrm{cm}-$ o.d. It specifies packing conditions and gives requirements for inspection and maintenance. Finally, maximum densities of fissile material in vessels of unlimited size are specified for three different volume percentages of glass. Typically, as the glass volume fraction ranges from 0.24 to 0.32 , density limits range from 150 to $200 \mathrm{~g} / \mathrm{L}$ for ${ }^{233} \mathrm{U}$, from 270 to $400 \mathrm{~g} / \mathrm{L}$ for ${ }^{235} \mathrm{U}$-enriched uranium, from 115 to $180 \mathrm{~g} \mathrm{Pu} / \mathrm{L}$ for ${ }^{239} \mathrm{Pu}$, and from 140 to $220 \mathrm{~g} \mathrm{Pu} / \mathrm{L}$ for plutonium containing more than $5 \mathrm{wt} \%{ }^{240} \mathrm{Pu}$.

Although it is unlikely that these reasonably generous limits would restrict a practical process, there could be unusual circumstances that would require greater glass fractions. Because computational models cannot closely approximate randomly packed Raschig rings, ${ }^{148}$ the preferred guidance for increased limits would be experimental data near the desired conditions or computational results verified by in situ neutron multiplication measurements. ${ }^{29}$ An example of an experimental system that is subcritical at a plutonium density greater than that permitted by the Standard is reported by Lloyd, Bierman, and Clayton. ${ }^{137}$ The subcritical density of plutonium $\left(8.3 \mathrm{wt} \%{ }^{240} \mathrm{Pu}\right)$ in nitrate solution was $391 \mathrm{~g} / \mathrm{L}$ when a $61-\mathrm{cm}$-diameter tank was filled to a depth of $99.1 \mathrm{~cm}$. Raschig rings containing $4.0 \mathrm{wt} \%$ boron occupied $18.8 \%$ of the volume, and there was an effectively infinite water reflector on the tank walls and base.

Nurmi ${ }^{149}$ reports the use of borosilicate-glass rings with enriched uranium solutions that have free fluoride-ion contents greatly exceeding the limit specified in the Standard. Because of this deviation, there is daily visual inspection and semiannual emptying of tanks for detailed examination. This is a more stringent maintenance schedule than that required by the Standard.

Another approach to environments that are hostile to borosilicate glass is suggested by experiments at Battelle Pacific Northwest Laboratories ${ }^{137}$ with plutonium solutions in a tank packed with stainless steel Raschig rings containing $1.0 \mathrm{wt} \%$ boron. A 45.7cm-diameter tank, water reflected on sides and bottom, was packed with $1.27-\mathrm{cm}-\mathrm{o} . \mathrm{d}$., 
$1.27-\mathrm{cm}$-long steel rings occupying $27.0 \%$ of the volume. At a depth of $99.1 \mathrm{~cm}$, plutonium $\left(8.3 \mathrm{wt} \%{ }^{240} \mathrm{Pu}\right)$ solutions at densities of $275 \mathrm{~g} \mathrm{Pu} / \mathrm{L}$ with $480 \mathrm{~g} \mathrm{NO}_{3} / \mathrm{L}$ and of $412 \mathrm{~g} \mathrm{Pu} / \mathrm{L}$ with $602 \mathrm{~g} \mathrm{NO}_{3} / \mathrm{L}$ were subcritical.

A further example includes data on plutonium-uranium nitrate mixtures in a $61-\mathrm{cm}-$ diameter tank, water reflected on the sides and bottom and packed with glass Raschig rings containing 4 wt $\%$ boron. ${ }^{137-138}$ The rings, which were $3.81-\mathrm{cm}-$ o.d. and $4.32 \mathrm{~cm}$ in length, displaced $18.8 \%$ of the solution volume. At a depth of $90.4 \mathrm{~cm}$, solution at a density of $180 \mathrm{~g} \mathrm{U} / \mathrm{L}\left(0.66 \mathrm{wt} \%{ }^{235} \mathrm{U}\right.$ in $\left.\mathrm{U}\right)$ and $78.4 \mathrm{~g} \mathrm{Pu} / \mathrm{L}\left(5.7 \mathrm{wt} \%{ }^{240} \mathrm{Pu}\right.$ in $\left.\mathrm{Pu}\right)$ containing $377 \mathrm{~g}$ $\mathrm{NO}_{3} / \mathrm{L}$ was subcritical.

\section{Solution Holdup Design}

A cell in a $\mathrm{U}(93.2)$ reprocessing facility has a concrete floor area of $9 \mathrm{~m}^{2}$ and analyses have shown that the neutron interaction between the process vessels and between the vessels and the floor is negligible. The floor with sidewalls will serve as a catch basin for solutions that may leak from the vessels. An overflow line is to be installed in the floor, draining to a poisoned catch tank, thereby limiting the thickness of solution. The maximum expected ${ }^{235} \mathrm{U}$ density in $\mathrm{UO}_{2}\left(\mathrm{NO}_{3}\right)_{2}$ is $250 \mathrm{~g} / \mathrm{L}$. A permitted solution height over the floor is to be determined. The configuration of the solution is conservatively approximated by an effectively infinite uniform slab with a thick concrete reflector on one side and incidental reflection on the other side.

From Table 1, the specified subcritical thickness of an infinite slab of $\mathrm{UO}_{2}\left(\mathrm{NO}_{3}\right)_{2}$ reflected by 30 -cm-thick water is $4.9 \mathrm{~cm}$. A thick water reflector on both surfaces is expected to be more effective than concrete reflection on one and incidental reflection on the other. It follows that the specified height of the overflow pipe should not exceed $4.9 \mathrm{~cm}$. The chosen height should be measured from the lowest portion of the floor as established by an elevation survey. 


\section{APPENDIX}

This Appendix provides a description of the calculational study leading to the curves presented in Figures 2 through 13 of this document. The motivation for this study was to provide quantitative examples illustrating the relationship between system reactivity ( $k_{\text {eff }}$ ) and system geometry. Inferential in these curves are the partial derivatives of geometrical size $(x)$ versus $\mathrm{k}_{\mathrm{eff}}$. Figures from report $L A-10860-M S$, Critical Dimensions of Systems Containing ${ }^{235} \mathrm{U},{ }^{239} \mathrm{Pu}$, and ${ }^{233} \mathrm{U}$, 1986 Revision, were adapted to provide a basis for the illustration. This adaptation appears directly in Figures 2 through 13 . The adaptation brings forward results from LA-10860-MS for experimentally determined critical systems. These data provide a reference to interpret the curves. The three well-established fissile nuclides ${ }^{233} \mathrm{U},{ }^{235} \mathrm{U}$, and ${ }^{239} \mathrm{Pu}$ were selected for the construction of the examples. The ${ }^{235} \mathrm{U}$ was taken to be present as U(93.2). System compositions were taken to be metal-water mixtures and were selected to systematically span the entire range from limiting critical fissile density ( 7 to 13 grams per liter in water) to pure metal density (approximately 20 kilograms per liter). For these systems, the neutron spectrum varies systematically from a thermalized distribution for dilute fissile densities to a slightly softened fission spectrum for the pure metal systems. Three system geometries were selected to complete the set of examples: spherical, infinite circular cylinder, and infinite planar slab. In each case, the fissile-bearing region is surrounded by a tight-fitting pure water reflector of effectively infinite thickness. These are classic geometries which occur repeatedly in the literature of criticality safety. The first documented occurrence of these geometries and the associated characteristic curves, known to the editors, is found in the report CP-400, Chain Reaction of Pure Fissionable Materials in Solution. ${ }^{150}$

The metal-water systems used in the examples have no direct experimental analog. Uranium metal and plutonium metal are not, in a chemical sense, soluble in water. However, the metal-water mixtures are neutronically approached in an asymptotic sense for dilute fissile systems. In such systems the atomic ratio of the hydrogen to the fissile atomic species is very high (above 1000). In these systems, the other nuclear species needed for a chemical solution, such as nitrogen and fluorine, are also very dilute and have a minimum perturbing effect. Hence, these dilute systems approach the idealized metal-water mixture. Over the remaining range, however, the chemical constituents, such as nitrogen and fluorine, represent a serious perturbation from the idealized metal-water mixture. Hence, any comparison between calculational and experimental results requires a careful and accurate determination of the impact of the presence of these other nuclear species.

Caution should be exercised in the application of the curves presented in Figures 2 through 13. First, the reader should recognize that the curves represent calculational results. Second, the reader should note that these calculations do not conform to current validation and verification criteria. No attempt has been made to document $\mathbf{a}$ rigorous compliance with such criteria. That is, software and platform verification and the comparison of calculational results with experimental results have not been carried out as described in Chapter I, Section B-4 of this document, The Role of Calculational 
Validation. Instead, we comply with the traditional criteria for reporting scientific results by providing sufficient detail to allow for independent reproducibility and confirmation of results.

The value of $\mathrm{k}_{\text {eff }}$ was calculated for a specific nuclide type, density, and system dimension $(x)$. The dimension $x$ corresponds to a spherical diameter, an infinite cylinder diameter, or an infinite slab thickness. For each nuclide type, density, and system geometry, four to five values of $x$ were selected which resulted in calculated $\mathrm{k}_{\text {eff' }} \mathrm{s}$ in the range 0.5 to 1.2 . In addition the value of $\mathbf{k}_{\infty}$ for an infinite metal-water mixture was calculated. To determine the value of $x$ for a particular value of $\mathrm{k}_{\text {eff }}$, the appropriate set of calculational results were fitted to a continuous curve having the following algebraic form.

$$
k_{\mathrm{eff}}(x)=k_{\infty}\left(1-e^{-\alpha x}\right)^{\beta x^{\gamma}}
$$

In the above expression $\alpha, \beta$, and $\gamma$ are fitting parameters. This form provides a monotonically increasing $\mathrm{k}_{\text {eff }}$ versus $x$ which asymptotically approaches $\mathrm{k}_{\infty}$ for large $x$. The curves shown in Figures 2 through 13 were generated by fitting a spline through the calculated values of $x$ for each selected fissile density. The calculational results were produced using the MCNP Monte Carlo code (see Ref. 13). The cross-sections were based on ENDF/B-V cross-section evaluations provided by the XTM group at Los Alamos. Specifically, the MCNP nuclide identifiers (ZAIDs) shown in Table 16 were used.

Table 16

Nuclides, Cross-Section Evaluations, and Atomic Weights Used for Calculational Results

\begin{tabular}{||r|r|r||}
\hline \hline Nuclide & \multicolumn{1}{|c|}{ ZAID } & Atomic Weight \\
\hline${ }^{1} \mathrm{H}$ & $1001.50 \mathrm{c}$ & 1.00782475 \\
${ }^{16} \mathrm{O}$ & $8016.50 \mathrm{c}$ & 15.99491480 \\
${ }^{233} \mathrm{U}$ & $92233.50 \mathrm{c}$ & 233.03962900 \\
${ }^{235} \mathrm{U}$ & $92235.50 \mathrm{c}$ & 235.04392497 \\
${ }^{238} \mathrm{U}$ & $92238.50 \mathrm{c}$ & 238.05078549 \\
${ }^{239} \mathrm{Pu}$ & $94239.55 \mathrm{c}$ & 239.05215781 \\
\hline \multicolumn{2}{|c|}{ Avogadro's number } \\
(atoms/b-cm) & 0.602204345 \\
\hline
\end{tabular}


The lwtr.01t version of the $\mathrm{S}(\alpha, \beta)$ scattering model was used for the water in the metal-water mixture and for the water in the reflector.

Table 17 gives values of the mass densities assumed for water and for the metal state of each nuclide. Table 18 gives the number densities of hydrogen and oxygen used for the $15.2-\mathrm{cm}$ water reflector. Tables 19 through 21 give the number densities calculated for 22 selected fissile mass densities for the three fissile nuclides ${ }^{233} \mathrm{U},{ }^{235} \mathrm{U}$, and ${ }^{239} \mathrm{Pu}$. Finally, Tables 22 through 24 list the final calculated geometrical dimensions ( $x$ values) used to produce the curves shown in Figures 2 through 13.

Table 17

Mass Densities Assumed for

Water and Fissile Metal

\begin{tabular}{||l|c||}
\hline \hline Material & $\begin{array}{c}\text { Mass Density } \\
\left(\mathrm{g} / \mathrm{cm}^{3}\right)\end{array}$ \\
\hline Water & 0.997801 \\
${ }^{233} \mathrm{U}$ Metal & 18.05 \\
${ }^{235} \mathrm{U}$ Metal & \\
$\left(93.2\right.$ wt\% $\left.{ }^{235} \mathrm{U}\right)$ & 18.76 \\
${ }^{239} \mathrm{Pu}$ Metal & 19.74 \\
\hline
\end{tabular}

Table 18

Calculated Number Densities for the $15.2 \mathrm{~cm}$ Water Reflector

\begin{tabular}{|c|c||}
\hline \hline Nuclide & $\begin{array}{c}\text { Number Density } \\
\text { (atoms/b-cm) }\end{array}$ \\
\hline${ }^{1} \mathrm{H}$ & 0.066725294 \\
${ }^{16} \mathrm{O}$ & 0.033362647 \\
\hline
\end{tabular}


Table 19

Fissile Mass Densities and Calculated Number Densities for ${ }^{233} \mathrm{U}$ Metal-Water Mixtures

\begin{tabular}{||c|c|c|c||}
\hline \hline \multirow{2}{*}{$\begin{array}{c}{ }^{233} \mathrm{U} \\
\text { Mass } \\
\text { Density }\end{array}$} & \multicolumn{3}{|c|}{ Number Density (atoms/barn-cm) } \\
\cline { 2 - 4 }$(\mathrm{kg} / \mathrm{L})$ & ${ }^{233} \mathrm{U}$ & ${ }^{1} \mathrm{H}$ & $16 \mathrm{O}$ \\
\hline & & & \\
0.005 & .000012921 & .066706810 & .033353405 \\
0.006 & .000015505 & .066703114 & .033351557 \\
0.007 & .000018089 & .066699417 & .033349709 \\
0.008 & .000020673 & .066695720 & .033347860 \\
0.009 & .000023257 & .066692024 & .033346012 \\
0.010 & .000025841 & .066688327 & .033344163 \\
0.011 & .000028425 & .066684630 & .033342315 \\
0.012 & .000031010 & .066680934 & .033340467 \\
0.013 & .000033594 & .066677237 & .033338618 \\
0.014 & .000036178 & .066673540 & .033336770 \\
0.020 & .000051683 & .066651360 & .033325680 \\
0.030 & .000077524 & .066614393 & .033307197 \\
0.050 & .000129206 & .066540459 & .033270230 \\
0.100 & .000258413 & .066355625 & .033177812 \\
0.200 & .000516826 & .065985955 & .032992978 \\
0.500 & .001292064 & .064876948 & .032438474 \\
1.000 & .002584128 & .063028602 & .031514301 \\
2.000 & .005168257 & .059331909 & .029665955 \\
5.000 & .012920642 & .048241833 & .024120916 \\
10.000 & .025841285 & .029758372 & .014879186 \\
14.000 & .036177799 & .014971603 & .007485802 \\
18.050 & .046643517 & .000000004 & .000000002 \\
& & & \\
\hline & & & \\
\hline
\end{tabular}


Table 20

Fissile Mass Densities and Calculated Number

Densities for U(93.2) Metal-Water Mixtures

\begin{tabular}{|c|c|c|c|c|}
\hline \multirow{2}{*}{$\begin{array}{c}{ }^{235} \mathrm{U} \\
\text { Mass } \\
\text { Density } \\
(\mathrm{kg} / \mathrm{L}) \\
\end{array}$} & \multicolumn{4}{|c|}{ Number Density (atoms/barn-cm) } \\
\hline & ${ }^{235} \mathrm{U}$ & ${ }^{238} \mathrm{U}$ & ${ }^{1} \mathrm{H}$ & ${ }^{16} \mathrm{O}$ \\
\hline 0.005 & .000012810 & .000000923 & .066706212 & .033353106 \\
\hline 0.006 & .000015373 & .000001107 & .066702396 & .033351198 \\
\hline 0.007 & .000017935 & .000001292 & .066698580 & .033349290 \\
\hline 0.008 & .000020497 & .000001477 & .066694764 & .033347382 \\
\hline 0.009 & .000023059 & .000001661 & .066690947 & .033345474 \\
\hline 0.010 & .000025621 & .000001846 & .066687131 & .033343565 \\
\hline 0.011 & .000028183 & .000002030 & .066683315 & .033341657 \\
\hline 0.012 & .000030745 & .000002215 & .066679498 & .033339749 \\
\hline 0.013 & .000033307 & .000002399 & .066675682 & .033337841 \\
\hline 0.014 & .000035869 & .000002584 & .066671866 & .033335933 \\
\hline 0.020 & .000051242 & .000003691 & .066648968 & .033324484 \\
\hline 0.030 & .000076863 & .000005537 & .066610805 & .033305403 \\
\hline 0.050 & .000128105 & .000009229 & .066534479 & .033267240 \\
\hline 0.100 & .000256209 & .000018457 & .066343665 & .033171832 \\
\hline 0.200 & .000512419 & .000036915 & .065962035 & .032981018 \\
\hline 0.500 & .001281046 & .000092286 & .064817147 & .032408574 \\
\hline 1.000 & .002562093 & .000184573 & .062909001 & .031454500 \\
\hline 2.000 & .005124186 & .000369145 & .059092707 & .029546354 \\
\hline 5.000 & .012810464 & .000922863 & .047643827 & .023821914 \\
\hline 10.000 & .025620928 & .001845726 & .028562361 & .014281180 \\
\hline 14.000 & .035869299 & .002584017 & .013297187 & .006648594 \\
\hline 17.484 & .044796448 & .003227126 & .000000004 & .000000002 \\
\hline
\end{tabular}




\section{Table 21}

Fissile Mass Densities and Calculated Number Densities for ${ }^{239} \mathrm{Pu}$ Metal-Water Mixtures

\begin{tabular}{||c|c|c|c||}
\hline \hline \multirow{2}{*}{$\begin{array}{c}{ }^{239} \mathrm{Pu} \\
\text { Mass } \\
\text { Density } \\
(\mathrm{kg} / \mathrm{L})\end{array}$} & \multicolumn{3}{|c||}{ Number Density (atoms/barn-cm) } \\
\cline { 2 - 4 } & ${ }^{239} \mathrm{Pu}$ & ${ }^{1} \mathrm{H}$ & $16 \mathrm{O}$ \\
\hline & & & \\
0.005 & .000012596 & .066708393 & .033354196 \\
0.006 & .000015115 & .066705013 & .033352506 \\
0.007 & .000017634 & .066701632 & .033350816 \\
0.008 & .000020153 & .066698252 & .033349126 \\
0.009 & .000022672 & .066694872 & .033347436 \\
0.010 & .000025191 & .066691492 & .033345746 \\
0.011 & .000027710 & .066688112 & .033344056 \\
0.012 & .000030230 & .066684731 & .033342366 \\
0.013 & .000032749 & .066681351 & .033340676 \\
0.014 & .000035268 & .066677971 & .033338985 \\
0.020 & .000050383 & .066657690 & .033328845 \\
0.030 & .000075574 & .066623888 & .033311944 \\
0.050 & .000125957 & .066556283 & .033278142 \\
0.100 & .000251913 & .066387273 & .033193637 \\
0.200 & .000503827 & .066049252 & .033024626 \\
0.500 & .001259567 & .065035190 & .032517595 \\
1.000 & .002519134 & .063345086 & .031672543 \\
2.000 & .005038267 & .059964879 & .029982440 \\
5.000 & .012595668 & .049824257 & .024912128 \\
10.000 & .025191337 & .032923220 & .016461610 \\
14.000 & .035267872 & .019402390 & .009701195 \\
19.740 & .049727697 & .000000003 & .000000002 \\
& & & \\
\hline
\end{tabular}


Table 22

Calculated Dimensions for ${ }^{233} \mathrm{U}$ Metal-Water Mixtures

\begin{tabular}{|c|c|c|c|c|}
\hline $\begin{array}{c}{ }^{233} \mathrm{U} \\
\text { Mass } \\
\text { Density } \\
(\mathrm{kg} / \mathrm{L}) \\
\end{array}$ & $\mathrm{k}_{\mathrm{eff}}$ & $\begin{array}{c}\text { Sphere } \\
\text { Diameter } \\
(\mathrm{cm})\end{array}$ & $\begin{array}{c}\text { Infinite } \\
\text { Cylinder } \\
\text { Diameter } \\
(\mathrm{cm}) \\
\end{array}$ & $\begin{array}{c}\text { Infinite } \\
\text { Slab } \\
\text { Thickness } \\
\text { (cm) }\end{array}$ \\
\hline 0.005 & $\begin{array}{l}0.8 \\
0.9 \\
1.0\end{array}$ & $\begin{array}{l}- \\
- \\
-\end{array}$ & $\begin{array}{l}- \\
- \\
-\end{array}$ & $\begin{array}{l}- \\
- \\
-\end{array}$ \\
\hline 0.006 & $\begin{array}{l}0.8 \\
0.9 \\
1.0\end{array}$ & $\begin{array}{l}- \\
- \\
-\end{array}$ & $\begin{array}{l}- \\
- \\
-\end{array}$ & $\begin{array}{l}- \\
- \\
-\end{array}$ \\
\hline 0.007 & $\begin{array}{l}0.8 \\
0.9 \\
1.0\end{array}$ & $\begin{array}{l}- \\
- \\
-\end{array}$ & $\begin{array}{l}- \\
- \\
-\end{array}$ & $\begin{array}{l}- \\
- \\
-\end{array}$ \\
\hline 0.008 & $\begin{array}{l}0.8 \\
0.9 \\
1.0\end{array}$ & $\begin{array}{c}317.12 \\
- \\
-\end{array}$ & $\begin{array}{c}238.93 \\
- \\
-\end{array}$ & $\begin{array}{c}149.53 \\
- \\
-\end{array}$ \\
\hline 0.009 & $\begin{array}{l}0.8 \\
0.9 \\
1.0\end{array}$ & $\begin{array}{c}105.78 \\
- \\
-\end{array}$ & $\begin{array}{c}78.38 \\
- \\
-\end{array}$ & $\begin{array}{c}47.43 \\
- \\
-\end{array}$ \\
\hline 0.010 & $\begin{array}{l}0.8 \\
0.9 \\
1.0\end{array}$ & $\begin{array}{r}76.12 \\
179.13 \\
-\end{array}$ & $\begin{array}{r}55.63 \\
135.31 \\
-\end{array}$ & $\begin{array}{c}32.51 \\
84.71 \\
-\end{array}$ \\
\hline 0.011 & $\begin{array}{l}0.8 \\
0.9 \\
1.0\end{array}$ & $\begin{array}{r}62.29 \\
104.73 \\
-\end{array}$ & $\begin{array}{c}45.22 \\
76.90 \\
-\end{array}$ & $\begin{array}{c}25.58 \\
46.12 \\
-\end{array}$ \\
\hline 0.012 & $\begin{array}{l}0.8 \\
0.9 \\
1.0\end{array}$ & $\begin{array}{r}54.16 \\
80.25 \\
177.95\end{array}$ & $\begin{array}{r}38.85 \\
58.24 \\
135.68\end{array}$ & $\begin{array}{l}21.67 \\
34.28 \\
84.06\end{array}$ \\
\hline 0.013 & $\begin{array}{l}0.8 \\
0.9 \\
1.0\end{array}$ & $\begin{array}{r}48.55 \\
67.26 \\
112.46\end{array}$ & $\begin{array}{l}34.78 \\
48.71 \\
83.69\end{array}$ & $\begin{array}{l}18.92 \\
28.02 \\
50.54\end{array}$ \\
\hline 0.014 & $\begin{array}{l}0.8 \\
0.9 \\
1.0\end{array}$ & $\begin{array}{l}44.71 \\
59.44 \\
88.23\end{array}$ & $\begin{array}{l}31.68 \\
42.72 \\
64.94\end{array}$ & $\begin{array}{l}16.96 \\
24.04 \\
38.59\end{array}$ \\
\hline 0.020 & $\begin{array}{l}0.8 \\
0.9 \\
1.0\end{array}$ & $\begin{array}{l}32.93 \\
39.88 \\
49.50\end{array}$ & $\begin{array}{l}22.72 \\
27.93 \\
35.19\end{array}$ & $\begin{array}{l}11.20 \\
14.47 \\
19.10\end{array}$ \\
\hline
\end{tabular}

\begin{tabular}{|c|c|c|c|c|}
\hline $\begin{array}{c}{ }^{233} \mathrm{U} \\
\text { Mass } \\
\text { Density } \\
(\mathrm{kg} / \mathrm{L})\end{array}$ & $k_{\text {eff }}$ & $\begin{array}{c}\text { Sphere } \\
\text { Diameter } \\
(\mathrm{cm})\end{array}$ & $\begin{array}{c}\text { Infinite } \\
\text { Cylinder } \\
\text { Diameter } \\
(\mathrm{cm})\end{array}$ & $\begin{array}{c}\text { Infinite } \\
\text { Slab } \\
\text { Thickness } \\
\text { (cm) }\end{array}$ \\
\hline 0.030 & $\begin{array}{l}0.8 \\
0.9 \\
1.0\end{array}$ & $\begin{array}{l}26.10 \\
30.40 \\
35.65\end{array}$ & $\begin{array}{l}17.50 \\
20.72 \\
24.74\end{array}$ & $\begin{array}{r}7.84 \\
9.87 \\
12.36\end{array}$ \\
\hline 0.050 & $\begin{array}{l}0.8 \\
0.9 \\
1.0\end{array}$ & $\begin{array}{l}21.26 \\
24.30 \\
27.85\end{array}$ & $\begin{array}{l}13.82 \\
16.09 \\
18.72\end{array}$ & $\begin{array}{l}5.46 \\
6.84 \\
8.45\end{array}$ \\
\hline 0.100 & $\begin{array}{l}0.8 \\
0.9 \\
1.0\end{array}$ & $\begin{array}{l}17.76 \\
20.08 \\
22.71\end{array}$ & $\begin{array}{l}11.07 \\
12.79 \\
14.75\end{array}$ & $\begin{array}{l}3.60 \\
4.64 \\
5.83\end{array}$ \\
\hline 0.200 & $\begin{array}{l}0.8 \\
0.9 \\
1.0\end{array}$ & $\begin{array}{l}15.74 \\
17.80 \\
20.09\end{array}$ & $\begin{array}{r}9.50 \\
11.00 \\
12.69\end{array}$ & $\begin{array}{l}2.50 \\
3.38 \\
4.38\end{array}$ \\
\hline 0.500 & $\begin{array}{l}0.8 \\
0.9 \\
1.0\end{array}$ & $\begin{array}{l}14.20 \\
16.11 \\
18.19\end{array}$ & $\begin{array}{r}8.25 \\
9.63 \\
11.18\end{array}$ & $\begin{array}{l}1.60 \\
2.37 \\
3.27\end{array}$ \\
\hline 1.000 & $\begin{array}{l}0.8 \\
0.9 \\
1.0\end{array}$ & $\begin{array}{l}13.27 \\
15.11 \\
17.12\end{array}$ & $\begin{array}{r}7.53 \\
8.87 \\
10.35\end{array}$ & $\begin{array}{l}1.14 \\
1.84 \\
2.68\end{array}$ \\
\hline 2.000 & $\begin{array}{l}0.8 \\
0.9 \\
1.0\end{array}$ & $\begin{array}{l}12.34 \\
14.07 \\
15.99\end{array}$ & $\begin{array}{l}6.85 \\
8.11 \\
9.50\end{array}$ & $\begin{array}{l}0.79 \\
1.39 \\
2.15\end{array}$ \\
\hline 5.000 & $\begin{array}{l}0.8 \\
0.9 \\
1.0\end{array}$ & $\begin{array}{l}10.75 \\
12.32 \\
14.04\end{array}$ & $\begin{array}{l}5.77 \\
6.89 \\
8.12\end{array}$ & $\begin{array}{l}0.43 \\
0.87 \\
1.47\end{array}$ \\
\hline 10.000 & $\begin{array}{l}0.8 \\
0.9 \\
1.0\end{array}$ & $\begin{array}{r}9.04 \\
10.40 \\
11.88\end{array}$ & $\begin{array}{l}4.71 \\
5.66 \\
6.71\end{array}$ & $\begin{array}{l}0.25 \\
0.54 \\
0.97\end{array}$ \\
\hline 14.000 & $\begin{array}{l}0.8 \\
0.9 \\
1.0\end{array}$ & $\begin{array}{r}7.94 \\
9.19 \\
10.52\end{array}$ & $\begin{array}{l}4.08 \\
4.91 \\
5.83\end{array}$ & $\begin{array}{l}0.18 \\
0.41 \\
0.75\end{array}$ \\
\hline 18.050 & $\begin{array}{l}0.8 \\
0.9 \\
1.0\end{array}$ & $\begin{array}{l}7.00 \\
8.11 \\
9.31\end{array}$ & $\begin{array}{l}3.58 \\
4.31 \\
5.11\end{array}$ & $\begin{array}{l}0.14 \\
0.33 \\
0.60\end{array}$ \\
\hline
\end{tabular}


Table 23

Calculated Dimensions for U(93.2) Metal-Water Mixtures

\begin{tabular}{|c|c|c|c|c|c|c|c|c|c|}
\hline $\begin{array}{c}{ }^{235} \mathrm{U} \\
\text { Mass } \\
\text { Density } \\
(\mathrm{kg} / \mathrm{L}) \\
\end{array}$ & $\mathrm{k}_{\text {eff }}$ & $\begin{array}{c}\text { Sphere } \\
\text { Diameter } \\
(\mathrm{cm})\end{array}$ & $\begin{array}{c}\text { Infinite } \\
\text { Cylinder } \\
\text { Diameter } \\
(\mathrm{cm}) \\
\end{array}$ & $\begin{array}{c}\text { Infinite } \\
\text { Slab } \\
\text { Thickness } \\
(\mathrm{cm}) \\
\end{array}$ & $\begin{array}{c}{ }^{235} \mathrm{U} \\
\text { Mass } \\
\text { Density } \\
(\mathrm{kg} / \mathrm{L}) \\
\end{array}$ & $\mathrm{k}_{\mathrm{eff}}$ & $\begin{array}{c}\text { Sphere } \\
\text { Diameter } \\
(\mathrm{cm})\end{array}$ & $\begin{array}{c}\text { Infinite } \\
\text { Cylinder } \\
\text { Diameter } \\
(\mathrm{cm}) \\
\end{array}$ & $\begin{array}{c}\text { Infinite } \\
\text { Slab } \\
\text { Thickness } \\
\text { (cm) } \\
\end{array}$ \\
\hline 0.005 & $\begin{array}{l}0.8 \\
0.9 \\
1.0\end{array}$ & $\begin{array}{l}- \\
- \\
-\end{array}$ & $\begin{array}{l}- \\
- \\
-\end{array}$ & $\begin{array}{l}- \\
- \\
-\end{array}$ & 0.030 & $\begin{array}{l}0.8 \\
0.9 \\
1.0\end{array}$ & $\begin{array}{l}28.17 \\
33.37 \\
40.18\end{array}$ & $\begin{array}{l}19.01 \\
22.94 \\
27.98\end{array}$ & $\begin{array}{r}8.77 \\
11.20 \\
14.42\end{array}$ \\
\hline 0.006 & $\begin{array}{l}0.8 \\
0.9 \\
1.0\end{array}$ & $\begin{array}{l}- \\
- \\
-\end{array}$ & - & $\begin{array}{l}- \\
- \\
-\end{array}$ & 0.050 & $\begin{array}{l}0.8 \\
0.9 \\
1.0\end{array}$ & $\begin{array}{l}23.20 \\
26.85 \\
31.22\end{array}$ & $\begin{array}{l}15.20 \\
17.96 \\
21.28\end{array}$ & $\begin{array}{l}6.28 \\
7.96 \\
9.99\end{array}$ \\
\hline 0.007 & $\begin{array}{l}0.8 \\
0.9 \\
1.0\end{array}$ & $\begin{array}{l}- \\
- \\
-\end{array}$ & $\begin{array}{l}- \\
- \\
-\end{array}$ & $\begin{array}{l}- \\
- \\
-\end{array}$ & 0.100 & $\begin{array}{l}0.8 \\
0.9 \\
1.0\end{array}$ & $\begin{array}{l}19.60 \\
22.51 \\
25.82\end{array}$ & $\begin{array}{l}12.44 \\
14.56 \\
17.02\end{array}$ & $\begin{array}{l}4.37 \\
5.68 \\
7.19\end{array}$ \\
\hline 0.008 & $\begin{array}{l}0.8 \\
0.9 \\
1.0\end{array}$ & $\begin{array}{l}- \\
- \\
-\end{array}$ & $\begin{array}{l}- \\
- \\
-\end{array}$ & $\begin{array}{l}- \\
- \\
-\end{array}$ & 0.200 & $\begin{array}{l}0.8 \\
0.9 \\
1.0\end{array}$ & $\begin{array}{l}17.78 \\
20.36 \\
23.32\end{array}$ & $\begin{array}{l}10.96 \\
12.88 \\
15.06\end{array}$ & $\begin{array}{l}3.30 \\
4.45 \\
5.79\end{array}$ \\
\hline 0.009 & $\begin{array}{l}0.8 \\
0.9 \\
1.0\end{array}$ & $\begin{array}{c}130.68 \\
- \\
-\end{array}$ & $\begin{array}{c}98.23 \\
- \\
-\end{array}$ & $\begin{array}{c}60.42 \\
- \\
-\end{array}$ & 0.500 & $\begin{array}{l}0.8 \\
0.9 \\
1.0\end{array}$ & $\begin{array}{l}16.63 \\
19.15 \\
22.06\end{array}$ & $\begin{array}{r}9.99 \\
11.83 \\
13.98\end{array}$ & $\begin{array}{l}2.47 \\
3.58 \\
4.88\end{array}$ \\
\hline 0.010 & $\begin{array}{l}0.8 \\
0.9 \\
1.0\end{array}$ & $\begin{array}{r}87.11 \\
1273.95 \\
-\end{array}$ & $\begin{array}{r}63.90 \\
833.96 \\
-\end{array}$ & $\begin{array}{r}37.71 \\
562.43 \\
-\end{array}$ & 1.000 & $\begin{array}{l}0.8 \\
0.9 \\
1.0\end{array}$ & $\begin{array}{l}16.20 \\
18.81 \\
21.76\end{array}$ & $\begin{array}{r}9.55 \\
11.47 \\
13.72\end{array}$ & $\begin{array}{l}2.06 \\
3.19 \\
4.52\end{array}$ \\
\hline 0.011 & $\begin{array}{l}0.8 \\
0.9 \\
1.0\end{array}$ & $\begin{array}{r}69.41 \\
137.49 \\
-\end{array}$ & $\begin{array}{r}50.49 \\
103.27 \\
-\end{array}$ & $\begin{array}{c}29.03 \\
62.92 \\
-\end{array}$ & 2.000 & $\begin{array}{l}0.8 \\
0.9 \\
1.0\end{array}$ & $\begin{array}{l}15.72 \\
18.41 \\
21.53\end{array}$ & $\begin{array}{r}9.17 \\
11.14 \\
13.41\end{array}$ & $\begin{array}{l}1.71 \\
2.83 \\
4.19\end{array}$ \\
\hline 0.012 & $\begin{array}{l}0.8 \\
0.9 \\
1.0\end{array}$ & $\begin{array}{c}59.51 \\
95.99 \\
-\end{array}$ & $\begin{array}{c}42.83 \\
70.72 \\
-\end{array}$ & $\begin{array}{r}24.20 \\
42.25 \\
-\end{array}$ & 5.000 & $\begin{array}{l}0.8 \\
0.9 \\
1.0\end{array}$ & $\begin{array}{l}14.30 \\
16.78 \\
19.64\end{array}$ & $\begin{array}{r}8.15 \\
9.98 \\
12.10\end{array}$ & $\begin{array}{l}1.24 \\
2.22 \\
3.45\end{array}$ \\
\hline 0.013 & $\begin{array}{l}0.8 \\
0.9 \\
1.0\end{array}$ & $\begin{array}{r}53.16 \\
77.93 \\
173.45\end{array}$ & $\begin{array}{r}38.10 \\
57.02 \\
129.51\end{array}$ & $\begin{array}{l}21.03 \\
33.35 \\
80.40\end{array}$ & 10.000 & $\begin{array}{l}0.8 \\
0.9 \\
1.0\end{array}$ & $\begin{array}{l}12.31 \\
14.37 \\
16.68\end{array}$ & $\begin{array}{r}6.90 \\
8.39 \\
10.09\end{array}$ & $\begin{array}{l}0.85 \\
1.60 \\
2.56\end{array}$ \\
\hline 0.014 & $\begin{array}{l}0.8 \\
0.9 \\
1.0\end{array}$ & $\begin{array}{r}48.64 \\
67.72 \\
115.37\end{array}$ & $\begin{array}{l}34.63 \\
49.04 \\
85.54\end{array}$ & $\begin{array}{l}18.77 \\
28.09 \\
52.14\end{array}$ & 14.000 & $\begin{array}{l}0.8 \\
0.9 \\
1.0\end{array}$ & $\begin{array}{l}11.08 \\
12.92 \\
14.97\end{array}$ & $\begin{array}{l}6.12 \\
7.44 \\
8.92\end{array}$ & $\begin{array}{l}0.67 \\
1.28 \\
2.07\end{array}$ \\
\hline 0.020 & $\begin{array}{l}0.8 \\
0.9 \\
1.0\end{array}$ & $\begin{array}{l}35.51 \\
43.94 \\
56.68\end{array}$ & $\begin{array}{l}24.62 \\
31.03 \\
40.69\end{array}$ & $\begin{array}{l}12.37 \\
16.47 \\
22.63\end{array}$ & 17.484 & $\begin{array}{l}0.8 \\
0.9 \\
1.0\end{array}$ & $\begin{array}{l}10.08 \\
11.76 \\
13.62\end{array}$ & $\begin{array}{l}5.52 \\
6.72 \\
8.05\end{array}$ & $\begin{array}{l}0.56 \\
1.09 \\
1.77\end{array}$ \\
\hline
\end{tabular}


Table 24

Calculated Dimensions for ${ }^{239} \mathrm{Pu}$ Metal-Water Mixtures

\begin{tabular}{|c|c|c|c|c|}
\hline $\begin{array}{c}{ }^{239} \mathrm{Pu} \\
\text { Mass } \\
\text { Density } \\
(\mathrm{kg} / \mathrm{L}) \\
\end{array}$ & $k_{\text {eff }}$ & $\begin{array}{c}\text { Sphere } \\
\text { Diameter } \\
(\mathrm{cm})\end{array}$ & $\begin{array}{c}\text { Infinite } \\
\text { Cylinder } \\
\text { Diameter } \\
(\mathrm{cm}) \\
\end{array}$ & $\begin{array}{c}\text { Infinite } \\
\text { Slab } \\
\text { Thickness } \\
\text { (cm) }\end{array}$ \\
\hline 0.005 & $\begin{array}{l}0.8 \\
0.9 \\
1.0\end{array}$ & $\begin{array}{c}235.44 \\
- \\
-\end{array}$ & $\begin{array}{c}178.13 \\
- \\
-\end{array}$ & $\begin{array}{c}114.24 \\
- \\
-\end{array}$ \\
\hline 0.006 & $\begin{array}{l}0.8 \\
0.9 \\
1.0\end{array}$ & $\begin{array}{r}84.59 \\
344.79 \\
-\end{array}$ & $\begin{array}{r}61.77 \\
264.35 \\
-\end{array}$ & $\begin{array}{c}36.54 \\
171.68 \\
-\end{array}$ \\
\hline 0.007 & $\begin{array}{l}0.8 \\
0.9 \\
1.0\end{array}$ & $\begin{array}{r}61.59 \\
100.75 \\
-\end{array}$ & $\begin{array}{c}44.46 \\
74.83 \\
-\end{array}$ & $\begin{array}{c}25.04 \\
44.68 \\
-\end{array}$ \\
\hline 0.008 & $\begin{array}{l}0.8 \\
0.9 \\
1.0\end{array}$ & $\begin{array}{r}50.95 \\
72.49 \\
135.53\end{array}$ & $\begin{array}{r}36.39 \\
52.66 \\
101.00\end{array}$ & $\begin{array}{l}19.95 \\
30.46 \\
61.68\end{array}$ \\
\hline 0.009 & $\begin{array}{l}0.8 \\
0.9 \\
1.0\end{array}$ & $\begin{array}{l}44.84 \\
59.55 \\
89.85\end{array}$ & $\begin{array}{l}31.70 \\
42.95 \\
66.19\end{array}$ & $\begin{array}{l}16.89 \\
24.16 \\
39.16\end{array}$ \\
\hline 0.010 & $\begin{array}{l}0.8 \\
0.9 \\
1.0\end{array}$ & $\begin{array}{l}40.65 \\
52.20 \\
72.23\end{array}$ & $\begin{array}{l}28.53 \\
37.36 \\
52.75\end{array}$ & $\begin{array}{l}14.89 \\
20.49 \\
30.27\end{array}$ \\
\hline 0.011 & $\begin{array}{l}0.8 \\
0.9 \\
1.0\end{array}$ & $\begin{array}{l}37.65 \\
47.26 \\
62.44\end{array}$ & $\begin{array}{l}26.24 \\
33.55 \\
45.03\end{array}$ & $\begin{array}{l}13.38 \\
18.02 \\
25.40\end{array}$ \\
\hline 0.012 & $\begin{array}{l}0.8 \\
0.9 \\
1.0\end{array}$ & $\begin{array}{l}35.38 \\
43.69 \\
56.03\end{array}$ & $\begin{array}{l}24.51 \\
30.77 \\
40.18\end{array}$ & $\begin{array}{l}12.27 \\
16.28 \\
22.32\end{array}$ \\
\hline 0.013 & $\begin{array}{l}0.8 \\
0.9 \\
1.0\end{array}$ & $\begin{array}{l}33.54 \\
40.96 \\
51.55\end{array}$ & $\begin{array}{l}23.12 \\
28.74 \\
36.76\end{array}$ & $\begin{array}{l}11.39 \\
14.91 \\
20.01\end{array}$ \\
\hline 0.014 & $\begin{array}{l}0.8 \\
0.9 \\
1.0\end{array}$ & $\begin{array}{l}32.06 \\
38.81 \\
48.15\end{array}$ & $\begin{array}{l}21.99 \\
27.11 \\
34.15\end{array}$ & $\begin{array}{l}10.66 \\
13.87 \\
18.34\end{array}$ \\
\hline 0.020 & $\begin{array}{l}0.8 \\
0.9 \\
1.0\end{array}$ & $\begin{array}{l}26.90 \\
31.67 \\
37.68\end{array}$ & $\begin{array}{l}18.05 \\
21.61 \\
26.22\end{array}$ & $\begin{array}{r}8.10 \\
10.33 \\
13.16\end{array}$ \\
\hline
\end{tabular}

\begin{tabular}{|c|c|c|c|c|}
\hline $\begin{array}{c}{ }^{239} \mathrm{Pu} \\
\text { Mass } \\
\text { Density } \\
(\mathrm{kg} / \mathrm{L}) \\
\end{array}$ & $\mathbf{k}_{\text {eff }}$ & $\begin{array}{c}\text { Sphere } \\
\text { Diameter } \\
(\mathrm{cm})\end{array}$ & $\begin{array}{c}\text { Infinite } \\
\text { Cylinder } \\
\text { Diameter } \\
(\mathrm{cm}) \\
\end{array}$ & $\begin{array}{c}\text { Infinite } \\
\text { Slab } \\
\text { Thickness } \\
\text { (cm) }\end{array}$ \\
\hline 0.030 & $\begin{array}{l}0.8 \\
0.9 \\
1.0\end{array}$ & $\begin{array}{l}23.31 \\
27.04 \\
31.52\end{array}$ & $\begin{array}{l}15.29 \\
18.04 \\
21.42\end{array}$ & $\begin{array}{r}6.26 \\
7.98 \\
10.08\end{array}$ \\
\hline 0.050 & $\begin{array}{l}0.8 \\
0.9 \\
1.0\end{array}$ & $\begin{array}{l}20.63 \\
23.74 \\
27.37\end{array}$ & $\begin{array}{l}13.16 \\
15.49 \\
18.19\end{array}$ & $\begin{array}{l}4.81 \\
6.22 \\
7.90\end{array}$ \\
\hline 0.100 & $\begin{array}{l}0.8 \\
0.9 \\
1.0\end{array}$ & $\begin{array}{l}18.66 \\
21.46 \\
24.68\end{array}$ & $\begin{array}{l}11.58 \\
13.68 \\
16.09\end{array}$ & $\begin{array}{l}3.63 \\
4.89 \\
6.34\end{array}$ \\
\hline 0.200 & $\begin{array}{l}0.8 \\
0.9 \\
1.0\end{array}$ & $\begin{array}{l}17.66 \\
20.37 \\
23.48\end{array}$ & $\begin{array}{l}10.73 \\
12.73 \\
15.07\end{array}$ & $\begin{array}{l}2.94 \\
4.14 \\
5.55\end{array}$ \\
\hline 0.500 & $\begin{array}{l}0.8 \\
0.9 \\
1.0\end{array}$ & $\begin{array}{l}16.75 \\
19.40 \\
22.44\end{array}$ & $\begin{array}{l}10.00 \\
11.93 \\
14.18\end{array}$ & $\begin{array}{l}2.35 \\
3.52 \\
4.88\end{array}$ \\
\hline 1.000 & $\begin{array}{l}0.8 \\
0.9 \\
1.0\end{array}$ & $\begin{array}{l}15.86 \\
18.38 \\
21.26\end{array}$ & $\begin{array}{r}9.33 \\
11.20 \\
13.35\end{array}$ & $\begin{array}{l}1.97 \\
3.06 \\
4.33\end{array}$ \\
\hline 2.000 & $\begin{array}{l}0.8 \\
0.9 \\
1.0\end{array}$ & $\begin{array}{l}14.56 \\
16.84 \\
19.42\end{array}$ & $\begin{array}{r}8.45 \\
10.12 \\
12.03\end{array}$ & $\begin{array}{l}1.55 \\
2.50 \\
3.62\end{array}$ \\
\hline 5.000 & $\begin{array}{l}0.8 \\
0.9 \\
1.0\end{array}$ & $\begin{array}{l}11.98 \\
13.80 \\
15.82\end{array}$ & $\begin{array}{l}6.74 \\
8.05 \\
9.53\end{array}$ & $\begin{array}{l}0.96 \\
1.61 \\
2.42\end{array}$ \\
\hline 10.000 & $\begin{array}{l}0.8 \\
0.9 \\
1.0\end{array}$ & $\begin{array}{r}9.27 \\
10.65 \\
12.14\end{array}$ & $\begin{array}{l}5.07 \\
6.04 \\
7.09\end{array}$ & $\begin{array}{l}0.57 \\
0.99 \\
1.49\end{array}$ \\
\hline 14.000 & $\begin{array}{l}0.8 \\
0.9 \\
1.0\end{array}$ & $\begin{array}{r}7.76 \\
8.91 \\
10.13\end{array}$ & $\begin{array}{l}4.19 \\
4.98 \\
5.84\end{array}$ & $\begin{array}{l}0.42 \\
0.73 \\
1.12\end{array}$ \\
\hline 19.740 & $\begin{array}{l}0.8 \\
0.9 \\
1.0\end{array}$ & $\begin{array}{l}6.23 \\
7.13 \\
8.08\end{array}$ & $\begin{array}{l}3.34 \\
3.95 \\
4.60\end{array}$ & $\begin{array}{l}0.31 \\
0.53 \\
0.81\end{array}$ \\
\hline
\end{tabular}


114 


\section{References}

1. A. D. Callihan, W. J. Ozeroff, H. C. Paxton, C. L. Schuske, "Nuclear Safety Guide," US Atomic Energy Commission report TID-7016 (1957).

2. J. T. Thomas, editor, "Nuclear Safety Guide, TID-7016, Revision 2," US Nuclear Regulatory Commission report NUREG/CR-0095, ORNL/NUREG/CSD-6 (1978).

3. "Nuclear Safety Guide," US Atomic Energy Commission report TID-7016, Rev. 1 (1961).

4. American National Standard for Nuclear Criticality Safety in Operations with Fissionable Materials Outside Reactors, ANSI/ANS-8.1-1983, American Nuclear Society, LaGrange Park, IL (1983).

5. American National Standard for Nuclear Criticality Control of Special Actinide Elements, ANSI/ANS-8.15-1981, American Nuclear Society, LaGrange Park, IL (1981).

6. F. William Walker, Josef R. Parrington, and Frank Feiner, editors, Nuclides and Isotopes, Fourteenth Edition, GE Nuclear Energy, San Jose, CA, 12-13 (1989).

7. Proceedings of the 4th Annual Scientific \& Technical Conference on Nuclear Energy and Human Safety, Nizhni Novgorod, Russia, June 28 - July 2, 1993, NE-93 (1993).

8. H. C. Paxton, "Glossary of Nuclear Criticality Terms," Los Alamos National Laboratory report LA-11627-MS (1989).

9. "Glossary of Terms in Nuclear Science and Technology," prepared by ANS-9, the American Nuclear Society Standards Subcommittee on Nuclear Terminology and Units, American Nuclear Society, LaGrange Park, IL (1986).

10. E. D. Clayton, "Anomalies of Nuclear Criticality," Pacific Northwest Laboratories report PNL-SA-4868 Rev. 5 (1979).

11. H. C. Paxton and N. L. Pruvost, "Critical Dimensions of Systems Containing ${ }^{235} \mathrm{U},{ }^{239} \mathrm{Pu}$, and ${ }^{233} \mathrm{U}, 1986$ Revision," Los Alamos National Laboratory report LA-10860-MS (1987).

12. L. M. Petrie and N. F. Landers, "KENO V.a, An Improved Monte Carlo Criticality Program With Supergrouping," NUREG/CR-0200, Volume 2, Section F11, ORNL/NUREG/CSD-2/VI/R2 (1984).

13. J. F. Briesmeister, editor, "MCNP - A General Monte Carlo N-Particle Transport Code, Version 4A," Los Alamos National Laboratory report LA-12625-M (1993).

14. "MONK6 - A Monte Carlo Code for Criticality Safety Calculations," ANSWERS Service, AEA Reactor Services, Winfrith Technology Center, Dorchester, UK (1990). 
15. S. Glasstone and M. C. Edlund, The Elements of Nuclear Reactor Theory, D. Van Nostrand Co., Inc., Princeton, NJ (1952).

16. A. M. Weinberg and E. P. Wigner, The Physical Theory of Neutron Chain Reactors, The University of Chicago Press, Chicago, IL (1958).

17. H. S. Isbin, Introductory Nuclear Reactor Theory, Reinhold Publishing Corp., New York, NY (1963).

18. G. I. Bell and S. Glasstone, Nuclear Reactor Theory, Van Nostrand Reinhold, New York, NY (1970).

19. J. R. Lamarsh, Introduction to Nuclear Reactor Theory, Addison-Wesley, Reading, MA (1972).

20. A. F. Henry, Nuclear-Reactor Analysis, MIT Press, Cambridge, MA (1975).

21. J. J. Duderstadt and L. J. Hamilton, Nuclear Reactor Analysis, Wiley, New York, NY (1976).

22. S. Glasstone and A. Sesonske, Nuclear Reactor Engineering, 3rd Edition, Van Nostrand Reinhold, New York, NY (1981).

23. R. A. Knief, Nuclear Criticality Safety, Theory and Practice, American Nuclear Society, LaGrange Park, IL (1985).

24. R. A. Knief Nuclear Engineering, Theory and Technology of Commercial Nuclear Power, 2nd Edition, Taylor \& Francis/Hemisphere, Washington, DC (1992).

25. American National Standard Administrative Practices for Nuclear Criticality Safety, ANSI/ANS-8.19-1984, American Nuclear Society, LaGrange Park, IL (1984).

26. American National Standard Nuclear Criticality Safety Training, ANSI/ANS-8.201991, American Nuclear Society, LaGrange Park, IL (1991).

27. American National Standard Criteria for Nuclear Criticality Safety Controls in Operations with Shielding and Confinement, ANSI/ANS-8.10-1983, American Nuclear Society, LaGrange Park, IL (1983).

28. American National Standard Safety Guide for the Performance of Critical Experiments, ANSI-N405-1975/ANS-1, American Nuclear Society, LaGrange Park, IL (1975).

29. American National Standard for Safety in Conducting Subcritical NeutronMultiplication Measurements in Situ, ANSI/ANS-8.6-1983, American Nuclear Society, LaGrange Park, IL (1983).

30. W. R. Stratton, revised by D. R. Smith, "A Review of Criticality Accidents," Lawrence Livermore National Laboratory report DOE/NCT-04 (1989). 
31. American National Standard Use of Borosilicate-Glass Raschig Rings as a Neutron Absorber in Solutions of Fissile Material, ANSI/ANS-8.5-1986, American Nuclear Society, LaGrange Park, IL (1986).

32. G. E. Hansen and H. C. Paxton, "Reevaluated Critical Specifications of Some Los Alamos Fast-Neutron Systems," Los Alamos Scientific Laboratory report LA-4208 (1969).

33. J. T. Mihalczo, J. J. Lynn, J. R. Taylor, and G. E. Hansen, "Measurements With an Unreflected Uranium (93.2\%) Metal Sphere," Proceedings of a Topical Meeting on Physics and Methods in Criticality Safety, Nashville, TN, September 19-23, 1993, American Nuclear Society, LaGrange Park, IL, 26-33 (1993).

34. G. R. Keepin, "Nuclear Fission and Nuclear Safeguards: Common Technologies and Challenges," Proceedings of the Conference 50 Years with Nuclear Fission, Gaithersburg, MD, April 26-28, 1989, National Academy of Sciences and National Institute of Standards and Technology, Washington, DC (1989).

35. R. L. Price and N. L. Pruvost, "Inventory Difference Information and Criticality Safety," Proceedings of an International Topical Meeting on Safety Margins in Criticality Safety, San Francisco, CA, November 26-30, 1989, American Nuclear Society report ISBN:89448-142-2, 165-167 (1989).

36. R. G. Taylor, "Monitoring for Uranium Accumulations in Diffusion Plant Equipment," Oak Ridge Gaseous Diffusion Plant report K-L-6316 (1973).

37. J. T. Mihalczo, E. D. Blakeman, G. E. Ragan, E. B. Johnson, and Y. Hachiya, "Dynamic Subcriticality Measurements Using the ${ }^{252}$ Cf-Source-Driven Noise Analysis Method," Nuclear Science and Engineering, 104, 314-338 (1990).

38. E. R. Martin, D. F. Jones, and L. G. Speir, "Passive Segmented Gamma Scan Operation Manual, " Los Alamos Scientific Laboratory report LA-5652-M (1974).

39. R. B. Walton, W. I. Whitted, and R. A. Forster, "Gamma-Ray Assay of LowEnriched Uranium Waste," Nuclear Technology, 24, 81-92 (1974).

40. C. J. Umbarger and L. R. Cowder, "Portable Radioactivity Monitor for Liquid Effluents, Surface Contaminations, and Bulk Solid Wastes," Nuclear Instruments and Methods, 121, 491-498 (1974).

41. J. T. Mihalczo, "Randomly Pulsed Neutron Measurements for Safeguards Interrogation," Oak Ridge Y-12 Plant report Y-DR-79 (1972).

42. J. E. Foley and L. R. Cowder, "Assay of the Uranium Content of Rover Scrap with the Random Source Interrogation System," Los Alamos Scientific Laboratory report LA-5692-MS (1974). 
43. R. Berg, R. Swennen, G. Birkhoff, L. Bondar, J. Ley, and B. Busca, "On the Determination of the Pu-240 in Solid Waste Containers by Spontaneous Fission Neutron Measurements. Application to Reprocessing Plant Waste," EUR 5158e, Joint Nuclear Research Centre, ISPRA Establishment, Italy (1974).

44. T. D. Reilly, E. R. Martin, J. L. Parker, L. G. Speir and R. D. Walton, "A Continuous In-Line Monitor for $\mathrm{UF}_{6}$ Enrichment," Nuclear Technology, 23, 318-327 (1974).

45. J. L. Forstner, "Nuclear Safety Control in the Chemical Processing Facilities of the Savannah River Plant," Proceedings of a Symposium on Criticality Control of Fissile Materials, Stockholm, November 1-5, 1965, International Atomic Energy Agency, Vienna, 627-639 (1965).

46. American National Standard Criticality Accident Alarm System, ANSI/ANS-8.31986, American Nuclear Society, LaGrange Park, IL (1986).

47. J. M. Juran, F. M. Gryna, Jr., and R. S. Bingham, Jr., editors, Quality Control Handbook, Third Edition, McGraw-Hill, New York, NY (1974).

48. American National Standard Quality Assurance Program Requirements for Nuclear Facilities, ASME NQA-1-1989 Edition, American Society of Mechanical Engineers, New York, NY (1989).

49. American National Standard Quality Assurance Requirements for Nuclear Facility Applications, ASME NQA-2-1989 Edition, American Society of Mechanical Engineers, New York, NY (1989).

50. J. S. Arendt, D. K. Lorenzo, and A. F. Lusby, "Evaluating Process Safety in the Chemical Industry, A Manager's Guide to Quantitative Risk Assessment," JBF Associates, Inc. (1989).

51. J. R. Wilson, "Applications of PRA to Criticality Safety at ICPP," Proceedings of an International Topical Meeting on Safety Margins in Criticality Safety, San Francisco, CA, November 26-30, 1989, American Nuclear Society report ISBN:89448-142-2, 186-191 (1989).

52. R. R. Jackson, "Science Applications International Corporation's Experience in Applying Probabilistic Safety Assessment Techniques to Nuclear Criticality Accident Analysis," Proceedings of an International Topical Meeting on Safety Margins in Criticality Safety, San Francisco, CA, November 26-30, 1989, American Nuclear Society report ISBN:89448-142-2, 179-182 (1989).

53. Nuclear Regulatory Commission Regulatory Guide 3.33, “Assumptions Used for Evaluating the Potential Radiological Consequences of Accidental Nuclear Criticality in a Fuel Reprocessing Plant," US Nuclear Regulatory Commission (1977). 
54. W. Thomas and B. Gmal, "In-Depth Analysis of Accidental Criticality in a Reprocessing Plant," Proceedings of an International Topical Meeting on Safety Margins in Criticality Safety, San Francisco, CA, November 26-30, 1989, American Nuclear Society report ISBN:89448-142-2, 207-213 (1989).

55. T. P. McLaughlin, "Process Criticality Accident Likelihoods, Consequences and Emergency Planning," Nuclear Energy, 31, No. 2, 143-147 (1992).

56. Proceedings of the Fifth International Conference on Nuclear Criticality Safety, Albuquerque, NM, September 17-21, 1995 (1995).

57. R. L. Seale, "Consequences of Criticality Accidents," Nuclear Criticality Safety, US Atomic Energy Commission report TID-26286, 16-24 (1974).

58. A. D. Callihan and J. T. Thomas, "Accidental Radiation Excursion at the Oak Ridge Y-12 Plant - I," Health Physics, 1, 363-372 (1959).

59. J. D. McLendon, "Accidental Radiation Excursion at the Oak Ridge Y-12 Plant II," Health Physics, 2, 21-29 (1959).

60. G. S. Hurst, R. H. Richie, and L. C. Emerson, "Accidental Radiation Excursion at the Oak Ridge Y-12 Plant - III," Health Physics, 2, 121-133 (1959).

61. T. L. Shipman, "Acute Radiation Death Resulting from an Accidental Nuclear Critical Excursion," Journal of Occupational Medicine, Special Supplement, 147-149 (1961).

62. H. C. Paxton, R. D. Baker, W. J. Maraman, and Roy Reider, "Nuclear-Critical Accident at the Los Alamos Scientific Laboratory on December 30, 1958," Los Alamos Scientific Laboratory report LAMS-2293 (1959).

63. W. C. Roesch et al., "Dosimetry Investigation of the Recuplex Criticality Accident," Health Physics, 9, 757-768 (1963).

64. T. G. Hughes, "Criticality Incident at Windscale," Nuclear Engineering International, 17, No. 189, 95-97 (1972).

65. W. Sweet, "Kyshtym Visit Gives First Look at Soviet Plutonium Production Complex," Physics Today, November 1989, 87-89 (1989).

66. L. A. Buldakov, S. N. Demin, V. A. Kostyuchenko, N. A. Koshurnikova, L. Yu. Krestinina, M. M. Saurov, Z. B. Tokarskaya, V. L. Shvedov, and I. A. Ternovskij, "Medical Consequences of the Radiation Accident in the Southern Urals," Proceedings of an International Symposium on Recovery Operations in the Event of a Nuclear Accident or Radiological Emergency, Vienna, November 6-10, 1989, IAEA-SM-316/55-2, 419-431 (1989).

67. "Investigation of Incident in Ion Exchange Resin," HRC report 3719, Atlantic Richfield Hanford Company, Richland, WA (1976). 
68. B. L. Broadhead and C. M. Hopper, "Updated Tool for Nuclear Criticality Accident Emergency Response," Transactions of the American Nuclear Society, 72, 218-220 (1995).

69. J. T. Thomas, "Criticality of Large Systems of Subcritical U(93) Components," Oak Ridge National Laboratory report ORNL-CDC-1 (1967).

70. P. Lécorché and R. L. Seale, "A Review of the Experiments Performed to Determine the Radiological Consequences of a Criticality Accident," Oak Ridge Y-12 Plant report Y/CDC-12 (1973).

71. American National Standard for Nuclear Criticality Control and Safety of Plutonium-Uranium Fuel Mixtures Outside Reactors, ANSI/ANS-8.12-1987, American Nuclear Society, LaGrange Park, IL (1987).

72. H. K. Clark, "Subcritical Limits for Plutonium Systems," Nuclear Science and Engineering, 79, 65-84 (1981).

73. H. K. Clark, "Subcritical Limits for Uranium-235 Systems," Nuclear Science and Engineering, 81, 351-378 (1982).

74. H. K. Clark, "Subcritical Limits for Uranium-233 Systems," Nuclear Science and Engineering, 81, 379-395 (1982).

75. E. D. Clayton, H. K. Clark, Gordon Walker, and R. A. Libby, "Basis for Extending Limits in ANSI Standard for Mixed Oxides to Heterogeneous Systems," Nuclear Technology, 75, 225-229 (1986).

76. J. W. Webster, "Calculated Neutron Multiplication Factors of Uniform Aqueous Solutions of ${ }^{233} \mathrm{U}$ and ${ }^{235} \mathrm{U}$," Oak Ridge National Laboratory report ORNL-CDC-2 (1967).

77. S. R. Bierman, G. R. Smolen, and T. Matsumoto, "Experimental Criticality Data Comparing Organic and Water Moderation," Transactions of the American Nuclear Society, 54, 195-196 (1987).

78. H. K. Clark, "Effect of Distribution of Fissile Material on Critical Mass," Nuclear Science and Engineering, 24, 133-141 (1966).

79. W. H. Roach and D. R. Smith, "Estimates of Maximum Subcritical Dimensions of Single Fissile Metal Units," Oak Ridge National Laboratory report ORNL-CDC-3 (1967).

80. D. R. Smith and W. U. Geer, "Critical Mass of a Water-Reflected Plutonium Sphere," Nuclear Applications and Technology, 7, No. 5, 405-408 (1969).

81. W. R. Stratton, "Criticality Data and Factors Affecting Criticality of Single Homogeneous Units," Los Alamos Scientific Laboratory report LA-3612 (1964). 
82. C. G. Chezem and R. G. Steinke, "Low-Enrichment Uranium-Metal Exponential Experiments," Nuclear Science and Engineering, 31, 549 (1967).

83. M. Darrouzet, J. P. Chaudat, E. A. Fischer, G. Ingram, J. E. Sanders, W. Scholtyssek, "Studies of Unit $\mathrm{K}_{\infty}$ Lattices in Metallic Uranium Assemblies Zebra 8H, Sneak 8, Ermine, and Harmonie UK," Proceedings of an International Symposium on Physics of Fast Reactors, Tokyo, October 16-19, 1973, Committee for the International Symposium on Physics of Fast Reactors, A28 (1973).

84. C. E. Newlon, "The Effect of Uranium Density on the Safe ${ }^{235} \mathrm{U}$ Enrichment Criterion," Oak Ridge Gaseous Diffusion Plant report K-1550 (1962).

85. E. D. Clayton, H. K. Clark, D. W. Magnuson, J. H. Chalmers, Gordon Walker, N. Ketzlach, Ryohei Kiyose, C. L. Brown, D. R. Smith, and R. Artigas, "Basis for Subcritical Limits in Proposed Criticality Safety Standard for Mixed Oxides," Nuclear Technology, 35, 97-111 (1977).

86. H. K. Clark, "Critical and Safe Masses and Dimensions of Lattices of $\mathrm{U}$ and $\mathrm{UO}_{2}$ Rods in Water," DP-1014, Savannah River Laboratory (1966).

87. H. K. Clark, "Maximum Safe Limits for Slightly Enriched Uranium and Uranium Oxide," Proceedings of a Symposium on Criticality Control of Fissile Materials, Stockholm, November 1-5, 1965, International Atomic Energy Agency, Vienna, 35-49 (1965).

88. R. C. Lloyd, "Buckling Measurements of Fuel Elements in a Random Array, Water Moderated," Nuclear Physics Research Quarterly Report, October-December, 195\%, Hanford Engineering Development Laboratory report HW-54591, 35-36 (1957).

89. R. C. Lloyd, "Buckling Measurements for Fuel Elements in a Random Array," Nuclear Physics Research Quarterly Report, January-March, 1958, Hanford Engineering Development Laboratory report HW-55879, 12-13 (1958).

90. J. T. Thomas, "Calculated Criticality of Water Moderated Oxides of Uranium-233, Thorium-232, and Carbon Mixtures," Oak Ridge Y-12 Plant report Y-DR-107 (1973).

91. R. C. Lloyd and E. D. Clayton, "Criticality Safety Data Applicable to Processing Liquid-Metal Fast Breeder Reactor Fuel," Nuclear Science and Engineering, 59, $21-26(1976)$.

92. J. K. Fox, L. W. Gilley, and D. Callihan, "Critical Mass Studies, Part IX, Aqueous U $^{235}$ Solutions," Oak Ridge National Laboratory report ORNL-2367 (1958).

93. J. K. Fox and L. W. Gilley, "Critical Parameters for Poisoned Annular Cylinders Containing Aqueous Solutions of $\mathrm{U}^{235}$," Neutron Physics Division Annual Progress Report for Period Ending September 1, 1958, Oak Ridge National Laboratory report ORNL-2609, 31-33 (1958). 
94. C. Clouet d'Orval, E. Deilgat, M. Houelle, and P. Lécorché, "Experimental Research in France on Criticality Problems" (in French), Proceedings of a Symposium on Criticality Control of Fissile Materials, Stockholm, November 1-5, 1965, International Atomic Energy Agency, Vienna, 193-213 (1965).

95. J. E. Tanner and H. M. Forehand, "Critical Experiments for Large Scale Enriched Uranium Solution Handling," Proceedings of a Topical Meeting on Criticality Safety in the Storage of Fissile Material, Jackson, WY, September 8-11, 1985, American Nuclear Society report ISBN:89448-119-3, 65-79 (1985).

96. R. C. Lloyd and T. Koyama, "Criticality Experiments with Mixed PlutoniumUranium Nitrate Solution at Plutonium Fractions of $0.2,0.5$, and 1.0 in Annular Cylindrical Geometry," Transactions of the American Nuclear Society, 56, 318-319 (1988).

97. American National Standard Nuclear Criticality Safety Criteria for Steel-Pipe Intersections Containing Aqueous Solutions of Fissile Material, ANSI/ANS-8.9-1987, American Nuclear Society, LaGrange Park, IL (1987).

98. D. Dickinson and C. L. Schuske, "An Empirical Model for Safe Pipe Intersections Containing Fissile Solution," Nuclear Technology, 10, 179-187 (1971).

99. E. B. Johnson, "The Nuclear Criticality of Intersecting Cylinders of Aqueous Uranyl Fluoride Solutions," Oak Ridge Y-12 Plant report Y-DR-129 (1974).

100. N. F. Cross, G. E. Whitesides, and R. J. Hinton, "Monte Carlo Analysis of Experimentally Critical Pipe Intersections," Transactions of the American Nuclear Society, 17, 268 (1973).

101. L. B. Engle, G. E. Hansen, and H. C. Paxton, "Reactivity Contributions of Various Materials in Topsy, Godiva, and Jezebel," Nuclear Science and Engineering, 8, $543-569(1960)$.

102. J. D. Orndoff, H. C. Paxton, and G. E. Hansen, "Critical Masses of Oralloy at Reduced Concentrations and Densities," Los Alamos Scientific Laboratory report LA-1251 (1951).

103. R. C. Lloyd, E. D. Clayton, and L. E. Hansen, "Criticality of Plutonium Nitrate Solutions Containing Soluble Gadolinium," Nuclear Science and Engineering, 48, 300-304 (1972).

104. R. C. Lloyd and E. D. Clayton, "Effect of Boron and Gadolinium on the Criticality of Plutonium-Uranium Systems," Transactions of the American Nuclear Society, 23, 234-237 (1976).

105. E. D. Clayton and C. L. Brown, "Criticality and Nuclear Safety of Slightly Enriched Uranium," Chemical Engineering Progress Symposium Series, 61, No. 60, 33-43 (1965). 
106. V. I. Neeley, J. A. Berberet, and R. H. Masterson, " $k_{\infty}$ of Three Weight Percent ${ }^{235} \mathrm{U}$ Enriched $\mathrm{UO}_{3}$ and $\mathrm{UO}_{2}\left(\mathrm{NO}_{3}\right)_{2}$ Hydrogeneous Systems," HW-66882, Hanford Engineering Development Laboratory (1961).

107. R. Gwin and D. W. Magnuson, "The Measurement of Eta and Other Nuclear Properties of ${ }^{233} \mathrm{U}$ and ${ }^{235} \mathrm{U}$ in Critical Aqueous Solutions," Nuclear Science and Engineering, 12, 364-380 (1962).

108. W. E. Converse, R. C. Lloyd, E. D. Clayton, and W. A. Yuill, "Critical Experiments Using High-Enriched Uranyl Nitrate with Cadmium Absorber," Transactions of the American Nuclear Society, 32, 328-330 (1979).

109. J. T. Thomas, "Reflectors, Infinite Cylinders, Intersecting Cylinders, and Nuclear Criticality," Nuclear Science and Engineering, 67, 279-295 (1978).

110. R. C. Lloyd, C. R. Richey, E. D. Clayton, and D. R. Skeen, "Criticality Studies with Plutonium Solutions," Nuclear Science and Engineering, 25, 165-173 (1966).

111. G. R. Handley, R. C. Robinson, and J. C. Cline, "Effects of Concrete Composition in Nuclear Criticality Safety Calculations," Transactions of the American Nuclear Society, 61, 182-184 (1990).

112. H. F. Henry, J. R. Knight, and C. E. Newlon, "General Application of a Theory of Neutron Interaction," Oak Ridge Gaseous Diffusion Plant report K-1309 (1956).

113. H. C. Paxton, "History of Density-Analog Storage Criteria," Proceedings of a Topical Meeting on Criticality Safety in the Storage of Fissile Material, Jackson, $W Y$, September 8-11, 1985, American Nuclear Society report ISBN:89448-119-3, 346-352 (1985).

114. J. T. Thomas, "Remarks on Surface Density and Density Analog Representation of Array Criticality," Transactions of the American Nuclear Society, 22, 299-300 (1975).

115. J. T. Thomas, "Surface Density and Density Analogue Models for Criticality in Arrays of Fissile Materials," Nuclear Science and Engineering, 62, 424-437 (1977).

116. M. C. Evans and J. R. Bowe, "Applications of the Limiting Surface Density Method to Transport and Storage of Special Nuclear Materials," Proceedings of a Topical Meeting on Criticality Safety in the Storage of Fissile Material, Jackson, $W Y$, September 8-11, 1985, American Nuclear Society report ISBN:89448-119-3, 307-321 (1985).

117. D. R. Smith, "Criteria and Evaluation for the Storage of Fissile Materials in a Large and Varied Reactor Research Development Programme," Proceedings of a Symposium on Criticality Control of Fissile Materials, Stockholm, November 1-5, 1965, International Atomic Energy Agency, Vienna, 667-677 (1965). 
118. H. C. Paxton, "Density-Analog Techniques," Proceedings of the Livermore Array Symposium, Livermore, CA, September 23-25, 1968, Lawrence Radiation Laboratory report LRL-CONF-680909, 6-11 (1968).

119. American National Standard Guide for Nuclear Criticality Safety in the Storage of Fissile Materials, ANSI-N16.5-1975/ANS-8.7, American Nuclear Society, LaGrange Park, IL (1975).

120. H. K. Clark, "A Simple Practical Method for Calculating Interaction," Proceedings of a Symposium on Criticality Control of Fissile Materials, Stockholm, November 1-5, 1965, International Atomic Energy Agency, Vienna, 87-102 (1965).

121. H. K. Clark, "Interaction of Fissionable Units," Nuclear Science and Engineering, 15, 20-28 (1963).

122. H. K. Clark, "Application of a Simple, Practical Method for Computing Interaction to Arrays Found Experimentally to be Critical," Nuclear Science and Engineering, 20, 307-313 (1964).

123. A. F. Thomas and R. A. Scriven, "Neutron Interaction in Fissile Assemblies," Progress in Nuclear Energy, Series IV, Vol. 3 - Technology, Engineering and Safety, Pergamon Press, London, 253-291 (1960).

124. J. T. Thomas, "Critical Three-Dimensional Arrays of U(93.2)-Metal Cylinders," Nuclear Science and Engineering, 52, 350-359 (1973).

125. O. C. Kolar, H. F. Finn, and N. L. Pruvost, "Livermore Plutonium Array Program: Experiments and Calculations," Nuclear Technology, 29, 57-72 (1976).

126. J. T. Thomas, "Experimental and Calculated System Criticality," Proceedings of a Symposium on Criticality Control of Fissile Materials, Stockholm, November 1-5, 1965, International Atomic Energy Agency, Vienna, 149-175 (1965).

127. J. T. Thomas, "The Criticality of Cubic Arrays of Fissile Materials," Oak Ridge Y-12 Plant report Y-CDC-10 (1971).

128. D. Yearwood, E. D. Clayton, and B. L. Koponen, "Anomalous Effects of Moderation in Transportation and Storage Arrays - Revisited," Proceedings of a Topical Meeting on Physics and Methods in Criticality Safety, Nashville, TN, September 19-23, 1993, American Nuclear Society, LaGrange Park, IL, 99-101 (1993).

129. J. T. Thomas, "Experimental Measurements with Arrays of U $(97.7) \mathrm{F}_{6}$ NeutronCoupled Through Concrete," Transactions of the American Nuclear Society, 19, 199-200 (1974).

130. G. D. Ellis and G. R. Handley, "Enriched Uranium Storage in Steel Tubes Embedded in Concrete," Proceedings of a Topical Meeting on Criticality Safety in the Storage of Fissile Material, Jackson, WY, September 8-11, 1985, American Nuclear Society report ISBN:89448-119-3, 186-198 (1985). 
131. J. T. Thomas, "A Criticality Indicator System for Storage of Fissile Materials," Oak Ridge National Laboratory report UCCND-CSD-INF-48 (1975).

132. J. T. Thomas, "Criticality of ${ }^{233} \mathrm{U}$ Aqueous Nitrate Solutions in Reflected and Unreflected Arrays," Transactions of the American Nuclear Society, 10, 538-539 (1967).

133. R. C. Lloyd, E. D. Clayton, and J. H. Chalmers, "Criticality of Arrays of ${ }^{233} \mathrm{U}$ Solution," Nuclear Applications, 4, 136-141 (1968).

134. R. E. Rothe, "A Survey of Fissile Solution Storage Methods: Champion the Poisoned Tube Tank," Proceedings of a Topical Meeting on Criticality Safety in the Storage of Fissile Material, Jackson, WY, September 8-11, 1985, American Nuclear Society report ISBN:89448-119-3, 42-64 (1985).

135. J. T. Thomas, J. K. Fox, and E. B. Johnson, "Critical Mass Studies, Part XIII. Borosilicate Glass Raschig Rings in Aqueous Uranyl Nitrate Solutions," Oak Ridge National Laboratory report ORNL-TM-499 (1963).

136. J. T. Thomas, "Critical Experiments with Aqueous Solutions of ${ }^{233} \mathrm{UO}_{2}\left(\mathrm{NO}_{3}\right)_{2}$," Neutron Physics Division Annual Progress Report for Period Ending May 31, 1968, Oak Ridge National Laboratory report ORNL-4280, 53-55 (1968).

137. R. C. Lloyd, S. R. Bierman, and E. D. Clayton, "Criticality of Plutonium Nitrate Solutions Containing Borated Raschig Rings," Nuclear Science and Engineering, 50, 127-134 (1973).

138. R. C. Lloyd and E. D. Clayton, "Criticality of Pu-U Nitrate Solution Containing Glass Raschig Rings," Transactions of the American Nuclear Society, 21, 236-237 (1975).

139. J. K. Fox and L. W. Gilley, "Critical Parameters of Aqueous Solutions of U23," Neutron Physics Division Annual Progress Report for Period Ending September 1, 1957, Oak Ridge National Laboratory report ORNL-2389, 71-83 (1959).

140. D. Callihan, "Experiments for Criticality Control," Proceedings of a Symposium on Criticality Control in Chemical and Metallurgical Plants, Karlsruhe, Germany, 589-614 (1961).

141. O. D. Thompson and D. D. Yearwood, "Plutonium Solution Storage in Arrays of Six-inch Pipes," Proceedings of a Topical Meeting on Criticality Safety in the Storage of Fissile Material, Jackson, WY, September 8-11, 1985, American Nuclear Society report ISBN:89448-119-3, 92-98 (1985).

142. Safety Series No. 6, Regulations for the Safe Transport of Radioactive Materials, 1985 Edition, International Atomic Energy Agency, Vienna (1985). 
143. Safety Series No. 37, Advisory Material for the Application of the IAEA Transport Regulations, Second Edition, International Atomic Energy Agency, Vienna (1982).

144. 49 CFR 173.4, Regulations, Packaging and Transportation, Radioactive Materials, Department of Transportation (1991).

145. 10 CFR 71, Packaging and Transportation of Radioactive Material, Nuclear Regulatory Commission (1991).

146. DOE Order 5480.3 (1985), Safety Requirements for the Packaging and Transportation of Hazardous Materials, Hazardous Substances, and Hazardous Wastes (1985).

147. W. C. Jordan, N. F. Landers, and L. M. Petrie, "Validation of KENO V.a, Comparison with Critical Experiments," Oak Ridge National Laboratory report ORNL/CSD/TM-238 (1986).

148. J. P. Nichols, C. L. Schuske, and D. W. Magnuson, "Use of Borosilicate-Glass Raschig Rings as a Neutron Absorber in Solutions of Fissile Material," Oak Ridge Y-12 Plant report Y-CDC-8 (1971).

149. E. O. Nurmi, "Use of Borosilicate-Glass Raschig Rings in a Hostile Environment," Transactions of the American Nuclear Society, 19, 181 (1974).

150. R. F. Christy and J. A. Wheeler, "Chain Reaction of Pure Fissionable Materials in Solution," US Government report CP-400 (1943). 